EXPLORING RURAL ADMINISTRATOR PERSPECTIVES OF THE DECLINE

IN SCIENCE AND MATH SECONDARY EDUCATION GRADUATES

FROM A REGIONAL PUBLIC UNIVERSITY IN A MIDWESTERN

STATE OVER THE LAST TEN YEARS: A CASE STUDY

\author{
A Dissertation Proposal \\ presented to \\ the Faculty of the Graduate School \\ at the University of Missouri-Columbia \\ In Partial Fulfillment \\ of the Requirements for the Degree \\ Doctor of Educational Leadership and Policy Analysis \\ by \\ KELSEY POWELL \\ Dr. Bret D. Cormier, Dissertation Supervisor \\ May, 2021
}


The undersigned, appointed by the dean of the Graduate School, have examined the dissertation titled:

EXPLORING RURAL ADMINISTRATOR PERSPECTIVES OF THE DECLINE

IN SCIENCE AND MATH SECONDARY EDUCATION GRADUATES

FROM A REGIONAL PUBLIC UNIVERSITY IN A MIDWESTERN

STATE OVER THE LAST TEN YEARS: A CASE STUDY

presented by Kelsey Powell

a candidate for the degree of Doctor of educational leadership and policy analysis, and hereby

certify that, in their opinion, it is worthy of acceptance.

\begin{tabular}{c}
\hline Dr. Bret D. Cormier \\
\hline Dr. William Bratberg \\
\hline
\end{tabular}

Dr. Jeremy Heider

Dr. Paul Watkins 


\section{ACKNOWLEDGEMENTS}

This dissertation is dedicated to my very first best friend, my Uncle Tom. The ultimate role model. The man who spent hours during my childhood giving me horsey rides on his hands and knees, drawing mazes, playing "hide the stick", filling my belly with grape soda and Cheetos, and making me feel like the most special little girl in the world. I will never be able to express what a profound impact you have made on my life and will forever be grateful for your love, patience, and the direction you have given me throughout my life. This entire journey was made possible by you and Aunt Teresa. You have both so generously paid for my tuition, something I will be eternally thankful for. I quite literally couldn't have accomplished this without your support. Thank you, from the bottom of my heart.

To my mama, my biggest fan, my go-to gal, I am so grateful for your selflessness during this process, and throughout my entire life. When I couldn't leave my three month old baby to travel to Mizzou, you took all of your vacation days from work to come with me so I only had to leave my sweet boy for a few hours at a time while I completed coursework on campus. You babysat for days and days throughout these last three years so I could have time to write. This is typical of you. You would move mountains to protect me and ensure that I am happy. You have always put me first. I didn't realize your love for me until I had my own baby, now I understand. Thank you mom, for your endless love, support, and encouragement.

To my late dad, your little princess finally did it! I can’t wait to see you again. I know you're so proud of me. You never let me forget that. You helped me get through this, too. I love you.

To my baby boy, Henry Michael. You are my greatest blessing and the best part of my life. Thank you for your patience as you have spent many hours on my lap writing papers with 
me and attending classes online during the coursework part of this process. You wrote your first paper while snuggling with me at seven days old, just days after coming home from the hospital. I pray that you will always follow your dreams and push yourself to achieve your biggest goals. Mommy will always be there to push you forward, just like you did for me.

To Jayson, my better half. Thank you for your unconditional love and patience. You continually encourage and support me. You tell me how proud you are of my hard work. You help me be the best version of myself. I don't really know how I did life before you. I love you endlessly and thank God every day for putting you by my side. You were the missing piece.

To my dissertation chair, Dr. Bret D. Cormier. Thank you for your guidance throughout this seemingly infinitely long process. I appreciate your fortitude and your friendship. It was a very large task to be my committee chair, but you did it with grace. Thank you.

To Dr. William Bratberg, you spent many years with me in undergraduate school shaping me to be a great teacher. If I am half as impactful and knowledgeable as you are one day, my students will be very lucky. I appreciate your endless support and dedication to me. I can never repay you. Thank you.

To the rest of my dissertation committee, Dr. Paul Watkins and Dr. Jeremy Heider, thank you for your contribution to my scholarship and direction during this trying process. You are greatly appreciated. Thank you.

Finally, to my coach, editor, teacher, and friend, Dr. Michael Verderaime. Thank you for your persistence and mentorship. I would not have been able to achieve this feat without the hours of editing you have put into this project, the endless phone calls and text messages you have fielded, your commitment to helping me succeed, or your relentless encouragement. I am forever indebted to you. 


\section{TABLE OF CONTENTS}

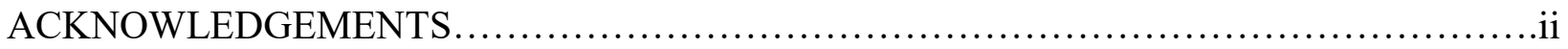

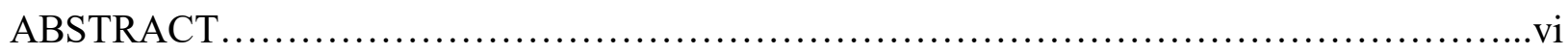

SECTION I: INTRODUCTION TO THE BACKGROUND OF THE STUDY ................

Introduction to the Background of the Study.....................................

Statement of the Problem...................................................4

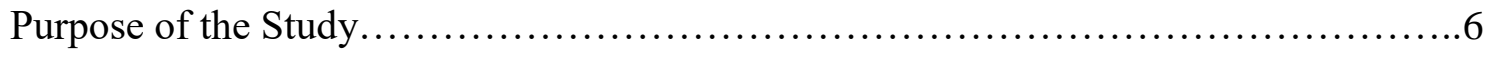

Research Questions.....................................................

Theoretical Framework...................................................... 8

Design of the Study.................................................... 10

Significance of the Study ................................................ 16

Limitations, Assumptions, and Design Controls................................17

Definition of Key Terms.................................................. 18

References............................................................. 20

SECTION II: PRACTIONER SETTING FOR THE STUDY $\ldots \ldots \ldots \ldots \ldots \ldots \ldots \ldots \ldots \ldots \ldots \ldots . \ldots \ldots$

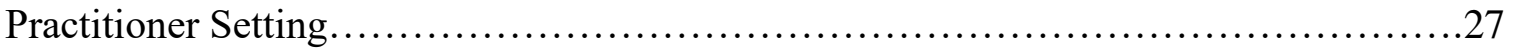

History of Organization.................................................27

Organizational Analysis...................................................27

Leadership Analysis...................................................... 33

References.......................................................... 40

SECTION III: SCHOLARLY REVIEW FOR THE STUDY $\ldots \ldots \ldots \ldots \ldots \ldots \ldots \ldots \ldots \ldots \ldots \ldots . \ldots . \ldots \ldots$

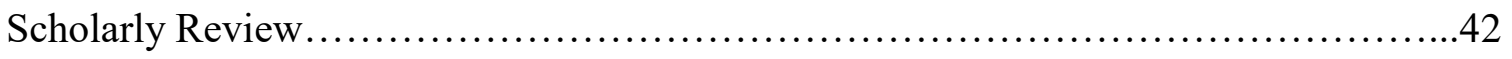

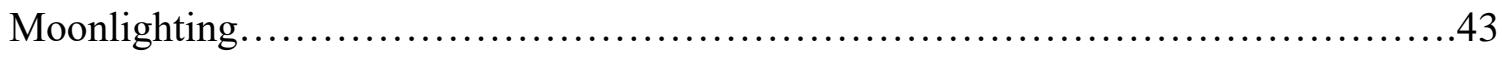

Declining Student Enrollment............................................43 
Bearing the Burdens of Teacher Shortages.................................... 45

Problem of Practice.........................................................46

Purpose of Study....................................................... 47

The Dilemma for Rural Students...........................................48

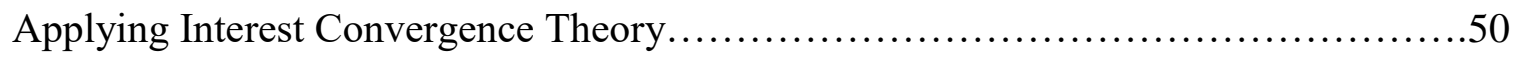

Trends in Supply and Demand of High School Teachers...........................52

Trends in Science and Math Education Graduates................................53

Student Academic Performance.................................................54

Struggles in Staffing of Rural Schools.........................................55

References...........................................................58

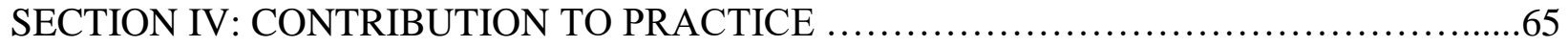

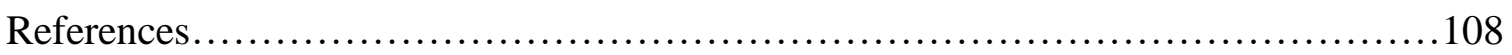

SECTION V: CONTRIBUTION TO SCHOLARSHIP $\ldots \ldots \ldots \ldots \ldots \ldots \ldots \ldots \ldots \ldots \ldots \ldots \ldots \ldots \ldots$

Target Journal.......................................................... 116

References........................................................ 171

SECTION VI: SCHOLARLY PRACTITIONER REFLECTION $\ldots \ldots \ldots \ldots \ldots \ldots \ldots \ldots \ldots \ldots . . \ldots 178$

Becoming a Scholarly Practitioner........................................... 179

APPENDIX A CONSENT FORM.................................................... 187

APPENDIX B RECRUITMENT EMAIL............................................. 188

APPENDIX C INTERVIEW PROTOCOL $\ldots \ldots \ldots \ldots \ldots \ldots \ldots \ldots \ldots \ldots \ldots \ldots \ldots \ldots \ldots \ldots \ldots \ldots \ldots \ldots$

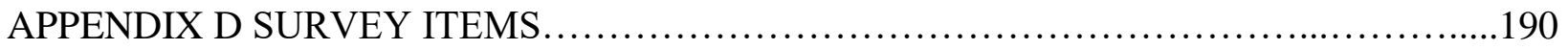

APPENDIX E INTERVIEW QUESTIONS ....................................... 191

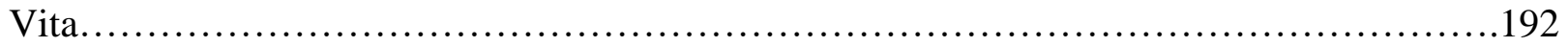




\begin{abstract}
There has been a marked decline in the number of graduates from the secondary education science and math program at a regional public university in a Midwestern state over the last ten years. Using qualitative and quantitative data gathered from interviews and surveys, this study revealed that this trend damages the ability of rural schools in the service area of this university to find and staff highly qualified science and math teachers in their high schools; thereby, unfairly impacting rural school students opportunities to learn from highly qualified teachers in those disciplines. To address the struggles that rural school administrators and students face because of this troubling reality, this study constructed its recommendations to directly combat the issues related to production of new teachers from this university and staffing teachers in rural schools.
\end{abstract}


SECTION I:

INTRODUCTION TO THE BACKGROUND OF THE STUDY 


\section{Introduction to the Background of the Study}

Since the turn of the 21 st century scholars have studied one of the greatest educational problems in recent history. Specifically, the failure of American schools to ensure that they are finding and staffing qualified teachers (Ingersoll, 1999). A key contributing factor to this dilemma is the decline in highly qualified teachers to fill vacancies in schools. Sutcher, Darling-Hammond, \& Carver-Thomas (2016) contended that the demand for teachers is growing but the supply is shrinking. They argued that if current trends continue, there will be an estimated $20 \%$ increase in annual teacher demand from 2015 levels, reaching 316,000 teachers per year by 2025 and as few as 200,000 available teacher hires each year by 2025 , resulting in a gap of more than 100,000 teachers annually. More specifically, Blank, Langesen, \& Petermann (2007) point to the challenges associated with finding and staffing science and math teachers to fill open positions in high schools. They cite insufficient production of new science and math teachers to meet the growing demand as the root of the problem. Moin, Dorfield, \& Schunn (2005) emphasized, "During the past four decades, the science and math kindergarten through twelfth teaching field has witnessed a marked decline in recruitment” (p. 981). They move on to say that the number of undergraduates who are seeking science and math teaching degrees is decreasing. Thus, the labor market for schools who are looking to hire highly qualified science and math teachers is heavily impacted by this downward trend.

Paired with the struggles to find and staff science and math teachers is the mounting concern related to the quality of teachers in these disciplines which are employed by our nation's public school sector. One of the seminal studies indicating evidence of this national pandemic is Shugart (1983) who argued declining scientific literacy, negative student attitudes toward science, declining achievement, and substantially reduced federal program support are 
all evidence of this crisis. Since the 1980's, many schools have been forced to lower their standards by hiring teachers who are not highly qualified to occupy openings in the fields of science and math leading to greater levels of underqualified teachers in these areas (Ingersoll and Perda, 2010). Ingersoll (1999) found that about a third of all secondary school teachers who teach math do not have a major or a minor in math, math education, or related disciplines like engineering or physics. Likewise, he found that one fifth of all secondary school teachers who teach science do not have the minimum requirements of at least a minor in one of the sciences or in science education. A product of this circumstance is the rise in "out-of-field teaching". A product of this circumstance is the rise in out-of-field teaching, defined as the instance when teachers are assigned to teach subjects that do not match their training or education (Ingersoll, 1998). Ingersoll (1998) defined out-of-field teaching as the instance when teachers are assigned to teach subjects that do not match their training or education. In the second decade of the 21st century, scholars note that schools who employ teachers without proper training and education will make it difficult for students to achieve their adequate yearly progress (AYP) goals (Berry, 2013). This is because those out-of-field teachers lack the content knowledge necessary to effectively teach their students about the standards required for the course.

The deficit of highly qualified instructors poses a significant problem with the intended goals and outcomes of the American education system as a whole, but especially in the rural parts of our country. Specifically, the conversation among scholars has shifted to focus on rural areas of the country. For nearly two decades, scholars have been identifying rural schools as some of the most disadvantaged school systems in the United States (Ingersoll, 2004). This disadvantage stems from the challenges rural schools face when competing for appropriately 
trained teachers to staff their schools. Lower salaries, undesirable working conditions, decreased insurance coverage and other benefits, and geographical isolation are often cited by teachers as deterrents in accepting positions at rural schools and as reasons for the lack of teacher retention in these districts (Darling-Hammond \& Sikes, 2003; Townsell, 2007; Handal, Watson, Petocz, \& Maher, 2013). Adding to the difficulties of rural education, one scholar in particular, Barley (2009) noted that multiple teaching assignments and teaching across several grade levels is a common grievance of rural teachers. Many of these issues are systemic and cannot be solved at the local level which, in turn, perpetuates the revolving door of teacher turnover in rural districts and also corresponds with the difficulties in staffing (DarlingHammond \& Berry, 2006). The struggles to staff rural schools may be related to the inequities rural teachers face. Scholars must look at major funding changes to address fair compensation, benefits, resources, and duties of rural educators in comparison to their urban and suburban counterparts.

As the pool of highly qualified secondary science and math teachers available to occupy vacancies continues to dwindle, the quest to fill open positions by highly qualified individuals becomes more difficult for rural schools as they compete for viable candidates. Better and more equitable educational opportunities must be established for children and their families in rural America.

\section{Statement of the Problem}

The demand for teachers in the science and math disciplines is continually increasing but the supply is not keeping pace (Department of Education, 2017). Reflective of this trend, there has been a decline in the number of science and math teachers graduating from the education program at a regional public university in a Midwestern state over the past ten years (River 
Town University Fact Book, 2017-2018, pp. 93-94). In 2014, its highest point within the last ten years, River Town University's college of education graduated 24 secondary science and math education majors. Its lowest, most recent graduating class in 2019, only included three. As a result, it is important to examine the perspectives of the rural administrators affected most by the decreasing graduation rate of secondary science and math teachers from this Midwestern University and the surrounding rural school districts' abilities to find and staff highly qualified high school teachers in those disciplines.

The dearth of highly qualified science and math teachers graduating from this specific regional public university reveals the problem at hand. Although many rural high schools in this study hire veteran teachers from other school districts, it is important to note the general relationship between student teaching and job placement. For example, Krieg, Theobald, \& Goldhaber (2016) confirmed, "Prospective teachers are likely to complete their student teaching near their college and hometowns, but that prospective teachers' student teaching positions are much more predictive of their first teaching positions than their hometowns" (p. 2). Specifically, the relationship between this regional university and the surrounding school districts is no exception. For example, many rural school districts start their searches for employing new teachers with the university and the university does tend to place many student teachers in its surrounding rural school districts.

It is known that rural schools in the United States are more likely to experience a deficit of math and science applicants for open positions (Bradley, 1999; Monk, 2007). However, the problem we know very little about is how or if the shortage of science and math teachers produced from this university affects the ability of rural school districts in the service area of the institution to hire highly qualified instructors. Likewise, the problems caused by the deficit 
of highly-qualified math and science teachers is not limited to rural education. In fact, many scholars have noted the similar trends between the urban and rural experience (Fan \& Chen, 1998; Howley \& Gunn, 2003; Showalter, Johnson, Klein, \& Hartmann, 2017). Although rural students fare well academically in comparison to their urban and suburban counterparts, affording rural school districts the same high quality, experienced teachers that those in other communities have will serve an underrepresented population. The problem is that rural education students are not given the same highly qualified and experienced teachers that those in other communities have.

Equitable access to high quality teachers is essential for student success and is the fundamental right of any student living in a state which has established a public school system (Darling-Hammond \& Berry, 2006). In fact, highly qualified teachers are one of the most important factors for the proper education of all children (Ingersoll, 1999). Finding a teacher to fill a vacancy in a rural district is a laborious task, but finding a highly qualified one is even more difficult, especially in the science and math disciplines (Bradley, 1999; Monk, 2007). Comparatively, the amount of highly qualified teachers employed in rural districts is below average (Monk, 2009). All children deserve a proper education, no matter where they live, and their location should not dictate the quality of their educational experience.

\section{Purpose of the Study}

The aforementioned struggles with the current state of supply and demand impact every corner of the United States. This study aims its focus on the rural school districts in the southeast portion of a Midwestern state which, conveniently, is also the service area of a regional public university. Rural districts are targeted in this study because the majority of districts in the service area for this university are classified as "rural". The decline of science 
and math teacher graduates from the university over the past ten years in conjunction with the increasing need for science and math teachers in the area's rural districts highlights an inverse relationship between the supply and demand of highly qualified instructors. Therefore, the purpose of this mixed-methods case study will be to explore the perspectives of rural administrators. Specifically, the degree to which secondary schools in the service area have experienced difficulties staffing science and math teachers in an effort to identify additional services that can be offered to support rural school districts within the university's service area. The perspectives of rural administrators will generally be defined by how they interpret their experiences, how they construct their worlds, and what meaning they attribute to their experiences (Merriam \& Tisdell, 2016).

There has not been adequate research conducted at this time to explore the perspectives of the decline of science and math teacher graduates from this university nor has there been a study to investigate the impact of this reality on the ability of local rural districts to find and staff high qualified teachers in these disciplines.

\section{Research Questions}

The research questions guiding this study are:

RQ 1: Has the decline in science and math secondary education graduates at River Town University impacted the ability of rural high schools in the service area of the University to find and staff highly qualified secondary science and math teachers?

RQ 2: What are the perceptions of rural high school administrators in the primary service area of River Town University regarding this trend?

RQ 3: According to rural administrators, why has there been a decline in science and 
math secondary education majors at River Town University over the last ten years?

\section{Theoretical Framework}

This study was grounded in Interest Convergence Theory. First developed by Derrick Bell in 1980, this theory rests in the belief that when white self-interest is supported, the white/majority will also promote racial advances for the racial minority (Bell, 1980). Interest Convergence Theory (ICT) explains the lack of equitable access to public education for students in rural areas in four distinct ways, which I will outline below. ICT can be used to define the equitable access to public education for students in rural areas in the following scenario. Data and statistics taken from the most recent census in 2010 show that rural schools enroll only $24 \%$ of students attending public schools in the United States (U.S. Department of Education, 2011). In this case rural students constitute a distinct minority demographic within the regional service area. Specifically, because rural school districts in America house only $24 \%$ of all students in American Public schools their perspectives are often times captive to the decisions made for the other $76 \%$ of students whose daily lives, activities, and perspectives may be distinctly different than those of rural education students.

The dilemma students are facing is that they are not being granted equitable access to highly qualified teachers, especially in science and math. This is specifically evident within the relationship between school districts. For example, even though households in rural areas have lower poverty rates than those in urban areas, they also have lower household incomes than those in urban areas (Bishaw \& Posey, 2017). This relationship is problematic because the current school funding model is structured in such a way that the average household income plays a large part in school funding. In fact, the federal government funds less than $10 \%$ of education expenses in the United States, which means that state governments are responsible 
for paying the balance (Derisma, 2013). The states use income and sales taxes to support the public education sector. The issue is that the revenue generated by these taxes is not stable. It could even drop in times of recession. This model unfairly allocates more funding to areas where property and income taxes are higher; therefore, lower taxes in rural areas means that less money funnels into the school system. Sadly, funding insecurities could be unintentionally created by this approach (Derisma, 2013). As a result, every community, regardless of their urban or rural status, whose property taxes are lower than their sales and income taxes are facing an incredible inequity in funding for their children's education.

Essentially, rural students are not afforded the same resources as their urban and suburban counterparts simply because of their geographic location. Highly qualified teachers are arguably the most significant resource a student has. A huge deterrent of teachers contemplating taking a job in a rural school district is the low salary and sub par health benefits (Kono, 2011). Interest Convergence Theory highlights the disparity between unequal money distribution between districts. For example, poorer school districts face harder times recruiting highly qualified teachers and attracting veteran teachers due to their inability to compensate them fairly. Being able to compete in the labor market for competent teachers could have a huge impact in rural education.

The study was based on interest convergence theory, focusing on specific policy actions in education and the rhetoric surrounding that given action from multiple perspectives. In the context of this study, this critical theory helped the researcher explore how rural school districts are managing to empower their communities to transcend the constraints placed on them by class and geographic location (Cresswell, p.65). All students should have equitable 
access to highly qualified teachers, no matter where they live or what their socioeconomic status is.

Unfortunately in this case, because the dominant group's needs are being met, the investment of inclusion has not yet emerged for rural schools. Although rural schools have existed under the current power dynamics caused by these policy structures, it is largely because rural schools have found creative strategies to extend their funding. The bottom line is that rural students are not being provided with the same resources. The conversation has not turned in such a way at this point so as to allow for rural districts to have the same means of recruiting and hiring highly qualified teachers.

\section{Design of the Study}

This mixed methods case study focused on the meaning and understanding of the decline in the number of secondary science and math teachers graduating from River Town University. River Town University is a public state university in a Midwestern state who is known for preparing teachers for future roles as educators. For the qualitative analysis piece of this study, the researcher was the primary instrument of data collection and relied on an inductive analysis process (Creswell, 2014; Merriam \& Tisdell, 2016).

For quantitative analysis the researcher collected data through a Likert survey to determine the level of impact the declining trend in graduates from River Town University has on rural high schools' ability to find and staff highly qualified secondary science and math teachers over the last ten years. The combination of qualitative and quantitative approaches provided a more complete understanding of the research problem than either approach alone (Creswell, 2014).

An explanatory sequential mixed methods design was used in this case study, and it was 
involved in collecting quantitative data first and then explaining the quantitative results with indepth qualitative data. In the first, quantitative phase of the study, the researcher surveyed local rural high school administrators to assess the level difficulty their districts have had in finding and staffing highly qualified science and math teachers. The second, qualitative phase was conducted as a follow up to the survey results. In this explanatory follow-up, the researcher explored the perceptions of rural high school administrators (Creswell, 2014). The validity of this study was based on utilizing three data collection tools: survey, interviews, and document analysis. Additionally, the researcher employed the adequate steps in developing good instruments to capture the richness of the qualitative findings (Creswell, 2014, p. 227).

\section{Setting}

The following university data has been collected from the university's fast facts webpage. This public university has an undergraduate population of approximately 9,524 students and a graduate population of just over 1,100 students. The female to male ratio is $59.9 \%$ to $40.1 \%$, respectively. The four-year graduation rate is $34.6 \%$; five-year $46.7 \%$; and six year $49.7 \%$. This university also offers more than 200 areas of study with approximately 1,500 courses extended for student registration each semester. There are also an impressive 300 courses offered online. The primary service area of this university is approximately 579 square miles and covers 26 counties (River Town University Fact Book, 2018, p. 4). This study focused on the rural school districts located in the primary service counties of this university. There are 67 school districts in this service area who are classified as "rural". For the purposes of this study, the definition of rural schools as identified by Ratcliffe, Burd, Holder, and Fields (2016) is "what is not urbanthat is, after defining individual urban areas, rural is what is left" (p.1). This definition is the official definition used by the U.S. Census Bureau. 
The demand for secondary science and math teachers who are being hired to fill vacancies in rural school districts paired with the decline in secondary science and math education graduates over the last ten years was examined in this study. Because survey respondents and interviewees came from multiple different school districts in the southeast portion of this Midwestern state, the location of the study is expansive. The study, however, only focused on a specific type of school district. Rural schools were the only kind of school considered to be part of the study even though there are other districts in the service area of the university who are not identified as rural.

\section{Participants}

Area administrators were used as the participant pool for the study. The researcher used an email to initiate contact with the participants. This email was sent to 67 rural administrators in the service area of RTU. Administrator responses who volunteered to participate in the interview were used to gather the qualitative data for the study. Due to the nature of the study, the researcher employed convenience sampling because data was only gathered by those participants who were willing and available for the interview (Creswell, 2014).

Administrators were chosen as appropriate participants because they are directly involved in hiring teachers to fill vacancies in their buildings. They were asked to complete a survey to gather data about the decline in science and math secondary education graduates from RTU in the past ten years and the ability to find and staff highly qualified science and math teachers in rural districts in the service area of the university. The survey was sent via Qualtrics software.

Amid the current global pandemic of COVID-19, alternate methods for conducting interviews were utilized. Phone interviews took place instead of face to face interviews to reduce person to person contact. Another helpful tool that was offered to participants in lieu of face to 
face conversations is the Zoom program. This virtual conference call can be done from any location with minimal technology.

\section{Data Collection Tools}

The literature review and principles of the interest convergence theory were used to create proper data collection tools including an electronic survey and interview questions. Proper ethical practices must be followed; therefore, all participation was voluntary and the study received IRB approval. A consent form was given to each participant before he or she began the study. The consent form reminded the respondent of their anonymity throughout the study as well as their voluntary participation. Participants were first asked to complete the electronic survey. The survey participants were a population of administrators in the rural school districts of the southeast portion of the state. This survey was composed of 17 items. The survey asked both qualitative and quantitative questions, both open-ended and multiple choice. The researcher asked survey questions relating to the participant's demographic data, the response to the shortage of highly qualified science and math teachers needed to fill vacancies, trends in vacancies for high school science and math positions, qualifications of science and math teachers hired within the past ten years, and teacher retention.

The researcher intended to receive a large amount of participation in both the survey and interview to provide a robust data set; however, the COVID-19 Pandemic severely limited the number of survey responses and interviews that took place. This data collection took place early in the fall semester of 2020 when administrators were navigating the reopening of their schools, creating contact tracing plans, and ensuring their staff and students were safe, all while taking care of their normal duties. Some school districts were reluctant to open in August so they began the year online, some started in person, and others had a "hybrid" schedule where they rotated 
students through online classes and face-to-face classes. It was very difficult to get a response from the 67 survey recipients and even harder to procure interviews with those area administrators.

Schoch (2016) said, "Sample sizes in case studies are usually small, which is common in most qualitative research" (p. 249). There were a total of 13 survey respondents and 6 interview participants. The researcher preferred there be a minimum of 30 responses to the survey; however, due to an atypical response rate of surveys and the fact that this research was conducted during a pandemic, adjustments were made. Additionally, a minimum of ten interviews were ideal for data collection, but six interviews took place. Although these numbers did not meet expectations, the researcher believes there are enough to adequately describe the impacts of the declining number science and math teacher graduates at RTU on the rural schools in the service area of the university. Tracy (2010) stated, "The most important issue to consider is whether the data will provide for and substantiate meaningful and significant claims" (p.841). The researcher does, in fact, believe that the rich description acquired from local rural administrators of the hardships they have endured in recent years because of a decreasing applicant pool for science and math positions does provide enough evidence to make substantiate meaningful and significant claims.

The six interview participants in this study all participated in the survey prior to being interviewed. The first interview participant, Louis Latham, is the principal from the only large school district in this study, Liberty High School. He's been the current principal for 6 years. McKenzie Miller, is the principal from Meadowbrook High, the only medium-sized school district in this study. She has held her position as head principal for 2 years but presided as vice principal of the school for 8 years prior to becoming the head principal. The four remaining 
participants are administrators from small schools in the service area of River Town University. Steve Snow, is the principal from Stillwater High School, Sharon Suntrup, is the principal from Shannon High School, Stuart Sweeney, is the principal from Shipman Senior High, and Simon Strand, rounds out the group of administrators as the principal from Sutton High. Mr. Snow has been the principal of Stillwater for 3 years, Ms. Suntrup has been the principal of Shannon High School for 12 years, Mr. Sweeney has been the principal of Shipman Senior High school for 7 years, and Mr. Strand has been the principal of Sutton High for 5 years.

Permission was obtained from Louis Latham, McKenzie Miller, Steve Snow, Sharon Suntrup, Stuart Sweeney, and Simon Strand to record the exchange. This provided the researcher with the opportunity to transcribe the conversation for a more accurate account of the interview. A series of open-ended questions were asked throughout the duration of the interview, which did not exceed one hour.

\section{Data Analysis}

Pre-existing data about graduation trends of science and math education majors of a regional public university in a Midwestern state over the past ten years was used to help validate the claim that there is a shortage of science and math teachers to fill vacancies in this area. The researcher examined the data collected in the survey responses and interviews to look for themes and code accordingly. Themes emerged as patterns in the administrators' responses in the survey were examined. While analyzing administrator survey responses, the researcher looked for commonalities in responses about demand for science and math teachers, teacher qualifications, and teacher retention. After transcription of the administrator interviews, the researcher performed a similar review of the data in search of parallel ideas relating to the hardships of rural education. The themes were then directly tied to the theoretical framework and research 
questions.

\section{Significance of the Study}

Rural school leaders often face perpetual staffing challenges (Riley and Sakimura, 2018). The majority of schools in the southeast portion of this Midwestern state are identified as being "rural" districts. This designation alone implies that it will be more difficult for these districts to find and staff qualified teachers but recent research indicates that science and math teachers are even more difficult to locate.

This case study provides a unique glimpse into the problem surrounding the decline of science and math teachers graduating from a regional public university over the past ten years and the impact it has had on the rural school districts in the service area of this university to find and staff highly qualified science and math teachers. An up-close, in-depth, and detailed examination of this condition will allow for conclusions to be made about if and to what extent the decline of science and math teachers is having on the ability of local rural school districts to provide highly qualified teachers in the subjects of science and math.

Regardless of the relationship between the two variables, or the lack thereof, this study explored the perspective that students in rural America are not granted the same opportunities as students in other communities. Because of the way the current school funding model is structured, there are many rural districts which are lacking the necessary means to be competitive in the labor market for highly qualified teachers and this research study aims to bring that revelation to light (Kono, 2011). While current research shows that rural students perform as well as or better than students not educated in rural settings academically, it is worthwhile to ask what rural students could achieve if they were afforded the same resources as students not taught in rural districts (Logan and Burdick-Will, 2017). 
This study explored the perspectives of rural school districts, focusing on the staffing of high school science and math teachers in this part of a Midwestern state. As a consequence of their location, students in these districts are being educated by teachers who receive a lower average salary than others in more affluent districts (Carr-Chellman, Raney, and Campbell, 2019). Studies have shown that students perform at lower levels when they are being educated by teachers with lower salaries (Ordway, 2018). This means that access to highly qualified science and math teachers may be more limited in this part of the state which, in turn, does not provide the same opportunity for learning to rural students. This research will point to the importance of policy makers to reevaluate their current funding model so as to supply rural districts with necessary funding to recruit and hire highly qualified teachers, especially in the science and math disciplines. It will also illuminate the responsibilities RTU has to recruit potential teachers from rural high schools in the service area of the university so that these rural schools will eventually have a bigger applicant pool of highly qualified science and math teachers to fill positions.

\section{Limitations, Assumptions, and Design Controls}

The obvious limitation to this study is that it was conducted during a nationwide pandemic. A time when schools were being shut down and administrators were being called on to deliver plans to keep students safe while maintaining an environment that promoted the same educational experiences students had prior to the outbreak of COVID-19. Administrators were already among some of the busiest professionals and their new on the job challenges only made them harder to get ahold of and potentially less willing to give up unscheduled time to take a survey and sit for an interview. Finding willing participants was the biggest challenge of this research study, specifically because they could only be from rural schools and had to complete both a survey and interview. The small sample size of this study is less than ideal, but the 
profound, emergent themes were established because of many similar responses within the limited responses the researcher did receive.

Additionally, a mixed methods case study, such as this one, presents a host of other limitations due to the nature of research methodology. Cresswell (2014) points to the importance of the researcher recognizing the challenges this type of research may pose indicating the "need for extensive data collection, the time-intensive nature of analyzing both qualitative and quantitative data, and the requirement for the researcher to be familiar with both quantitative and qualitative forms of research" (p. 218).

\section{Definition of Key Terms}

Highly qualified teachers are those who have obtained a full State Certification as a teacher, have received a minimum of a bachelor's degree, and have demonstrated content-specific knowledge in the subject areas in which they teach.

Moonlighting refers to the practice working outside of an individual's full-time primary job.

Rural school districts refer to what is not urban - that is, after defining individual urban areas, rural is what is left.

Service area refers to the geographic locations in close proximity to the university where student recruits come from and where university outreach services can be administered.

\section{Summary}

The perspectives of local high school administrators about the specific supply and demand relationship between science and math teacher graduates at this university and the vacancies in these disciplines in their school districts was explored in depth and all research questions were adequately answered in the findings. Although efforts have been made to equalize opportunity for all students, there is still a disparity between the resources available to 
students in rural areas and those in other areas. Elmore and Furhman (1995) said, "Opportunity to learn means providing all students in society equal opportunity to reach ambitious outcomes, and that implies that schools must not only have resources but use them well so that quality instruction results" (p. 438). The purpose of this mixed methods case study was to seek understanding about the implications of the recent teacher shortage through qualitative and quantitative inquiry while applying Derrick Bell's interest convergence theory. The researcher was able to communicate findings and act as a change agent by advocating for equitable access to highly qualified teachers for students in rural America. In fact, Borman and Dowling (2008) said, "The resource demands associated with employing teachers and the strong empirical evidence linking teacher quality to improved achievement are compelling reasons to focus on policies related to teachers as key levers to improve efficiency, equity, and productivity in public education" (p. 368). High quality teachers must be provided to all students by whatever means possible because proper education is a fundamental right for all children, regardless of their location. 


\section{References}

Balkıs, M., Arslan, G., \& Duru, E. (2016). The school absenteeism among high school students: Contributing factors. Educational Sciences: Theory \& Practice, 16(6).

Barley, Z. A. (2009). Preparing teachers for rural appointments: Lessons from the mid-continent. The Rural Educator, 30(3).

Berkowitz, R., Moore, H., Astor, R. A., \& Benbenishty, R. (2017). A research synthesis of the associations between socioeconomic background, inequality, school climate, and academic achievement. Review of Educational Research, 87(2), 425-469.

Berry, B. (2004). Recruiting and retaining" highly qualified teachers" for hard-to-staff schools. NASSP bulletin, 88(638), 5-27.

Bishaw, A., \& Posey, K. B. (2017, November 30). Incomes and poverty higher in urban areas. Retrieved July 5, 2019, from https://www.census.gov/library/stories/2017/11/incomepoverty-rural-america.html

Blank, R., Langesen, D., \& Petermann, A. (2007). State Indicators of Science and Mathematics Education: Washington, DC, The Council of Chief State School Officers.

Borman, G. D., \& Dowling, N. M. (2008). Teacher attrition and retention: A meta-analytic and narrative review of the research. Review of educational research, 78(3), 367-409.

Bradley, A. (1999). States' uneven teacher supply complicates staffing of schools. Education Week, 18(26), 1. 
Carr-Chellman, A., Raney, T., \& Campbell, D. (2019, April 29).

Castro, M., Expósito-Casas, E., López-Martín, E., Lizasoain, L., Navarro-Asencio, E., \& Gaviria, J. L. (2015). Parental involvement on student academic achievement: A meta-analysis. Educational research review, 14, 33-46.

Creswell, J. W. (2014). Research design: Qualitative, quantitative, and mixed methods approaches. Sage publications.

Cross, F. (2017, June). Teacher Shortage Areas Nationwide Listing(United States, U.S. Department of Education, Postsecondary Education). Retrieved June 27, 2019.

Darling-Hammond, L., \& Sykes, G. (2003). Wanted, a national teacher supply policy for education: The right way to meet the" highly qualified teacher" challenge. education policy analysis archives, 11, 33 .

Darling-Hammond, L., \& Berry, B. (2006). Highly qualified teachers for all. Educational Leadership, 64(3), 14.

Derisma, M. (2013). Opposing Views: The Divide in Public Education Funding-Property Tax Revenue. Child. Legal Rts. J., 34, 122. 
Elmore, R. F., \& Fuhrman, S. H. (1995). Opportunity-to-learn standards and the state role in education. Teachers College Record, 96(3), 432-57. Retrieved from http://proxy.mul.missouri.edu/login?url=https://search-proquest-com.proxy.mul.missour i.edu/docview/62758919?accountid=14576

Fan, X., \& Chen, M. J. (1998). Academic achievement of rural school students: A multi-year comparison with their peers in suburban and urban schools.

Fast facts: Enrollment, retention, and academic offerings (Fall 2019). Retrieved March 31, 2020, from https://semo.edu/ir/facts.html

Handal, B., Watson, K., Petocz, P., \& Maher, M. (2013). Retaining mathematics and science teachers in rural and remote schools. Australian and international journal of rural education, 23(3), 13.

Honicke, T., \& Broadbent, J. (2016). The influence of academic self-efficacy on academic performance: A systematic review. Educational Research Review, 17, 63-84.

Howley, C. B., \& Gunn, E. (2003). Research about mathematics achievement in the rural circumstance. Journal of Research in Rural Education, 18(2), 86-95.

Ingersoll, R. M. (1998). The problem of out-of-field teaching. The Phi Delta Kappan, 79(10), 773-776. 
Ingersoll, R. M. (1999). The problem of underqualified teachers in American secondary schools. Educational researcher, 28(2), 26-37.

Ingersoll, R. M., \& Perda, D. (2010). Is the supply of mathematics and science teachers sufficient?. American Educational Research Journal, 47(3), 563-594.

Jerald, C. D., \& Ingersoll, R. (2002). All Talk No Action: Putting and End to Out-of-Field Teaching.

Kono, C. D. (2011). School traits: A report on rural schools new and aspiring teachers choose first. Journal of College Teaching \& Learning (TLC), 8(4), 1-6.

Krieg, J. M., Theobald, R., \& Goldhaber, D. (2016). A foot in the door: Exploring the role of student teaching assignments in teachers' initial job placements. Educational Evaluation and Policy Analysis, 38(2), 364-388.

Logan, J. R., \& Burdick-Will, J. (2017). School segregation and disparities in urban, suburban, and rural areas. The Annals of the American Academy of Political and Social Science, 674(1), 199-216.

Moin, L. J., Dorfield, J. K., \& Schunn, C. D. (2005). Where can we find future K-12 science and math teachers? a search by academic year, discipline, and academic performance level. Science Education, 89(6), 980-1006. 
Monk, D. H. (2007). Recruiting and retaining high-quality teachers in rural areas. The Future of Children, 155-174.

National Commission on Mathematics, \& Science Teaching for the 21st Century (US). (2000). Before it's too late: A report to the nation from the National Commission on Mathematics and Science Teaching for the 21st Century. Diane Publishing Company.

Ordway, D-M. (2018). Teacher salaries impact the types of educators working in schools. Journalist's Resource.

Pekrun, R., Lichtenfeld, S., Marsh, H. W., Murayama, K., \& Goetz, T. (2017). Achievement emotions and academic performance: Longitudinal models of reciprocal effects. Child development, 88(5), 1653-1670.

Riley, B., \& Sakimura, V. (2018). Alignment: The Cornerstone of Teacher Prep. Educational Leadership, 75(8), 32-37.

Showalter, D., Johnson, J., Klein, R., \& Hartman, S. L. (2017). Why rural matters 2015-2016: Understanding the changing landscape. Rural School and Community Trust.

Shugart, S. C. (1983). The context of the physical science and mathematics teacher shortage. The High School Journal, 66(4), 245-250.

Sutcher, L., Darling-Hammond, L., \& Carver-Thomas, D. (2016). A coming crisis in teaching? Teacher supply, demand, and shortages in the US. Learning Policy Institute. 
Townsell, R. (2007). Human Resource Management in Small Rural Districts: The Administrator's Role in Recruitment, Hiring and Staff Development. Online

Submission, 20(3).

U.S. Department of Education. (2011). The status of rural education. Retrieved July 5, 2019, from https://nces.ed.gov/programs/coe/pdf/coe_tla.pdf 
SECTION II:

\section{PRACTITIONER SETTING FOR THE STUDY}




\section{Practitioner Setting}

This study focused on the decreasing graduation rate of science and math education majors over the last ten years from a regional public university located in the Midwest, River Town University (RTU), and the impacts of this trend on surrounding high schools who are identified as being both "rural" and within the "primary service counties" of this university. In this section, the history of these organizations will be described. Organizational and leadership analyses will also be provided as well as implications for research in the practitioner setting.

\section{History of Organization}

According to the "about" section of the University at the center of this study's webpage, it was founded in 1873 and initially established as a teacher's college. It has grown to house a very diverse number of academic programs totaling in excess of 150 different areas of study. The rural school districts in the primary service counties of this university will be investigated during this study. There are 67 rural school districts which fall under the definition of "rural school" as defined by Ratcliffe et al. 2016. The history of each of these rural districts is quite broad, but each is a public school entity in this Midwestern state.

\section{Organizational Analysis}

The population size of school districts participating in this study varies, but the network of people involved in each organization remains constant for each district. The organizational structure of the public school system as a whole can be best described by Bolman and Deal's (2013) structural and human resource frames. Using Bolman and Deal (2013), this analysis will break down the educational system using the structural and human resource frames, "to see and understand more clearly what goes on from day to day" (p. 41). A rich description of the public 
school system can be established by using these frames. The purpose of this organizational analysis is to incorporate all facets of these frames to establish a clear understanding of the public school organization.

Analysis of the Public School System from the Structural Frame

Bolman and Deal's (2013) structural frame is first used to examine the public school system. There are six assumptions Bolman and Deal identify as upholding the structural frame:

- Organizations exist to achieve established goals and objectives.

- Organizations increase efficiency and enhance performance through specialization and appropriate division of labor.

- Suitable forms of coordination and control ensure that diverse efforts of individuals and units mesh.

- Organizations work best when rationality prevails over personal agendas and extraneous pressures.

- Effective structures fit an organization's current circumstances.

- Troubles arise and performance suffers from structural deficits, remedied through problem solving and restructuring (p. 45).

All school districts involved in this study are from the public sector; therefore, all of them have a similar organizational design with a clear hierarchical structure. Although they vary in size, they all strive toward a common goal: to educate students. To accomplish this goal, each school, regardless of size, employs many individuals that are housed in different departments which all seek to appropriate the division of labor. Those of which directly linked to the education of students are as follows: school board, administration, support staff, and classroom 
teachers. Lunenberg (2012) stated that departments are connected to establish organizational structure. Nelson and Quick (2011) further explained that this structure exists to allow the organization to achieve its intended purpose. Therefore, each department of the organization is an integral cog and maintaining this orderly system of management is necessary for the attainment of the common goal of educating students. Lunenberg (2012) said, "The term organizational structure refers to the formal configuration between individuals and groups regarding the allocation of tasks, responsibilities, and authority within the organization" (p. 1). Each of the departments mentioned above has a specific role which informs their tasks, responsibilities, and authority within the public school system.

The main parts of the public school education system can be identified using Henry Mintzberg's model of the key parts of an organization. Mintzberg (1980) determined the five basic parts of an organization as: operating core, strategic apex, middle line, technostructure, and support staff. In the public school setting, each of these can be clearly identified. The operating core consists of the classroom teachers who carry out the hefty task of educating students each day. The strategic apex houses the superintendent and administrative cabinet. The middle line is composed of the principals of each school. The technostructure includes personnel in the school district responsible for public relations, research and development, and other related staff. Support staff who provide indirect services such as maintenance, clerical, food service, and busing personnel round out Mintzberg's five basic parts of an organization. By recognizing the parts of an organization it is clear that the structure of this organization is deliberate. By creating an organization that has a stable structural arrangement, the public school system increases individual performance of the key players involved in accomplishing the common goal.

For the purposes of this study, all participating school districts were also described as 
either small, medium, or large rural school districts. This classification was determined by this state's high school activities association. The classification structure was determined by school population size, which can be fluid from year to year. According to the high school activities association for this state's webpage, the largest schools based on student enrollment in grades 912 are classified in Class 6, while the smallest schools are assigned to Class 1. The next-largest group of schools are then classified in Class 2, the next in Class 3, and the next in Class 4. The remaining schools are assigned to Class 5. In this study, Classes 1 and 2 were labeled "small" districts and do not exceed a total enrollment of 427 students. Classes 3 and 4 were classified as "medium" districts and do not exceed a total enrollment of 1,314 students. Classes 5 and 6 were classified as "large" districts and have a total enrollment of 1,315 students or more.

Of the 67 rural school districts in the service area of RTU, 51 have a student population of 427 students or less, classifying them as a "small" school. Of these 51 schools, the average student enrollment is 214 students. 15 schools have a student population between 428 and 1,314, classifying them as a "medium" sized school. Of these 15 schools, the average student enrollment is 740 students. There are two schools that have a population of between 1,315 and 2,803, making them the only two "large" sized schools. The average student enrollment is 1,519 students.

Of the small schools, the average percentage of students who qualify for free and reduced school lunch is $64.5 \%$. Of the medium schools, the average percentage of students who qualify for free and reduced school lunch is $46.5 \%$. The percentage of students who qualify for free and reduced school lunch in the large schools is $41.8 \%$.

The distribution of various races in the small, medium, and large schools is not the same, but very similar. Of the small schools, the average racial distribution is as follows: 0\% American 
Indian/Alaska Native, 0\% Asian, 6.4\% Black, 0\% Hawaiian/Pacific Islander, 2.7\% Hispanic, $0.67 \%$ Multi Racial, and $88.5 \%$ White. Of the medium schools, the average racial distribution is as follows: $0.08 \%$ American Indian/Alaska Native, 0.3\% Asian, 3.03\% Black, 0\% Hawaiian/Pacific Islander, 2.21\% Hispanic, 1.04\% Multi Racial, and 92.6\% White. Of the large schools, the average racial distribution is as follows: $0.4 \%$ American Indian/Alaska Native, $0.4 \%$ Asian, 6.75\% Black, 0\% Hawaiian/Pacific Islander, 2.05\% Hispanic, 2.8\% Multi Racial, and $87.55 \%$ White.

Analysis of the Public School System from the Human Resource Frame Bolman and Deal's (2013) human resource frame is also used to examine the public school system. There are four assumptions Bolman and Deal identify as upholding the human resource frame:

- Organizations exist to serve human needs rather than the converse.

- People and organizations need each other. Organizations need ideas, energy, and talent; people need careers, salaries, and opportunities.

- When the fit between individual and system is poor, one or both suffer. Individuals are exploited or exploit the organization-or both become victims.

- A good fit benefits both. Individuals find meaningful and satisfying work, and organizations get the talent and energy they need to succeed (p. 117).

The purpose of schools is twofold: educating students and providing a livelihood for those invested in the academic scholarship of those students. The human needs of students and district employees are being met because of the existence of the public school system. Employees and students both succeed when there is a good fit with the public school 
organization. This fit between the individuals (employees and students) and the school system allows the success of the organization. A good fit is established when the organization meets the needs of both groups of people and when the employees and students meet the needs of the organization.

Careers, opportunities, and salaries are provided by the organization to the employees for their services associated with the education of students. In return, employees provide ideas, energy, and talent that the school districts need to achieve rigorous learning standards for students that are set by the state. Students receive invaluable instruction that provides them with skills and knowledge they need for their postsecondary success. Whether entering the workforce, armed services, or pursuing further education, students are gifted with the tools they need for their future. In return, student academic performance partially influences each school district's Annual Performance Report created by the state. The score for this report is determined by five factors measured by the state: (1) Academic Achievement, (2) Subgroup Achievement, (3) High School Readiness (K-8 districts) or College and Career Readiness (K-12 districts), (4) Attendance Rate, and (5) Graduation Rate (K-12 districts).

Bolman and Deal (2013) suggest that if the respective needs of the people and of the organization are well aligned, or if there is a "good fit", then both groups will benefit and be successful. When organizations invest in people, success is seen. Bolman and Deal (2013) said, "High-performing companies do a better job of understanding and responding to the needs of both employees and customers" (p. 133). Likewise, when the public school system acknowledges and answers to the needs of the employees and students, they will likely see more success. 


\section{Leadership Analysis}

This research study looked at the perspectives of local rural high school administrators regarding the decreasing graduation rate of high school science and math education majors from a regional public university in a Midwestern state and their ability to staff highly qualified science and math teachers in their high schools. Therefore, the leadership analysis was conducted for both the university and the public school system in the rural areas of this state. Although the sizes of these two entities are quite different, their common goal in the educational arena is the same. High schools aim to educate the students entrusted in their care and the university provides highly qualified, competent, prepared, and passionate teachers to carry out this task. Leadership teams in both systems are working for the good of the students. They operate to serve students and prepare them for what's to come as their time in secondary education comes to a close. I would argue that both institutions operate under the servant leadership paradox. Greenleaf (1970) provides the most commonly cited definition of servant leadership. In his 1970 publication, Greenleaf says:

[Servant leadership] begins with the natural feelings that one wants to serve, to serve first. Then conscious choice brings one to aspire to lead...The difference manifests itself in the care taken by the servant-first to make sure the other people's highest priority needs are being served. The best test...is: do those served grow as persons; do they, while still being served, become healthier, wiser, freer, more autonomous, more likely themselves to become servants? And, what is the effect on the least privileged in society; will they benefit, or, at least, will they not be further deprived? (p.15)

Northouse (2016) produces a model of servant leadership based on the works of Liden, Wayne, Zhao, and Henderson (2008) and Liden, Panaccio, Hu, and Meuser (2014). The model 
Northouse presents is composed of three main categories: antecedent conditions, servant leader behaviors, and leadership outcomes. I will follow this model as I explain how the decision makers of the rural secondary education districts in the service area of this university provide excellent examples of servant leadership.

\section{Antecedent Conditions}

Northouse (2016) defines antecedent conditions as existing conditions that have an effect on servant leadership. Context and culture, leader attributes, and follower receptivity are all all antecedent conditions that have an impact on servant leadership. In reference to context and culture, one should note that the culture of the organization dictates the way servant leadership is able to be achieved. In education, leaders are expected to serve. It is expected of them to make decisions based on the culture of caring and serving students. In this regard, servant leadership fits well in the culture of the system.

Leader attributes also strongly influence the servant leadership process. Each leader is different and has their own personal qualities that they use to direct their decision making. Reasons behind why a person is called to be a servant leader influence how they carry out their role. Some may credit their will to lead to a higher calling while others see leadership as their way to serve at a higher level. Another factor associated with an individual's display of servant leadership is their personal self-determinedness, emotional intelligence, and moral development (Northouse, 2016). These traits directly merge with their ability to practice servant leadership.

Follower receptivity is concerned with how servant leadership is perceived by those taking direction from leaders. Some people crave a leader's instruction. Some people need the help and guidance they receive from a servant leader. However, some people see this type of 
direction as micromanagement and it yields a negative response in return (Northouse, 2016). Servant leadership will be most effective when the follower receptivity is high. From my experience as an educator, many teachers receive direction from leaders much easier when the leaders present their guidance in such a way that makes the teachers feel like they are part of the process. I have observed this from leaders at the high school level as they ask for feedback and address concerns of their followers without ignoring their worries. This way of increasing follower receptivity allows the servant leader to have a greater impact on their followers.

\section{Servant Leader Behaviors}

Northouse (2016) identifies several behaviors that are foundational to the servant leadership process. I will describe how the leaders within the public school system exhibit some of these behaviors so the essence of servant leadership can be fully understood as it applies to these educational institutions.

Northouse (2016) describes the servant leader behavior of conceptualizing to be the act of thoroughly understanding the organization in such a way that the leader knows the organization's purposes, complexities, and mission. The public school system is an advocate for the education of all students. The leaders of this organization are constantly dealing with multifaceted problems that arise and attempt to throw the goal of the system off course. For example, the current COVID-19 pandemic has left educational leaders everywhere, university and K-12 administration alike, strategically working to ensure that teachers are still able to provide instruction and students are not left without educational resources as this time. This ability to conceptualize allows the servant leader to solve the problems sought to undermine the goals of the system. 
Putting followers first is also a characteristic of the servant leader. Northouse (2016) says this behavior is, "the defining characteristic of the servant leader" (p. 234). In this scenario, the follower can be identified as the teacher or the student. Teachers are followers of the administrative school leaders and students are followers of the teachers. Northouse explains this behavior as being able to display that concerns of followers are valid and important; furthermore, the true servant leader makes it apparent that the followers' interests and success are of the highest priority, even above the leader himself. From my personal experience, I have noticed that administrators at the collegiate and high school levels who are most effective employ this behavior often in their daily routines as they lead their followers. When teachers feel heard and supported by their administrators, whether it be in the post-secondary or K-12 setting, the leaders are met with greater compliance and respect. Of course this statement comes from my own personal experience, but I can reveal that I am more prone to become a loyal follower when my leader shows me they are putting me first. I exhibit this characteristic in my own classroom daily and have noticed tremendous results from my followers. I have little to no discipline problems and have built incredible relationships with my students because, as their leader, I show them that they matter. They know this because I demonstrate that their concerns are a priority.

Helping followers grow and succeed is another distinguishing behavior of the servant leader and quite literally lends itself to being a foundational component of the educational system. Higher education provides their instructors with mentors and proper supports to help them accomplish their goals and fulfil their duties just as K-12 educational leaders grant their followers the same assistance. Teachers propel their students forward not only by providing content specific knowledge but by helping them accomplish their aspirations in life through education and encouragement. 


\section{Leadership Outcomes}

Northouse (2016) outlines not only the importance of leadership behaviors, but also the careful examination of servant leadership outcomes. These outcomes are follower performance and growth, organization performance, and societal impact. Clearly the effectiveness of the servant leader is vital to these outcomes. When servant leaders nurture, help with goals, and give power to their followers, the followers, in turn, have a realization of their capabilities (Northouse, 2016). This happens every day in the realm of education. As an educator, my administrative team provides constant nurturing of my professional career, guiding me through difficult classroom situations and helping to address problems that often arise. They also help me to establish teaching goals and provide feedback after evaluation which aids me in creating my own plan for instruction.

Northouse (2016) says servant leadership has an impact on organizational performance. He references organizational citizenship behaviors (OCBs) when explaining the relationship between servant leadership and organizational performance. He states that followers within the organization are likely to exhibit behaviors that go beyond the basic requirements of their job descriptions and act to positively impact the overall functioning of their organization. I see this happening in educational institutions everywhere as the pandemic already mentioned continues to unfold in our country today. College professors and K-12 educators are going above and beyond what they were originally called to do because of the dedication and commitment they have to their organization, which may have been fostered because of the servant leadership of their leaders.

Societal impact is the final outcome Northouse (2016) explores. He says a positive impact on society is a likely consequence of servant leadership. Not that servant leadership will 
altogether change society as a whole; rather, servant leadership will contribute to positive social change. Positive social change is accomplished through followers who are a part of a healthy organization, thus benefiting society. Educators who are supported by servant leaders can create the next generation of servant leaders, or even become servant leaders themselves within their organization.

Through evidence explained above, one can reasonably assume that servant leadership is a probable factor influencing the improvement of outcomes at the individual, organizational, and societal levels.

\section{Implications for Research in the Practitioner Setting}

The negative trend in production of science and math education graduates from this university is a growing concern for local rural school districts who already struggle with finding highly qualified teachers to fill vacant positions in their districts. Having a more shallow pool of applicants because of a decreasing availability of new teachers is reason for districts to have increased anxieties over the quality of education they are providing for their students. By highlighting the perceptions of local rural administrators about the relationship between the graduation rate of highly qualified candidates to fill science and math positions and the ability to hire those professionals to fill vacancies, this research can bring light to the importance of

recruiting and retaining teachers for rural school districts. This study brings about both scholarly and practical implications that impact the quality of education for rural students in relation to availability of highly qualified teachers. 


\section{Summary}

Describing the history of the organization and performing both an organizational and leadership analysis have allowed me to fully describe the practitioner setting for the study. By utilizing Bolman and Deal's (2013) structural and human resource frames, I accurately detailed the organizational composition of the public school system. The leadership analysis of both the university and public school system has shed light on how servant leadership detailed by Northouse (2016) manifests itself within the infrastructure of the educational system. 


\section{References}

Bolman, L. G., \& Deal, T. E. (2013). Reframing organizations: artistry, choice, and leadership (5th ed.). San Francisco: Jossey Bass.

Cresswell, J.W. (2014). Research design. Thousand Oaks: Sage publications.

Greenleaf, R. K. (1970). The servant as leader (an essay). Greenleaf Organization.

Lunenburg, F. C. (2012). Organizational structure: Mintzberg's framework. International journal of scholarly, academic, intellectual diversity, 14(1), 1-8.

Mintzberg, H. (1980). Structure in 5's: A Synthesis of the Research on Organization Design. Management science, 26(3), 322-341.

Nelson, D. B., \& Quick, J. C. (2011). Understanding organizational behavior. Mason, $\mathrm{OH}$ : South-Western Cengage Learning. 
SECTION III:

SCHOLARLY REVIEW FOR THE STUDY 


\section{Scholarly Review}

Educational outcomes of students are most heavily influenced by the work of the teachers entrusted with the great honor of educating them (Allegretto and Mishell, 2016). Likewise, Stronge and Hindman (2003) listed many factors that lead to higher student achievement such as smaller class size, funding, curricula, and family and community involvement, but very deliberately identified the single most important factor in student academic achievement is the teacher. In fact, Chetty, Friedman, and Rockoff (2014) reported that teachers are able to influence their students to attend college, earn higher salaries, and avoid teen pregnancy, among other things, which over time, is likely to have substantial economic and social benefits for the child during the entirety of their lifetime.

Why then are teachers from all disciplines, at all levels, in every geographic location in the United States not compensated the same as other professionals in occupations with a comparative training and education? Statistics from 2015 show that teachers' weekly wages are 17\% lower than those of comparable workers (Allegretto and Mishell, 2016). Put simply, teachers are severely underpaid and have, arguably, one of the most important jobs in today's society.

This disproportionate gap in equal pay for teachers and their peers of similar education and training, along with other factors, has stifled the supply of highly qualified teachers to fill vacancies in schools across America. Ingersoll (2003) found that of teachers leaving the profession, $54.3 \%$ identified poor salary as the motivating factor to change careers. Of those teachers who stay in the profession, approximately $19 \%$ of them "moonlight" to supplement their teacher salaries so they can provide for themselves and their families or raise their standard of living (Fitchett, Heafner, and Harden, 2016). 


\section{Moonlighting}

With so many teachers "moonlighting" to provide for themselves and their families, one must ask what impact this has on students in the classroom. Johnson (1990) asserted that teachers who moonlight have reported that they have less energy to give to their students. Concurrently, Winters (2010) concluded that working a second job may also affect teaching through reduced energy and effort. Teachers need as much energy as possible because students depend on them to create lessons, give feedback, assess progress, lecture, mentor, evaluate, and so much more. Moonlighting does not allow teachers to be well rested but also monopolizes their time. Teachers who moonlight spend less time on school-related tasks (Farber, 1991). While they could be using spare time to lesson plan and prepare for school, many teachers use that time to make extra income. There is also evidence suggesting that teachers who moonlight are more likely to leave the profession (Raffel and Groff, 1990).

Garcia and Weiss (2019) found that a large amount of moonlighters, 44.1\%, take on second jobs within the school system such as coaching, student activity sponsorship, mentoring other teachers, or teaching evening classes. According to Raffel and Groff (1990), $17 \%$ of moonlighting teachers held managerial positions in their out-of-school jobs and $14 \%$ held sales positions. These statistics show that teachers are ready and willing to dole out their extra time fulfilling responsibilities to a part-time position to make ends meet. This, in turn, leaves them feeling tired and having less time to work on their primary job obligations.

\section{Declining Enrollment}

The pay-related inability to retain teachers isn't the only factor contributing to the discrepancy in supply and demand though. Berry and Shields (2017) stated that enrollments in teacher preparation programs dropped 35\% nationwide between 2009 and 2014. The reason for 
this decline is illuminated by D'Orio (2019) where he identified low pay as one of the key factors for the downward trend in enrollment of students in teacher preparation programs. The staggering amount of teachers leaving the profession each year due to unfair compensation paired with the downturn in enrollment in teacher education programs has created the perfect storm of chaos at the epicenter of staffing schools with highly qualified teachers.

To make matters worse, the decline in supply of teachers is impacting high need areas like special education, foreign languages, bilingual education, math, and science the worst (Barth, Dillon, Hull, \& Higgins, 2016). Sutcher, Darling-Hammond, and Carver-Thomas (2016) noted that in 2015-2016 school year, 48 states and the District of Columbia reported a shortage of special education teachers; 42 states and DC reported a shortage of math teachers; and 40 states and DC reported a shortage of science teachers. They also identified this same trend for the 2014-2015 school year but included bilingual education and foreign language as subject areas who were also facing a shortage of teachers.

With this dilemma having such a widespread impact across the country, it is more important than ever to increase the retention rate of America's teachers, especially in rural areas. Small, rural schools have the greatest problem with teacher retention, especially in science and math (Monk, 2007). Toropova, Myrberg, and Johansson (2020) reported that teacher job satisfaction regarding working conditions, such as pay, is closely related to retention. Geographic and social isolation have both been indicated as prominent reasons for leaving rural districts (Aragon, 2016). Toropova, Myrberg, and Johansson (2020) moved on to identify student discipline, teacher cooperation, and teacher workload to be other significant factors impacting job satisfaction. It is important to teachers that they have the support of their administrative team when faced with disciplinary issues regarding students who misbehaved in their classrooms. 
Likewise, they noted that teachers need to be part of an environment in which their coworkers collaborate well together. Toropova et al. (2020) uncovered the direct relationship between excessive teacher workload and emotional exhaustion paired with motivation to quit teaching. These factors, among others, are significant contributors to the job dissatisfaction of today's teachers.

\section{Bearing the Burden of Teacher Shortages}

Another key concern is that students in high minority, high poverty, rural, urban, or lowachieving schools are bearing the burden of the teacher shortage (Aragon, 2016; DarlingHammond and Podolsky, 2019). This means that students in these schools face inequities such as being taught by less qualified teachers. In fact, Sutcher et al. (2016) stated that high-minority and high-poverty schools had four times as many uncertified teachers as low-minority and lowpoverty schools. Robinson (2017) highlighted the relationship between rural locations and poverty noting that poverty manifests itself in these areas. Unfortunately, rural schools, because of their correlation with poverty, are more likely to employ teachers who lack conventional licensure (Dee and Goldhaber, 2017). Garcia and Weiss (2019) explained this phenomena by detailing the inability for schools in high poverty locations to attract and retain teachers because they are not able to offer a competitive wage like low poverty schools.

In 2015, President Barack Obama signed the Every Student Succeeds Act (ESSA) giving new hope to America's elementary and secondary school students. This bipartisan statute was a well-received revision of the No Child Left Behind Act (NCLB) enacted in 2002 by the Bush administration and promised to ensure student success in all schools in the United States of America. While ESSA has made great strides in reshaping the American education system and making it more workable for schools and educators, there are still areas in which there must be a 
swift call to action. In particular, special attention must be paid to the challenges associated with finding and staffing highly qualified teachers in the United States, especially in the science and math disciplines at rural schools. There are many variables which impact student achievement; however, teachers are the single most important factor in influencing student performance (Haycock, 1998; Holme, Jabbar, Germain, \& Dinning, 2018). This scholarly review examines the conversation surrounding the impacts of the current teacher shortage crisis by specifically addressing the following topics: the current supply and demand of secondary school teachers in the United States, the specific trend in science and math teacher education graduates, student achievement, and challenges rural schools face relating to hiring highly qualified teachers. All sources used in this review met the following specific criteria: (a) scholarship, (b) quality, and (c) relevance.

\section{Problem of Practice}

The recession of 2008 brought about a time in American education where the supply of teachers far outweighed the demand. In recent years, however, the relationship between supply and demand of teachers has changed dramatically, especially in the subjects of science and math. As the economy began to recover, school systems were able to hire more teachers to staff their schools and provide them with classes and programs that were once eliminated because of insufficient funding. During this time, however, enrollment in teacher preparation programs had decreased by 35\% and teacher attrition had reached a high (Sutcher, Darling-Hammond, \& Carver-Thomas, 2016). The consequence of this reality is that finding and staffing highly qualified teachers to fill vacancies in school districts became increasingly challenging. Not only is it hard to find and staff highly qualified teachers, but it is even more difficult to procure teachers in the fields of science and math, especially for rural school districts (Cowan, 
Goldhaber, Hayes, \& Theobald, 2016; Bland, Church, \& Luo, 2016).

\section{How Rural Students Differ}

Often, rural public school students are not given the same opportunity as students not being educated in rural districts to learn from highly qualified teachers because finding teachers to serve in those districts is very challenging (Dee \& Goldhaber, 2017; Aragon, 2016; Malatras, Gais, \& Wagner, 2017; Barth et al. 2016; Brenner, 2016). This unfortunate circumstance threatens the intended goals and outcomes of the education system for rural students and could potentially inhibit or delay future student successes because of the possibility for lack of learning. While evidence shows insufficient funding contributes to difficulties rural schools face in being a competitive employment option for qualified teachers (Ulferts, 2016; Azano \& Stewart, 2016; Curtin, 2018; Bland et. al 2016), it does not specifically explore the perceptions of rural high school administrators regarding the decreasing number of science and math teacher graduates.

\section{Purpose of the Study}

Although the ratification of ESSA propelled the education system forward advancing equity for the disadvantaged and high need students, like those in rural areas, this area of oppression still needs to be explored so resolutions can be made. This study aimed its focus on rural administrators' perceptions of how their schools and students have been impacted by the sharp decline in science and math secondary education graduates from a public regional university in a Midwestern state. An explanatory sequential mixed methods design was used, and it involved the initial collection of quantitative data then explained those results with detailed qualitative data. In the first, quantitative phase of the study, survey data was collected from administrators at local rural high schools to establish a supply and demand relationship between 
teacher graduates from the local university and the vacancies in science and math positions from the last ten years in rural districts in the service area of the college. The second, qualitative phase was conducted as a follow up to the quantitative results to help explain those results. In this exploratory follow-up, administrators' perceptions about the decreasing number of science and math teachers graduating from River Town University was examined. Derrick Bell's interest convergence theory was then used as the lens to view the problem.

\section{Theoretical Framework: Interest Convergence Theory}

The problem at hand is that rural American students are not being afforded the same educational opportunities to learn by highly qualified teachers as those who are not being educated in rural school districts. This situation can be explored by identifying rural students as a subpopulation within all students in the American public education system and classifying them as the minority because they represent a smaller, more underprivileged population. This can be done by utilizing Derrick Bell's Interest Convergence Theory which he developed in 1980. This theory rests in the belief that when white self-interest is supported, the white/majority will also promote racial advances for the racial minority (Bell, 1980). This theory can be applied to any situation where a minority population exists. In this case, rural students are the disadvantaged group because, comparatively, enrollment in rural schools is much less. Data and statistics taken from the most recent census in 2010 show that rural schools enroll only $24 \%$ of students attending public schools in the United States (U.S. Department of Education, 2011). Rural students, in this situation, are considered the minority while all others are in the majority.

\section{The Dilemma for Rural Students}

The dilemma rural students are facing is that they are not being granted equitable access to highly qualified teachers, especially in science and math (Harmon, Gordanier, Henry, \& George, 
2007; Powell, Higgins, Aram, \& Freed, 2009). Although households in rural areas have lower poverty rates than those in urban areas, they also have lower household incomes than those in urban areas (Bishaw \& Posey, 2017). The way the current school funding model is set up, the average household income plays a large part in school funding. The federal government funds less than $10 \%$ of education expenses in the United States, which means that state governments are responsible for paying the balance (Derisma, 2013). They do so by using income and sales taxes to support the public education sector. The problem is that the revenue generated by these taxes is not stable. It could even drop in times of recession or when a population size decreases (Harmon et. al 2007). This model allocates more funding to areas where property and income taxes are higher; therefore, lower taxes in rural areas means that less money funnels into the school system. Sadly, funding insecurities could be unintentionally created by this approach (Derisma, 2013).

Essentially, rural students are not afforded the same resources as their urban and suburban counterparts simply because of their geographic location. There are many reasons why teachers have cited for not wanting to teach in rural districts such as inadequate benefits, lower pay, insufficient support through mentoring programs, and less than desirable teaching conditions but many of them could be solved with proper funding (Gannon and Mattingly, 2015). A huge deterrent of teachers contemplating taking a job in a rural school district is the low salary and sub-par health benefits (Harmon et. al 2007; Ingersoll, 2004). Both of these issues could be resolved by redistribution of monies so that districts could recruit and hire highly qualified teachers and compensate them fairly. Fair compensation would mean that a teacher's geographical location does not directly impact their salary. Player (2015) noted that after experience and degree level are accounted for, rural teachers make almost $\$ 10,000$ less per year 
than their urban and suburban counterparts. Being able to compete in the labor market for competent teachers could have a huge impact in rural education.

\section{Applying Interest Convergence Theory}

Interest convergence theory is about action and the rhetoric surrounding that action. All students should have equitable access to highly qualified teachers, no matter where they live or what their socioeconomic status is. Unfortunately in this case, because the dominant group's needs are being met, the investment of inclusion has not yet emerged for rural schools. The conversation has not turned in such a way at this point so as to allow for rural districts to have the same means of recruiting and hiring highly qualified teachers.

Using Bell's interest convergence theory, the researcher examined this dilemma by calling attention to the fact that rural schools, the minority, are not being allotted the same resources as their urban and suburban counterparts because staffing highly qualified science and math teachers in those districts has not yet reached the level of crisis that is has in rural districts. Currently, the majority's needs are being met, therefore, a call to action has not been made to formalize a specific plan aimed to satisfy the urgency to fill science and math vacancies in rural schools. Despite the fact that nearly a quarter of all American students are being educated in rural districts, national educational policies in the United States do not fit with the needs of rural districts (Eppley, 2009). Gallo \& Beckman (2016) explained, "Without policies tailored to the unique context of rural schools and communities, ensuring equity of access, resources, and opportunity in schools across the United States becomes a difficult task” (p. 2). Unfortunately, when this problem is viewed using Bell's theory, meaningful change will only occur if the rhetoric involved shows a benefit for the majority. 
When there is a convergence of interests between the majority and minority populations, equity will be established. Milner (2008) gives an example of the interest convergence theory in action when he cites an example between Whites and non-English speakers in a school system which introduced new policies to fund the busing and financing of additional resources for immigrant students in one of the "best" local schools in the county. The reason why these new policies were put in place is because the majority White students were going to benefit in some way. Specifically, the interest of the majority would be advanced because they would be provided with new resources which would allow them to become multilingual. Exposure to various linguistic, ethnic, and cultural differences would benefit the majority because it would prepare them for the ever changing, diverse world.

The interest convergence theory can be applied in a multitude of situations, even those in a legislative context. Lee (2007) used interest convergence to explain why some immigrant and minority criminal defendants who introduce cultural evidence in their defense are more successful than others. When the cultural norms of their defense align with those of the majority, their attempts to introduce cultural evidence are usually successful. Other notable cases Lee (2007) mentions in which interest convergence is utilized to explain United States Supreme Court decisions, lower state court cases, or legal enactments are as follows: Hernandez v. Texas, Plyler v. Doe, and Grutter v. Bollinger. The relevance of these court cases related to the application of interest convergence theory in this study lies in the ability to illuminate injustice of minority stakeholders like those in rural schools.

Interest convergence theory is also used to explain why the curriculum of many teacher education programs is not structured in a way that addresses racial, language, and/or cultural diversity and is also lacking in the preparation of teachers for the diverse students they will 
encounter in schools. Sleeter (2007) said, "It is very difficult to shift the center of gravity of a program in which the center is defined by White interests, and any proposed change must align with White interests to gain support" (p. 4). Many programs do have diversity courses integrated into their curriculum but they come in the form of one or two classes and race, ethnicity, and culture are not prominent themes through the remainder of the coursework (King \& Butler, 2015).

\section{Summary of the Theory}

Derrick Bell's interest convergence theory is a tenet of critical race theory but can be applied to this condition because it allows the researcher to view the problem in a way that permits understanding that the interests of the minority group are impacted by those of the majority group. Specifically, the minority groups' interests will be advanced if the majority group also benefits. In this case, rural students' opportunities will be advanced if non-rural students are also benefited by new policy addressing the inadequacies of the current system.

\section{Trends in Supply and Demand of High School Teachers}

In 2016, the Learning Policy Institute released a powerfully candid report written by Leib Sutcher, Linda Darling-Hammond, and Desiree Carver-Thomas. This report about the state of education in America holds the only direct estimate of the national teacher shortage to date. Sutcher et. al (2016) said that the demand for teachers is growing but the supply is shrinking. Their research concluded that if current trends continue, there will be about a $20 \%$ increase in annual teacher demand from 2015 levels, reaching 316,000 teachers per year by 2025 and as few as 200,000 available teacher hires each year by 2025 , resulting in a gap of more than 100,000 teachers annually. Cole \& Mitchell (2017) also concluded that the teacher shortage is growing but that each state is experiencing these supply and demand trends in different ways and to 
varying degrees. The supply and demand relationship of teachers is not managed by federal or state governments; therefore, proper incentives are not created to attract more interest in the field of education, especially in specific disciplines (Darling-Hammond, 2010). Blank, Langesen, \& Petermann (2007) identified the subjects of science and math to be particularly challenging to staff. They cite insufficient production of new science and math teachers to meet the growing demand as the root of the problem. Moin, Dorfield, \& Schunn (2005) stated, "During the past four decades, the science and math K-12 teaching field has witnessed a marked decline in recruitment" (p. 981). They move on to say that the number of undergraduates who are seeking science and math teaching degrees is decreasing. Thus, the labor market for schools who are looking to hire highly qualified science and math teachers is heavily impacted by this downward trend.

\section{Declining Teacher Retention}

Another important element affecting the teacher shortage crisis is the decreasing rate of teacher retention. Beginning teachers, especially, are leaving the profession at an astounding rate, thus increasing the demand for qualified teachers (Brill \& McCartney, 2008). Unfortunately, $25 \%$ of beginning teachers in the United States leave the field before they start their fourth year and $40 \%$ leave by year five (Skaalvic \& Skaalvic, 2011). Barnes, Crowe, \& Schaeffer (2007) found that rural schools have a lower retention rate of teachers with less than ten years of experience than other schools. These high rates of attrition are having tremendous effects on the supply and demand for qualified teachers in the United States.

\section{Trends in Science and Math Education Graduates}

The number of students pursuing education degrees in the United States are trending downward. House \& Chatlani (2018) said in 2015, less than one out of ten students were 
studying education and even less planned to pursue an education degree in the future. This number equates to about $4.6 \%$ of college freshmen which is down nearly $10 \%$ since 2005 . Colleges who have education programs are needed now more than ever to train highly qualified teachers but this trend has been stifling their enrollment numbers. Will (2018) found that between the 2007-2008 and 2015-2016 academic years, there was a 23\% decline in the number of people completing teacher-preparation programs. More specifically, according to the U.S. Department of Elementary and Secondary Education, in 2016 only 2\% of all education majors were pursuing a science degree and only $3 \%$ were pursuing a math degree. An overwhelming $22 \%$ of education majors in 2016 were focusing their studies in elementary education. Secondary education majors in high need areas are dwindling and becoming a major crisis in the U.S. This comes at a time when the demand for highly qualified teachers is steadily increasing making it a struggle to find people to fill open positions. The impact of this trend is so immense that in his 2011 State of the Union address, President Barack Obama called on universities to train 100,000 new elementary and secondary school science and math teachers by 2021.

\section{Student Academic Performance}

The shortage of science and math teachers has many ramifications. Unfortunately, one of the greatest consequences of this reality is that students are adversely affected. Students' ability to learn is hampered by the deficiency of highly qualified teachers available to fill vacant positions (Darling-Hammond, 2000; Barnes et. al, 2007; Ladd \& Sorensen, 2017). The levels of underqualified teachers in the science and math disciplines are increasing because many schools are unwillingly lowering their standards in hopes of simply filling the open positions in those subjects (Ingersoll and Perda, 2010). In fact, Monk (2007) found that rural teachers are more likely than their urban counterparts to have majored primarily in education, which means they 
have completed less coursework in science and math. They are also less likely to have graduate degrees than urban teachers.

Another damaging outcome of the teacher shortage is the revolving door of teachers students see from year to year, or in some cases, term to term. Schools who serve the most underprivileged or vulnerable populations like those in rural America are the ones who most often experience this high teacher turnover which, in turn, has negative effects on student achievement and can lead to the ineffectiveness of teachers (Garcia \& Weiss, 2019; Guha, Hyler, \& Darling-Hammond, 2017). Novice teachers have a much higher turnover rate than experienced teachers which limits the effectiveness of the new teachers who are hired in rural areas (Glennie, Mason, \& Edmunds, 2016).

\section{Struggles in Staffing of Rural Schools}

Districts are finding it more difficult each passing year to recruit and retain teachers in rural schools in the United States (Lowe, 2006). Teacher shortages are most apparent in disadvantaged places throughout the country, like those in rural areas, and often force districts to hire teachers without conventional licensure to fill open positions (Dee \& Goldhaber, 2017). There are many reasons why rural districts have difficulties recruiting and retaining teachers. Some of the most common reasons why potential employees reject positions in rural districts or leave rural districts are social isolation, multiple grade or subject teaching assignments, insufficient salaries, and lack of familiarity with rural schools and communities (Barley \& Brigham, 2008; Garcia \& West, 2019).

\section{Struggles of Rural Teachers: Multiple Roles}

Rural districts are unique in that each individual often fills many roles. Oftentimes teachers in these districts are also coaches, bus drivers, mentors, and counselors (Sawchuk, 2018). This 
multiple responsibilities expectation is quite overwhelming and sometimes off putting to new teachers which can lead to the attrition of teachers in these districts. Additionally, even though teachers in these districts are often expected to take on many different duties, their pay is not substantial enough to compensate them for their additional roles. Tran \& Smith (2019) said that for rural districts to retain the teachers they do hire, present level salaries will have to be increased to be more comparable to the salaries of teachers in other parts of the country. Essentially, rural districts have a much greater difficulty hiring and retaining teachers because of factors specific to these areas in which there is no easy solution.

\section{Teacher Decline, Rural Schools, and Student Achievement}

There are less science and math education degrees being conferred now than ever before. This has made a huge impact on the labor market for highly qualified teachers in the United States. Rural schools are constantly plagued by struggles relating to recruiting and retaining teachers, but their efforts are futile because of their inability to be competitive in the mission to hire and keep teachers. Unfortunately, students who are subjected to a revolving door of teachers are not afforded the same opportunity to succeed as those who have consistent instruction. All students should be offered a fair chance to be instructed by highly qualified teachers in every discipline, regardless of their location. The minority rural population deserves the same right as those not taught in rural districts to be taught by competent, effective teachers.

Rural districts have had to offer competitive benefits to attract potential candidates to fill vacancies in their districts. Oftentimes, recruitment for rural districts revolves solely around the ability to provide highly competitive perks. Ulferts (2016) identifies some of the most effective recruitment and retention factors as: ability to provide competitive insurance packages, salaries competitive with other states, financial assistance for advanced degrees, mentoring and support 
programs for new teachers, and assistance with student loan debt. 


\section{References}

Allegretto, S. A., \& Mishel, L. (2016). The Teacher Pay Gap Is Wider than Ever: Teachers' Pay Continues to Fall Further behind Pay of Comparable Workers. Economic Policy Institute.

Aragon, S. (2016). Teacher Shortages: What We Know. Teacher Shortage Series. Education Commission of the States.

Azano, A. P., \& Stewart, T. T. (2016). Confronting Challenges at the Intersection of Rurality, Place, and Teacher Preparation: Improving Efforts in Teacher Education to Staff Rural Schools. Global Education Review, 3(1), 108-128.

Barley, Z. A., \& Brigham, N. (2008). Preparing Teachers to Teach in Rural Schools. Issues \& Answers. REL 2008-No. 045. Regional Educational Laboratory Central.

Barnes, G., Crowe, E., \& Schaefer, B. (2007). The Cost of Teacher Turnover in Five School Districts: A Pilot Study. National Commission on Teaching and America's Future.

Barth, P., Dillon, N., Hull, J., \& Higgins, B. H. (2016). Fixing the holes in the teacher pipeline.

Berry, B., \& Shields, P. M. (2017). Solving the teacher shortage: Revisiting the lessons we've learned. Phi Delta Kappan, 98(8), 8-18.

Blank, R., Langesen, D., \& Petermann, A. (2007). State Indicators of Science and Mathematics Education: Washington, DC, The Council of Chief State School Officers.

Brenner, D. (2016). Rural educator policy brief: Rural education and the Every Student Succeeds Act. The Rural Educator, 37(2).

Brill, S., \& McCartney, A. (2008). Stopping the revolving door: Increasing teacher retention. Politics \& Policy, 36(5), 750-774. 
Chetty, R., Friedman, J. N., \& Rockoff, J. E. (2014). Measuring the impacts of teachers II: Teacher value-added and student outcomes in adulthood. American economic review, 104(9), 2633-79.

Cowan, J., Goldhaber, D., Hayes, K., \& Theobald, R. (2016). Missing elements in the discussion of teacher shortages. Educational Researcher, 45(8), 460-462.

Cole, C., \& Mitchell, R. (2017). Teacher shortages across the nation and colorado: Similar issues, varying magnitudes(pp. 1-49, Rep.). Denver, CO: Colorado Department of Higher.

Curtin, S. (2018). Teacher Recruitment and Retention in the Rural Midwest: Academic Leaders' Perceptions. Voices of Reform: Educational Research to Inform and Reform, l(1), 4487.

Creswell, J. W. (2014). Research design: Qualitative, quantitative, and mixed methods approaches. Sage publications.

Darling-Hammond, L. (2000). Teacher quality and student achievement. Education policy analysis archives, 8,1 .

Darling-Hammond, L. (2010). Teacher education and the American future. Journal of teacher education, 61(1-2), 35-47.

Darling-Hammond, L., \& Podolsky, A. (2019). Breaking the cycle of teacher shortages: What kind of policies can make a difference?. education policy analysis archives, 27, 34.

Dee, T. S., \& Goldhaber, D. (2017). Understanding and addressing teacher shortages in the United States. The Hamilton Project. 
D'Orio, W. (2019, September 18). Why colleges are struggling to graduate more teachers. Retrieved June 18, 2020, from https://www.educationdive.com/news/why-colleges-are-struggling-to-graduate-more-teac hers/563131/

Eppley, K. (2009). Rural schools and the highly qualified teacher provision of No Child Left Behind: A critical policy analysis. Journal of Research in Rural Education (Online), $24(4), 1$.

Farber, B.A. (1991). Crisis in education: Stress and burnout in the American teacher. Jossey-Bass.

Fitchett, P. G., Heafner, T. L., \& Harden, S. (2016). Characteristics and working conditions of moonlighting teachers: Evidence from the 2011-2012 Schools and Staffing Survey. Current Issues in Education, 19(1).

Gallo, J., \& Beckman, P. (2016). A global view of rural education: Teacher preparation, recruitment, and retention. Global Education Review, 3(1).

Gagnon, D. J., \& Mattingly, M. J. (2015). State policy responses to ensuring excellent educators in rural schools. Journal of Research in Rural Education, 30(13), 1-14.

Garcia, E., \& Weiss, E. (2019, March 26). The teacher shortage is real, large and growing, and worse than we thought. Retrieved July 5, 2019, from https://www.epi.org/publication/the-teacher-shortage-is-real-large-and-growing-and-wo rse-than-we-thought-the-first-report-in-the-perfect-storm-in-the-teacher-labor-market-se $\underline{\text { ries/ }}$ 
Glennie, E. J., Mason, M., \& Edmunds, J. A. (2016). Retention and satisfaction of novice teachers: Lessons from a school reform model. Journal of Education and Training Studies, 4(4), 244-258.

Guha, R., Hyler, M. E., \& Darling-Hammond, L. (2017). The teacher residency: A practical path to recruitment and retention. American Educator, 41(1), 31.

Harmon, H. L., Gordanier, J., Henry, L., \& George, A. (2007). Changing Teaching Practices in Rural Schools. Rural Educator, 28(2), 8-12.

Haycock, K. (1998). Good Teaching Matters: How Well-Qualified Teachers Can Close the Gap. Thinking k-16, 3(2), n2.

Holme, J. J., Jabbar, H., Germain, E., \& Dinning, J. (2018). Rethinking teacher turnover: Longitudinal measures of instability in schools. Educational Researcher, 47(1), 62-75.

House, J., \& Chatlani, S. (2018, February 15). Declining education majors could impact the K-12 to college pipeline. Retrieved July 16, 2019, from https://www.educationdive.com/news/declining-education-majors-could-impact-the-k12-to-college-pipeline/517156/

Ingersoll, R. M. (1999). The problem of underqualified teachers in American secondary schools. Educational researcher, 28(2), 26-37.

Ingersoll, R. M. (2003). The teacher shortage: Myth or reality?. Educational Horizons, 81(3), 146-152. 
Ingersoll, R. M. (2004). Why Do High-Poverty Schools Have Difficulty Staffing Their Classrooms with Qualified Teachers?. Renewing Our Schools, Securing Our Future - A National Task Force on Public Education; Joint Initiative of the Center for American Progress and the Institute for America's Future, Retrieved from https://repository.upenn.edu/gse_pubs/493

Ingersoll, R. M., \& Perda, D. (2010). Is the supply of mathematics and science teachers sufficient?. American Educational Research Journal, 47(3), 563-594.

Johnson, S. M. (1990). Teachers at work: Achieving success in our schools. Basic Books.

King, E., \& Butler, B. R. (2015). Who cares about diversity? A preliminary investigation of diversity exposure in teacher preparation programs. Multicultural Perspectives, 17(1), 46-52.

Ladd, H. F., \& Sorensen, L. C. (2017). Returns to teacher experience: Student achievement and motivation in middle school. Education Finance and Policy, 12(2), 241-279.

Lee, C. (2007). Cultural convergence: Interest convergence theory meets the cultural defense. Ariz. L. Rev., 49, 911.

Lowe, J. M. (2006). Rural education: Attracting and retaining teachers in small schools. Rural Educator, 27(2), 28-32.

Malatras, J., Gais, T., \& Wagner, A. (2017). A background on potential teacher shortages in the United States. SUNY Rockefeller Institute of Government.

Matthews, C. M. (2007). Science, engineering, and mathematics education: Status and issues.

Milner IV, H. R. (2008). Critical race theory and interest convergence as analytic tools in teacher education policies and practices. Journal of teacher education, 59(4), 332-346. 
Monk, D. H. (2007). Recruiting and retaining high-quality teachers in rural areas. The future of children, 155-174.

Player, D. (2015). The supply and demand for rural teachers. Rural Opportunities Consortium of Ohio.

Powell, D., Higgins, H. J., Aram, R., \& Freed, A. (2009). Impact of No Child Left Behind on Curriculum and Instruction in Rural Schools. Rural Educator, 31(1), 19-28.

Raffel, J. A. and Groff, L. R. (1990) Shedding light on the dark side of teacher moonlighting, Educational Evaluation and Policy Analysis, 12, 403-414.

Ratcliffe, M., Burd, C., Holder, K., \& Fields, A. (2016). Defining rural at the US Census Bureau. American community survey and geography brief, 1,8 .

Robinson, B. (2017). Structural Poverty and College Enrollment: The Impact of Rural American Determinism.

Skaalvik, E. M., \& Skaalvik, S. (2011). Teacher job satisfaction and motivation to leave the teaching profession: Relations with school context, feeling of belonging, and emotional exhaustion. Teaching and teacher education, 27(6), 1029-1038.

Sleeter, C. E. (2017). Critical race theory and the whiteness of teacher education. Urban Education, 52(2), 155-169.

Stronge, J. H., \& Hindman, J. L. (2003). Hiring the best teachers. Educational Leadership, 60(8), 48-52.

Sutcher, L., Darling-Hammond, L., \& Carver-Thomas, D. (2016). A coming crisis in teaching? Teacher supply, demand, and shortages in the US. Learning Policy Institute. 
Tran, H., \& Smith, D. (2019). Insufficient money and inadequate respect: What obstructs the recruitment of college students to teach in hard-to-staff schools. Journal of Educational Administration, 57(2), 152-166.

Ulferts, J. D. (2016). A brief summary of teacher recruitment and retention in the smallest Illinois rural schools. The Rural Educator, 37(1).

Will, M. (2018, August 9). Enrollment is down at teacher colleges. So they're trying to change. Education Week, 38(1), 6. Retrieved July 16, 2019, from https://www.edweek.org/ew/articles/2018/08/09/enrollment-is-down-at-teacher-colleges $\underline{\text {-so.html }}$

Winters, J. V. (2010). Teacher moonlighting: evidence from the US Current Population Survey. Applied Economics Letters, 17(11), 1111-1114. 
SECTION IV:

CONTRIBUTION TO PRACTICE 


\section{Contribution to Practice}

Being a fairly recent product of the education program at River Town University myself, I am familiar with the practices within the teacher education program at this institution. Although I am sure there have been some changes since my graduation, I am certain their rich history of cultivating a crop of competent, prepared educators to serve all students remains constant. One of the primary expectations of teacher candidates in the education program at RTU is to maintain the ability to use skills to differentiate instruction so that all students can benefit from instructional strategies. This expectation is meant to ensure that every prospective educator is ready to take on the honorable responsibility of educating today's youth. There are, however, issues related to production of these new teachers from River Town University. An even deeper problem persists in the ability of rural districts in the service area of this university to find and staff highly qualified teachers in the disciplines of science and math. This research study looked at the decline of science and math teacher graduates at RTU over the last ten years and the ability of rural schools in the service area of the university to provide their students with instruction from highly qualified teachers.

RTU has recently started a new program for soon to be teacher graduates called "River Scholars Program" which aims to help them attain the many rigorous expectations of this degree. This program forges a beneficial partnership between RTU's Educator Preparation program, local school districts, and teacher candidates who are beginning their advanced field experience placements. It enhances RTU students' hands-on field experiences, gives them additional opportunities for paid substitute teaching positions and networking, and provides potential access to the hiring process. However, the school districts affiliated with the River Scholars Program are not the ones who are struggling to find highly qualified science and math teachers. Additionally, 
the River Scholars Program neglects to address the lack of recruitment for the secondary education science and math program or extreme decline in graduates with these degrees over the last ten years. I see this as a huge problem which needs to be addressed immediately.

I plan on presenting my findings to the associate dean for Education Preparation and the director of the Office of Field Experiences in RTU's Educator Preparation Program. These individuals play a key role in guiding students toward potential job opportunities. While the goal of the River Scholars Program is very respectable, it lacks attention to the most high need districts in the service counties of RTU. I would propose partnerships with districts who struggle the most to staff highly qualified educators as well as starting a recruitment program for science and math secondary education majors. My research not only illuminates the inequities rural districts face, but acknowledges the disservice public education pays to those students enrolled in hard to staff rural districts.

This presentation will take place following my dissertation defense in the form of a white paper. This white paper will work as a guide to inform the readers about the complex issue stated above and then move to create an informed solution. I believe a white paper is the most efficient way to relay this information as it effectively disseminates the information of the issue at hand and aids in decision making.

\begin{abstract}
There has been a marked decline in the number of graduates from the secondary education science and math program at a regional public university in a Midwestern state over the last ten years. Using qualitative and quantitative data gathered from interviews and surveys, this study revealed that this trend damages the ability of rural schools in the service area of this
\end{abstract}


university to find and staff highly qualified science and math teachers in their high schools; thereby, unfairly impacting rural school students opportunities to learn from highly qualified teachers in those disciplines. To address the struggles that rural school administrators and students face because of this troubling reality, this study constructed its recommendations to directly combat the issues related to production of new teachers from this university and staffing teachers in rural schools.

\section{Introduction}

This research project has brought to light the unfortunate consequence of the declining production of new high school science and math teachers from RTU over the last ten years. Surveys and interviews were utilized to collect both qualitative and quantitative data regarding the impact this trend has had on the ability of rural high schools in the service area of this university to find and staff highly qualified science and math teachers. It also delved into the perspectives of local administrators about this troubling trend.

\section{Problem}

The downward decline of graduates from River Town University who have earned a degree in science or math secondary education over the past ten years has hindered the ability of rural districts in the service area of the university to find and staff highly qualified teachers in those disciplines; thereby, effectively limiting rural school student access to highly qualified teachers.

\section{Design of the Study}

This mixed methods case study focused on the meaning and understanding of the decline in the number of secondary science and math teachers graduating from River Town University. 
River Town University is a public state university in a Midwestern state who is known for preparing teachers for future roles as educators. For the qualitative analysis piece of this study, the researcher was the primary instrument of data collection and relied on an inductive analysis process (Creswell, 2014; Merriam \& Tisdell, 2016).

For quantitative analysis the researcher collected data through a Likert survey to determine the level of impact the declining trend in graduates from River Town University has on rural high schools' ability to find and staff highly qualified secondary science and math teachers over the last ten years. The combination of qualitative and quantitative approaches provided a more complete understanding of the research problem than either approach alone (Cresswell, 2014).

An explanatory sequential mixed methods design was used in this case study, and it was involved in collecting quantitative data first and then explaining the quantitative results with indepth qualitative data. In the first, quantitative phase of the study, the researcher surveyed local rural high school administrators to assess the level difficulty their districts have had in finding and staffing highly qualified science and math teachers. The second, qualitative phase was conducted as a follow up to the survey results. In this explanatory follow-up, the researcher explored the perceptions of rural high school administrators (Cresswell, 2014). The validity of this study was based on utilizing three data collection tools: survey, interviews, and document analysis. Additionally, the researcher employed the adequate steps in developing good instruments to capture the richness of the qualitative findings (Creswell, 2014, p. 227).

\section{Methods}

This mixed methods study focused on the meaning and understanding of the decline in the number of secondary science and math teachers graduating from River Town University. For 
the qualitative analysis piece of this study, the researcher was the primary instrument of data collection and relied on an inductive analysis process (Creswell, 2014; Merriam \& Tisdell, 2016).

For quantitative analysis the researcher collected data through a Likert survey to determine the level of impact the declining trend in graduates from River Town University has on rural high schools' ability to find and staff highly qualified secondary science and math teachers. The combination of qualitative and quantitative approaches provided a more complete understanding of the research problem than either approach alone (Cresswell, 2014). An explanatory sequential mixed methods design was used in this case study, and it was involved in collecting quantitative data first and then explaining the quantitative results with indepth qualitative data. In the first, quantitative phase of the study, the researcher surveyed local rural high school administrators to assess the level difficulty their districts have had in finding and staffing highly qualified science and math teachers. The second, qualitative phase was conducted as a follow up to the survey results. In this explanatory follow-up, the researcher explored the perceptions of rural high school administrators (Cresswell, 2014). The validity of this study was based on utilizing three data collection tools: survey, interviews, and document analysis. Additionally, the researcher employed the adequate steps in developing good instruments to capture the richness of the qualitative findings (Creswell, 2014, p. 227).

\section{Setting}

The following university data has been collected from the university's fast facts webpage. This public university has an undergraduate population of approximately 9,524 students and a graduate population of just over 1,100 students. The female to male ratio is $59.9 \%$ to $40.1 \%$, respectively. The four-year graduation rate is $34.6 \%$; five-year $46.7 \%$; and six year $49.7 \%$. This 
university also offers more than 200 areas of study with approximately 1,500 courses extended for student registration each semester. There are also an impressive 300 courses offered online. The primary service area of this university is approximately 579 square miles and covers 26 counties (River Town University Fact Book, 2018, p. 4). This study focused on the rural school districts located in the primary service counties of this university. There are 67 school districts in this service area who are classified as "rural". For the purposes of this study, the definition of rural schools as identified by Ratcliffe, Burd, Holder, and Fields (2016) is "what is not urbanthat is, after defining individual urban areas, rural is what is left" (p.1). This definition is the official definition used by the U.S. Census Bureau.

The demand for secondary science and math teachers who are being hired to fill vacancies in those 67 rural school districts paired with the decline in secondary science and math education graduates over the last ten years was examined in this study. Because survey respondents and interviewees came from multiple different school districts in the southeast portion of this Midwestern state, the location of the study is expansive. The study, however, only focused on a specific type of school district. Rural schools were the only kind of school considered to be part of the study even though there are other districts in the service area of the university who are not identified as rural.

\section{Participants}

Area administrators were used as the participant pool for the study. The researcher used an email to initiate contact between the researcher and the participants. Convenience sampling of the administrators who volunteer to participate in the interview was used to gather the qualitative data for the study. Due to the nature of the study, the researcher employed convenience sampling because data was only gathered by those participants who were willing and available for the 
interview (Creswell, 2014).

Administrators were chosen as appropriate participants because they are directly involved in hiring teachers to fill vacancies in their buildings. They were asked to complete a survey to gather data about the relationship of this decline in graduates and the ability to find and staff highly qualified science and math teachers. The survey was sent via Qualtrics software.

Amid the current global pandemic of COVID-19, alternate methods for conducting interviews were utilized. Phone interviews took place instead of face to face interviews to reduce person to person contact. Another helpful tool that was offered to participants in lieu of face to face conversations is the Zoom program. This virtual conference call can be done from any location with minimal technology.

\section{Data Collection Tools}

The literature review and principles of the interest convergence theory were used to create proper data collection tools including an electronic survey and interview questions. Proper ethical practices must be followed; therefore, all participation was voluntary and the study received IRB approval. A consent form was given to each participant before he or she began the study. The consent form reminded the respondent of their anonymity throughout the study as well as their voluntary participation. Participants were first asked to complete the electronic survey. The survey participants were a population of administrators in the rural school districts of the southeast portion of the state. This survey was composed of approximately 17 items. The survey asked both qualitative and quantitative questions, both open-ended and multiple choice. The researcher asked survey questions relating to the participant's demographic data, the response to the shortage of highly qualified science and math teachers needed to fill vacancies, trends in vacancies for high school science and math positions, qualifications of science and 
math teachers hired within the past ten years, and teacher retention. The researcher preferred there be a minimum of 20 responses to the survey; however, due to a typical response rate of surveys and the fact that this research was conducted during a pandemic, adjustments were made.

Additionally, a minimum of five interviews were ideal for data collection, but six interviews took place. Permission was obtained from Louis Latham, McKenzie Miller, Steve Snow, Sharon Suntrup, Stuart Sweeney, and Simon Strand to record the exchange. This provided the researcher with the opportunity to transcribe the conversation for a more accurate account of the interview. A series of open-ended questions were asked throughout the duration of the interview, which did not exceed one hour.

\section{Data Analysis}

Pre-existing data about graduation trends of science and math education majors of a regional public university in a Midwestern state over the past ten years was used to help validate the claim that there is a shortage of science and math teachers to fill vacancies in this area. The researcher examined the data collected in the survey responses and interviews to look for themes and code accordingly. Themes emerged as patterns in the administrators' responses in the survey were examined. While analyzing administrator survey responses, the researcher looked for commonalities in responses about demand for science and math teachers, teacher qualifications, and teacher retention. After transcription of the administrator interviews, the researcher performed a similar review of the data in search of parallel ideas relating to the hardships of rural education. The themes were then directly tied to the theoretical framework and research questions. 


\section{Findings}

There has recently been a decline in the number of science and math secondary education graduates from River Town University (RTU). This study aimed to explore the depth and extent of the impact this trend had on the ability of rural schools in the service area of this university to find and staff secondary science and math teachers. Data were collected by conducting 13 surveys and six interviews.

\section{Ability to Hire Teachers}

The decline in science and math graduates damages service area-rural high schools' ability to find and staff highly qualified secondary science and math teachers. In fact, the findings from this study highlight some of the problems caused by the declining pool of highly qualified candidates. The researcher created a scale for administrators to rate, over the last ten years, how the decline in secondary science and math education graduates at RTU has impacted their ability to find and staff highly qualified teachers in science and math. While the scale for this question ranged from one (high impact), three (moderate impact), to five (no impact), the average survey response for this study was 2.33 , with a standard deviation of 0.9428090416 , indicating moderate-to-high impact. Even though rural districts may be unique to their geographic area, culture, and size, one commonality they seem to share is their endeavor to place highly qualified instructors in front of their students. In fact, the declining number of graduates in the area has become an increasing problem for local school districts over the past decade. For example, 12 of the 13 survey respondents said that, over the last ten years, they have found it more difficult to find and staff highly qualified science and math teachers at the secondary level. The mean response of this survey question was 2.08 on a 1-5 scale, where 1 was extremely difficult and 5 was not at all difficult. The standard deviation for this question was 
0.8620067026. This coincides with the declining number of science and math secondary education graduates at RTU over the last ten years. Survey respondents were also asked to rate the feasibility of finding and staffing science and math teachers for their high schools. The average of the 13 respondents was 2.0 with a standard deviation of 1.08012345 , indicating a difficult to very difficult rating.

Of the six interview participants, four were from a "small" school, one was from a "medium" school, and one was from a "large" school, according to the state high school activities association for this state. Louis Latham, is the principal from the only large school district in this study, Liberty High School. He's been the current principal for 6 years. McKenzie Miller, is the principal from Meadowbrook High, the only medium-sized school district in this study. She has held her position as head principal for 2 years but presided as vice principal of the school for 8 years prior to becoming the head principal. The four remaining participants are administrators from small schools in the service area of River Town University. Steve Snow, is the principal from Stillwater High School, Sharon Suntrup, is the principal from Shannon High School, Stuart Sweeney, is the principal from Shipman Senior High, and Simon Strand, rounds out the group of administrators as the principal from Sutton High. Mr. Snow has been the principal of Stillwater for 3 years, Ms. Suntrup has been the principal of Shannon High School for 12 years, Mr. Sweeney has been the principal of Shipman Senior High school for 7 years, and Mr. Strand has been the principal of Sutton High for 5 years. When asked about his perception regarding this trend, Louis Latham, from the large school said:

Sometimes it's not always easy to see the trend of graduates from year to year since we don't have to actually pursue and hire science and math teachers yearly, but I have had years that I have made calls to see what the graduate pool is like 
that year at RTU. I have noticed the applicant pool in general over the last several years has decreased though. Definitely less applicants for jobs now compared to when I first took this job. I've also noticed the placement of student teachers at my school has decreased as well.

Similarly, McKenzie Miller from the medium sized school said:

Since we are a larger, higher paying school, we really don't struggle very hard to find teachers and don't have a bunch of yearly turn over so I haven't really noticed a specific trend in graduates at RTU. We did have a science opening two years ago though and had three applicants. It worried me a little because it's not a huge number and is less than we typically get for an opening, but probably better than other smaller area schools. We picked the best candidate and offered her the position. She verbally accepted but then changed her mind and went to a school closer to her hometown so we had to reopen the position. We ended up choosing one of the other previous applicants and she is currently still with us

The two schools not identified as small both mentioned not recognizing a decline in the number of science and math secondary education graduates at RTU in particular and neither have significant retention problems, but both noted a decline in the general applicant pool over the past several years.

The four small school administrators who took part in an interview shared a common hardship regarding the staffing of science and math teachers. Small schools often welcome placement of student teachers in hopes of cultivating relationships with teachers who could potentially fill vacancies that are hard for them to staff. Steve Snow said: 
It's always hard for us to find science and math teachers but I have noticed it has been worse over the last several years. We have a lot of turnover so it's a constant hardship. We beg for placement of student teachers hoping that we can hire them if needed or make relationships for the future but I have noticed the number of student teachers assigned to our school has become less frequent in recent years

\section{Partnership with RTU}

With the decline in student teacher placement, it is becoming harder and harder for schools to recruit new graduates to work in their schools. Many districts actively seek out these new graduates by contacting RTU directly asking them to refer upcoming graduates to their campus to apply for openings. Stuart Sweeney highlighted:

The first place I call when I know I have an opening coming up is RTU. I have a good working relationship with the people up there so I can get a good idea of how many people they're going to graduate. I let them know to send people my way if they want a job. We usually don't keep people for a long time unless they are from here already or somewhere close by so I make the call to RTU often. I have noticed they haven't been graduating as much as they used to so that's been difficult on me. I have had to struggle more to find people to fill spots

Simon Strand noted taking a similar approach when trying to recruit new staff. He said:

I knew about the decline in grads from RTU's ed program before you contacted me about the study. I usually call them up to see if they can send anyone to me when I know someone is leaving and over time have gotten to know them and how they operate. They have been sorry to tell me on more than one occasion that they have very limited people ready to graduate or even ready for student teaching. 
The affiliation these small schools have established with RTU is important to their recruitment efforts and have proven to be helpful in many instances. For example, Sharon Suntrup said: We recently hired a guy for our science opening from RTU that is currently in his student teaching. I had to use my network at RTU to get a hold of him because we were pretty desperate. Because of the state guidelines, we can't start paying him until he completes 60 days of teaching so he will officially start his career before he even gets his diploma. We told him we would like to keep him for two years, at minimum, because it is so hard to get people to come here. This isn't the first time this has happened in our district. We actually get a lot of first year teachers who come here to get experience for their resume and then leave. Even that has been harder though in recent years.

\section{Less Qualified Applicants}

Additionally, with the decreased number of new teachers produced from RTU, schools have had to turn to other, less qualified job applicants just to fill vacancies in science and math. Administrators have had to become very resourceful when seeking out educators to fill openings. Steve Snow indicated that he had to look elsewhere in the community after he didn't get a single applicant for a recent opening. He explained:

We had no applicants for our math opening a couple years ago. Not one. I contacted every college from Commerce to Springfield trying to find someone that would be interested in filling the position. I turned to the community for help and found a retired engineer who was able to temporarily fill the spot until I could find someone. It wasn't ideal, but it was someone who knew math, had a college degree, and could keep the kids from killing each other. 
Sharon Suntrup and Stuart Sweeney shared a similar story when they referenced hiring someone who didn't have the content qualification necessary to teach the class they were hired for. Ms. Suntrup noted:

We recently hired a young man that was not certified in high school science, only middle school 5-9 science.We really needed someone for our sophomore biology class but did not have any other qualified applicants. He was actually our only applicant so we took him. I moved the current 9th grade teacher up to 10th since she was certified for that class and the new hire filled the 9th grade spot. This was not ideal because he won't be able to teach any other classes during his time with us and we had to move our current teacher to a new class even though she is fantastic in the 9th grade class but it's what we had to do.

Similarly, Stuart Sweeney stated:

We hired a teacher that wasn't qualified to teach the 11th grade science class at our school but she could teach both 9th and 10th grade. She had one section of the 11th grade class, or maybe two I can't remember, but she was our only applicant so we hired her with the contingency that she would obtain the additional certification before the next school year. From what I could tell she did well in the 11th grade class and did end up passing the content exam to be certified for the following year.

In both cases the administrators hired teachers who did not have the content knowledge required for the posted position but manipulated the teaching assignments or created a contract contingency to legitimize the hire.

Small rural schools have struggled the most with this issue, but even the medium sized school in this study shed light on the consequence of this trend. To illustrate, McKenzie Miller explained: 
In one instance, we had an opening for a science position and only had two applicants. One was a newly graduated teacher from RTU who did not have the certification to teach physical science, but did have one for biology. The other had three years of experience and was already certified for physical science but was let go of their previous job for unsatisfactory performance. We chose to hire the new teacher who was not qualified for the position and have her take the content knowledge test after she was hired so she would be certified to teach the class. We felt if she could pass the test she could teach herself the content throughout the year. With the limited pool of applicants, we thought it would be a better choice for students to choose the less qualified teacher who didn't have the negative mark on their resume.

Again, this new hire was not qualified for the position but was hired under the contingency that she would complete the certification test and teach herself the content since she had not received it during her post secondary education classes.

Some area administrators have noted that the quality of student teachers and/or new hires from RTU has changed in some areas such as curriculum development, planning, and classroom management. However, the content knowledge of science and math RTU grads and student teachers has consistently met expectations. The average answer of survey participants on a 1-5 scale for content knowledge of RTU graduates was 4.75 with a standard deviation of 0.4330127019. Sharon Suntrup explained, "I have been consistently impressed with the content knowledge of the graduates I hire from RTU." Simon Strand concurs, but moves on to describe his evaluation of student teacher leadership and class management abilities.

I can't make a generalization about all RTU student teachers, but some of the ones I have spent time with don't seem confident in their ability to take lead in the classroom. 
Even though they seem to have excellent content knowledge, they are still hesitant to take control. I realize some of that is their personality but to be successful in the classroom you have to lead with confidence and maintain control of the classroom at all times. That could come with practice but RTU has to make sure teachers come out of their program with that ability.

\section{RTU Graduate Weaknesses}

Instructional design and lesson planning capabilities have also seemed to be a concern of area administrators. Steve Snow articulated his perception of RTU graduates' abilities to design curriculum through instructional design. He explained:

I have noticed that a few teachers we have hired from RTU are lacking the ability to create curriculum. For instance, we hired a secondary math teacher last year to start this year. He is struggling with the pacing of his class because the previous teacher did not leave him any materials and he has no experience. He doesn't know how to build a curriculum and he doesn't feel comfortable moving on to the next lesson if every student hasn't mastered the content. I spent a good deal of time texting him last night trying to explain that expectation is not reality and the students are never going to know as much as he knows. He is really struggling with building arranging his lessons and spent an hour in my office this morning talking about it. I tried to explain that he needs to look at the big picture, pick the important content, teach it, move on, and reteach specific kids when needed. I don't think he was expected to create a structured unit during his student teaching and probably just used whatever his cooperating teacher gave him. That probably wasn't RTU's fault because I believe they probably expect their student 
teachers to develop a whole unit of teaching, but this specific student was not prepared for starting from scratch. I suspect he isn't the only first year teacher to struggle with this. I have seen it in a few other recent RTU grads.

Learning to teach from an already established curriculum is almost a luxury to many rural school districts. Not even the district size can distinguish between the haves and have not's when it comes to learning the true art of teaching. For example, Louis Latham, from the large school in this study, had a similar view. He said:

We are getting less and less student teachers, especially in math. I don't spend a lot of time observing those we do get but I do try to stay informed about them in case I need to try to recruit them later. I ask for teacher feedback on them. They mostly have great things to say from student teachers at every level of the program, but instructional design has seemed to be a concern in some cases. I think just the ability to fill the class period with meaningful exercises or activities is important. That is tricky for a lot of new teachers though.

As rural communities in the service area of this university are experiencing a more difficult time finding highly qualified applicants for job openings, they are also receiving less and less student teaching placements. This paired with the changes in abilities of new teachers to create curriculum and plan lessons is allowing for gaps in opportunity to learn for rural school students who depend on these teachers and student teachers.

The perceptions of the six administrators who were interviewed about the trend in the decline of secondary science and math education graduates are diverse but common themes emerged through careful analysis of the data. 


\section{Alternatively Certified Teachers}

The pool of applicants for vacant science and math teaching positions is not only decreasing, but those who are hired are less qualified. In some cases, administrators have to hire science and math teachers who have taken an alternative route to education because they cannot find highly qualified instructors to fill the vacant positions. By taking this alternative route, some administrators say that those new to the teaching profession are lacking the ability to communicate their knowledge to students. Simon Strand identified this reality during his interview. He said:

I have had to hire some people who followed the alternative certification route into education. I actually took that path myself. Some are brilliant in math, but they have no idea how to teach someone to do that math. They can solve problems and are very bright but they don't have the teacher talk they need to relay information to their students since they didn't actually go to college to learn to teach and plan lessons. They struggle with communicating content knowledge but also have a hard time recognizing when students have reached a satisfactory level of achievement and when they haven't. Getting a good read of the classroom is not always their strong suit since they haven't taken any formal student assessment classes in college.

Likewise, Sharon Suntrup stated:

One of our current teachers left her job in the private sector because she wanted a better schedule since she has two small children and didn't want a commute to work. We were of course happy to have her since we were in need of a qualified math teacher in our high school. She has a math degree and completed the alternative certification to fulfill requirements. She does a good job in the classroom but I know it took her a few years to 
learn how to teach. It's harder than most people think to actually be able to communicate what you know in a way that's easy to understand.

Placing a knowledgeable, capable person in the classroom is important, but these two small school administrators indicated the struggles associated with hiring a teacher who has taken the alternative route to education. Still though, this route is better than having no teacher at all in the classroom. Stuart Sweeney, another small school administrator said:

We have very few applicants. When we needed a science teacher we received no applicants, so we hired our full-time sub. He doesn't have a science degree but we needed someone in the classroom who could control the kids and at least keep order in the room. $\mathrm{He}$ is in the process of completing his science ed degree now.

\section{Revolving Door of Teachers in Rural Schools}

Another common emergent theme revealed after dissection of the data is that many rural schools are considered "feeder" schools by administrators because they often hire and train teachers who only stay for a brief period of time before moving home or to a larger, better paying school. This is a recurring problem for small schools especially and these administrators have to combat this trend yearly. Steve Snow highlighted this truth by saying:

I have had 6 new math teachers for the same position in the last 5 years. I had to let one go midyear because of inappropriate behavior but luckily I was able to get a student teacher who we were able to pay during student teaching. It's a constant revolving door here. I am sure you have heard this from other people you've interviewed though. It's a pretty common problem in these really small schools. It's just something we've learned to adapt to over the years. Things just aren't like they used to be in education. A lot of 
people aren't lifers anymore because of the stress and expectations. It can be crazy. That's added to the turnover for sure. But back to your original question, I think it's been harder and harder to find people since not many people want to be teachers anymore.

Simon Strand moved on to explain:

All new teachers want a job. That's why they spend years in school. And most take whatever they can get so they are happy to come work for us. The trend here though is that we take on new teachers, train them, then they leave us for more money the bigger schools can provide. It's a little frustrating because it seems like we are constantly on the hunt for someone who is qualified to teach here. Not just in science and math.

Unfortunately, this research study revealed several districts in the same situation. Many local rural schools have been in a pattern of experiencing a revolving door of teachers each year. Administrators cited pay and benefits as being two factors leading to this constant turnover. Sharon Suntrup explained:

We've just accepted the fact that we won't keep anybody very long. Except those who were born and raised here. That's not really common though. We have a couple.

Everybody wants to make more money because teaching is hard and takes a lot out of you. We sort of funnel our teachers to the bigger schools because they can pay more and often offer better benefits.

The large teacher turnover is a consistent problem recognized by many rural school administrators. Navigating the problems associated with this reality can be challenging but Stuart Sweeney has developed his own method for overcoming this troubling trend. He said: Retaining teachers has been a focus here because training new teachers takes so much effort and time. I haven't really figured out the perfect solution yet but we try to make 
new teachers at our school feel welcomed and valued in hopes of keeping them around. I take time to show interest in their growth and development as a professional. I try to give as much feedback and evaluation as possible to build the new teachers but also realize they are an investment and hope that it pays off. I don't blame any of them for moving closer to home or going where there is more money, that's what anyone would do, I just try to make that decision a little harder for them by creating an environment they want to be in.

Even the medium sized rural school administrator spoke of her school district's inability to retain teachers. McKenzie Miller said:

We cannot keep people that use Meadowbrooke as a starting point. If they are from north of here they typically stay a few years and then go back north to be with family. They usually get paid more and have better benefits up in the large, urban schools too. An additional perception many administrators share is that they believe low pay is the biggest reason why teachers do not come to rural districts or do not stay very long once they get there. Rural school districts have a lower teacher salary, compared to larger districts and this salary differential is often a deterrent for those looking for a teaching job. Simon Strand explained:

The reasons why most people leave us is because we just can't compete with the bigger schools. We can't pay like the guys in Jonesboro or Commerce. The small town charm is great for some, but sometimes it's not enough to keep people here. When the dollar signs get bigger, people tend to go towards them. And it makes sense. Especially when a lot of those people are just starting out and want to save money for buying a house or starting a family. 
Likewise, Steve Snow explained:

We simply cannot compete with other larger districts in terms of pay. We don't have a big enough tax base. I was lucky to fill a science spot last year with a girl who is a graduate of Stillwater so she was elated to have a job back at home. I don't see her leaving since she is from here but most of the time if we hire someone not from here or the immediate area they don't stay long.

Stuart Sweeney from a neighboring small school said, "We are so small and rural. It is not as difficult for us to get teachers as it is to retain them. We seem to be used as a stepping stone for experience and then are left for higher pay." Sharon Suntrup is faced with the same dilemma in her school but offers a possible solution to the problem. She says:

We don't have a grown your own program here, but I wish we did. I don't think people would consider coming and staying here for a long period of time if they aren't from here already because we don't have the ability to compete with the bigger areas like Commerce and those communities surrounding it since our base salary is so much lower. If we could sink some time into talking up the profession and showing our kids that teaching is a great career, then I think we might be able to begin a grow your own sort of thing here. Working that into our already jam packed schedule is the tricky part.

\section{Other Variables Causing Turnover}

There are variables other than pay that impact the ability for small rural schools in the southeast portion of this Midwestern state to attract and retain science and math teachers. Additional responsibilities because of small size, larger, more diverse course loads, and social isolation are three additional factors cited by area administrators that play a key role in the ability to attract and retain teachers. 


\section{Extra Duties}

Regarding multiple duties and responsibilities, administrators say that since their schools are so small, they often have to ask teachers to take on additional out of school assignments to be able to provide students with opportunities to engage in clubs and sports. These additional tasks placed on teachers are often taken begrudgingly to obtain or keep their current position, sometimes even being written into their hiring contract. Stuart Sweeney stated:

We have to ask many of our teachers to be coaches or sponsors of clubs because we want to offer as many extracurriculars as possible but with such a small staff, it's really difficult. Almost every staff member here is in charge of some after school activity or is a coach of some kind. There are several who are sponsors for multiple clubs and actually coach year round. Some people are meant for it, but some aren't. We have to ask our first year teachers to also fulfill these extra duties and it can be really overwhelming for them. They are usually included in the contract before hiring is complete. Many want to be in a school where they aren't expected to also coach or sponsor clubs, and I don't blame them. It's a lot of work, but unfortunately it's necessary at our school. I think this is one of the reasons why teachers haven't stayed long here.

Similarly, Steve Snow from another small school said:

Many times we post a job but during the interview we ask the candidate if they are also okay with coaching or being a club sponsor. Even if they haven't coached the sport before or ever been the head of a club we have to have them so our kids can participate in these activities. We have had some people who weren't able to take on the extra duties because of other commitments but we can't possibly pile more onto the existing faculty. Some people even take the job but realize the extra responsibility isn't worth the money 
so they actively seek out another job the following year.

These extra roles being placed on new teachers is something administrators identified as a possible reason for turnover. Extra responsibilities means both extra work and extra time, something that is hard to find more of as a new teacher. As Stuart Sweeney said, the extra work is probably contributing to the turnover he experiences.

\section{Large Workload}

Being a science or math teacher in a rural school also lends itself to teaching many science or math classes instead of just one or two. Some rural teachers are the only science or math teacher at their school, which means their course load requires much planning. Sharon Suntrup illustrates this point stating:

It's challenging for new teachers to have multiple classes to prepare lessons for each day. It's hard for anyone, really. In our case we have one teacher for 9th-12th grade science and one for 9th-12th grade math. We do get a lot of first year teachers here trying to get experience for their resume and they give it their all, but I can tell they are not prepared for planning multiple classes. I don't think it's easy for anyone in the beginning but I think that's one of the reasons we have a lot of turnover. Most teachers, I would say, do teach more than one class per day so I feel like students in the student teaching process should have a better idea of what to expect when they actually go out on their own. I think this may be one of the reasons why people don't stay long at our school. The overwhelming workload can be so draining.

She indicates that she doesn't believe student teachers are prepared for the reality of planning for multiple classes each day and may decide to leave because of the stress associated with preparing 
for so many different courses. Simon Strand also identifies the same problem at his school. He said:

Something that is hard to combat is that both our math and science departments are the only faculty in their department, meaning they have multiple preps. They may teach 5 different classes throughout the day. That's a lot. Especially for a new teacher, which is what we get the most of here. They just don't stay around long because of that. New teachers are just trying to keep their head above water the first year, planning and preparing for multiple classes is extremely difficult. That's why a lot of new hires leave. And I don't blame them, but I don't have any other options. The workload is just so much for them and I don't think they are prepared for it. Student teaching doesn't always show real life.

He refers to this problem of a large course load as one of the reasons why teachers don't stay long at his school either. Being responsible for planning many different lessons is a very tough task, one that even veteran teachers can sometimes struggle with, but Sharon and Simon both identified the diverse workload of small, rural schools to be one of the factors that correlates to the retention of teachers. They both mentioned that new teachers are not prepared for this kind of extensive planning. Adding a new perspective, Louis Latham, from the large school in this study, shared a different story about how a diverse course load affects his employees. He said:

Because we are a bigger school, we have been pushed by the board to have a more diverse set of math and science offerings over the last several years. This means that some of the core classes are a little larger than normal, but in turn, we are able to offer more electives or stepping stone classes. For example, a kid who hates math shouldn't be forced to take Algebra I as many times as it takes to pass the class. So we are able to offer 
Algebra A and Algebra B which is essentially just Algebra I in two years instead of just one. It has worked out well so far but has increased the course load for a few of our teachers. For example, one teacher who only taught biology and dual credit biology had to give up one of her biology classes and teach an elective science class. This means she got an additional class to prep for but the other biology teachers' classes got a little bigger. I know, in this case, the biology teacher wasn't thrilled to have an additional prep and more work, but I wasn't worried about losing her since she is from here and we are a good paying district. She knew it was best to provide opportunity to kids who need it. Opening opportunities for students is always a positive change but, even for big schools, this change can lead to more work for teachers.

\section{Social Isolation}

Social isolation is another key factor identified through data analysis that leads to low retention rates of new teachers and the inability to fill open positions in rural schools. Stuart Sweeney said:

We pretty much only have a gas station, a small grocery store, lots of churches, and some banks in our town. It's so small that most people who teach here don't live here but we are so isolated that the next closest place doesn't have a ton more stuff to offer, especially for young, newly graduated students looking for their first job. This isn't a place with a social scene where you can meet a bunch of new friends so it's definitely a challenge to get the new kids in here, especially if they aren't already from a small town.

He describes how the small town does not have the attractions of a larger, more populous area so it is hard to sell the location to potential new employees. He explains that neither the town nor 
surrounding areas have much to offer as far as things to do so it doesn't appeal to the young, new graduates. Simon Strand mirrored this concern saying:

Our town does not attract new people very often. Mostly because it's out here in the middle of nowhere and there's not much of anything to see or do. The thought of moving to an unfamiliar town that's isolated is not something many people want to do, especially since we can't afford to pay a lot.

Even rural schools who are able to pay more have similar struggles though. Sharon Suntrup illustrates this reality by describing the hardship she encounters when trying to fill an opening at her school.

For our area, we are one of, if not the highest, paying districts. We have increased our base pay to try and help in recruiting highly qualified staff. However, that doesn't always entice someone to come to our small community. It's a nice place, low crime, a great place to live. But if you didn't grow up here it can be hard to get used to being so far away from everything. Some people try it out and decide it's just not for them. There can be a feeling of loneliness for those who aren't used to the small town life, especially when they don't know many people. I'm glad the board approved the increase in base pay but sometimes that's just not enough to overcome the remote location of our school and town.

McKenzie Miller, from the medium sized school moves on to describe how the location of her school doesn't really deter potential employees from coming to her district but she understands the hardships other local rural schools face when looking to hire new teachers. She said:

I know some of the more rural areas around our district struggle to find people because they are so far out of the way. I mean, they aren't close to anything. It's really hard to sell 
a school to someone when they are going to be thrown into the middle of corn fields and

woods with nothing to do. We are lucky enough to be between two bigger areas that have large shopping areas and entertainment.

Clearly, these administrator perceptions suggest that remote locations of rural schools in this part of the state have a large impact on the school's ability to attract and retain teachers. The social isolation factor paired with the diverse course load and additional responsibilities placed on rural school teachers have all been identified by administrators as key elements in the formula of finding and staffing high school teachers. All of these variables are directly related to the location of the school. The rural location of these schools is what makes them socially isolated but also contributes to the large course load and additional responsibilities of teachers.

There has been a sharp decline in secondary science and math education graduates from River Town University in the last ten years. Local rural administrators have identified three main reasons why they believe this trend is happening. Low pay and lack of respect for the profession are two of the most common themes which emerged from analyzing the data collected from both the survey and interview process. Another important factor administrators believe is leading to the decline of secondary science and math education graduates from RTU is the lack of recruitment by RTU for students to enroll in the education program at the university.

\section{Different Careers}

All agree that the single most influential factor that drives potential students away from the teaching profession is the low pay compared to the amount of stress and responsibility associated with the job. Additionally, those who have the aptitude to complete the rigorous science and math classes needed to obtain a secondary education degree in these disciplines can make more money by choosing a different career. Students could make more money in a 
different profession with the same level of math and science training. Those who excel at math and science are more likely to choose other careers because of the pay unless they are passionate about teaching kids. Simon Stand illustrated this point saying

In my opinion, those planning to go into the education field typically choose easier paths than science and math. Those that excel in science and math can make more money going into other fields besides education. It is rare to find someone who excels in these areas and has a passion to work with kids in education.

Stuart Sweeney made a very similar claim when he said. "With higher level math and science skills, I suspect many potential candidates are seeking careers with higher salaries." Sharon Suntrup also points to the idea that a potential teacher must possess a genuine passion for working with kids or else they will use their skills to pursue an alternate degree which will offer a larger salary. She said:

It's possible that young people do not have the same empathy and feeling of responsibility for the next generations. If they don't have a passion for working with kids and helping them prepare for what lies ahead, then teaching isn't going to be what they pursue, especially since they can make more money doing something different given that they possess a unique skill set to succeed in the fields of science and math. Or any subject for that matter.

Clearly, knowing that teachers do not receive the same kind of compensation as those in careers with comparable levels of education is a deterrent for students who have the skills to excel in science and math preparatory classes, unless they have an authentic love for teaching students. 


\section{High Stress}

Administrators also noted that the stress level a teacher experiences is not equitable to the amount of pay they receive, which they believe is a reason why there has been a decline in the enrollment in the education program at RTU. Teaching is no longer an 8:00 to 3:00 job and teachers are made to fill many additional roles, not just teaching. They are often responsible for monitoring the social emotional well being of students as well as other variables that impact students' lives. Students know this prior to graduating high school. They know that teachers foster relationships with their students, they become the safe places and sounding board for many of their students. Administrators believe that these extra stressors are turning students away from the teaching field since it is well known that teachers are not making the kind of money other professionals are. McKenzie Miller stated:

I believe it's the field as a whole. Stressors are so much more than they used to be and it is not equal to the pay. Kids know that. They see their teachers struggling. That's got to be one of the reasons why there are less and less kids going into this field when they get to college.

Similarly, Sharon Suntrup explained:

I am always there to support my teachers, or I try to be. But I know they are continually feeling overworked and underpaid. They have to be more than teachers nowadays. They have to overcome lots of other significant factors that a student walks into the classroom with. Kind of like baggage. I think the students see this. We've put so much extra on the teachers' plates, but their pay hasn't changed. This is probably one of the reasons it has been harder for me to find newly graduated teachers to do this job. 
Steve Snow asks the obvious question, "Why put yourself through the extra stress for low pay?" He moves on to say, "I would guess money is the number one factor. The pay doesn't equal the amount of time that needs to be spent to do the job effectively or the amount of stress I see my teachers deal with on a regular basis."

\section{Poor Man's Career}

Administrators believe that the teaching profession is not "celebrated" like it used to be. They noted that many students see teaching as a "poor" man's career. According to the administrators, many students believe teachers can't afford to support a family on a teacher's salary. Students know that teachers don't make as much money as those in other professions with comparable degrees and don't receive the amount of respect that other professions do. Steve Snow illustrated this idea saying:

In our small community, we can't pay our teachers a lot so many of them have second jobs and students see them out doing something other than teaching so they develop this idea that all teachers are poor and have to work two jobs to make ends meet. That may be true for some of my employees but certainly not all of them. Since kids see this happening some of them have the opinion that teaching isn't something they would ever do because you have to go to college and still end up working two jobs.

Similarly, McKenzie Miller stated, "I think the teaching profession does a poor job selling the merits of becoming a teacher. Too many people have the perception that teachers do not make enough money to support a family or that teachers deal with unruly students all day long." Stuart Sweeney condensed these ideas into a concise statement claiming, "Perhaps potential candidates think teaching is too difficult or not worth some of the negative stereotypes such as low pay and 
poor working conditions." Sharon Suntrup also mentioned the reality that teaching is not the same as it used to be, especially regarding discipline. She said:

I think there's less interest in becoming a teacher because it isn't respected the same way it used to be. It doesn't come with the same praise it once did. Students certainly don't respect authority like they used to either. Discipline problems have increased and the way we are allowed to hand out discipline has changed significantly. I've been doing this a long time and working in the classroom is harder now than it used to be and that's one of the reasons.

\section{No Recruitment by RTU}

The survey also brought to light another potential reason why there has been a decrease in secondary science and math education graduates from RTU in the last ten years. 13 out of 13 respondents were not aware of any efforts made by River Town University to recruit students to the education program. The data shows that RTU sends representatives to some rural schools but they are speaking about information related to the general admission requirements and majors offered at the university, not about entering the education program specifically. There is no active recruitment process by RTU whatsoever on any of the 13 rural campuses who took part in this survey. Steve Snow said:

RTU comes a couple times a year to talk about the application process. Being the biggest four year college around, we are always happy to have them and glad to see our kids get accepted since there isn't a large push to succeed academically down in this area. They do a great job explaining how to apply and helping the kids understand the requirements. I haven't heard them specifically talk about becoming a teacher though or what the requirements are for obtaining a teaching degree from RTU. 
Similarly, McKenzie Miller stated, "RTU sends a representative to our school to recruit students but I would have to ask the counselor's office if they know about anything specifically related to the teaching program at RTU. I would think that if they really wanted to attract candidates they would send a specific rep to get kids interested in teaching." Simon Strand describes the same situation at his school. He said, "Someone from RTU comes to present to the senior class about the college but I have never heard them try to actively recruit students to join their education program." Additionally, 9 out of 13 survey respondents identified RTU as one of the primary four year colleges their students attend, but their students are not majoring in education. This failure to actively recruit education majors paired with student perceptions of the teaching career and the stress it brings with it are all factors that local rural administrators perceive to be the biggest reasons why there has been a decline in graduation rates in the education.

\section{Recommendations}

The focus of these recommendations is aimed at ways for River Town University to produce more high school science and math teachers and actions local rural schools could take to cultivate a "grow your own" program in their schools to encourage and prepare their current high school students for entry into teacher preparation programs, specifically at RTU. The "grow your own" plan could provide rural schools in the southeast portion of the state, who are in the service area of RTU, with highly qualified teachers willing to live and work in their communities. Additionally, recommendations were made about how RTU can better prepare students who do end up teaching in districts that will expect them to plan for multiple classes each day and fulfil additional responsibilities. 


\section{Recruitment}

None of the administrators who took part in the survey or interview said they were aware of any formal recruitment practices by RTU for the purposes of attracting students to enroll in their secondary education program. RTU does send representatives to rural schools to give interested students information about attending the university, but none of that information is targeted at pointing students toward pursuing a degree in secondary education. It seems RTU has not made efforts to garner interest for obtaining a secondary education degree in science or math in secondary education, given the number of graduates in these two programs has plummeted over the last ten years, but also since they have not established a recruitment program for science and math education majors. This research study has established that local administrators believe it is very challenging for rural schools in the southeast portion of this state to find and staff highly qualified science and math teachers, and the failure of RTU to recruit new science and math teacher candidates accentuates the problem.

Derrick Bell's interest convergence theory highlights how rural students are not afforded the same resources as their urban and suburban counterparts simply because of their geographic location. Put plainly, because of their rural school status, rural school students are not provided with the same access to highly qualified teachers that other non-rural students are. Rural schools do not have the funding available to attract highly qualified teachers by offering a competitive salary. This means that, in the fight to attract and retain teachers, rural schools are often struggling to fill their open positions in these content areas. This is not a new trend. Many participants in this study noted that they make regular contact with RTU to ask if they have any soon to be graduates they could send them in an effort to fill vacancies. RTU is aware of the struggles these small schools face and has yet to address this problem. ICT would suggest that 
because the needs of the non-rural schools are being met, RTU has not yet pivoted toward taking responsibility for production of teachers who will teach in these rural towns.

This isn't an easy task, but any efforts toward helping these rural schools attract high school science and math teachers would benefit students in those districts. As the literature review pointed out, many students move back to their hometowns to start their career. If attempts were made to pull kids out of rural schools and into the teacher preparation program at RTU, specifically in the areas of high school science and math, then there may be a larger pool of candidates for these rural schools to choose from when attempting to fill a vacant position. Some schools would be satisfied with even one highly qualified applicant.

Conscious efforts are made to attract new students to RTU, as stated above. Rural schools welcome RTU representatives into their schools every year to speak about admission. But they have not developed a program aimed at teaching students about the realities of teaching. No efforts are made by RTU to help students overcome the misconceptions they may have about the teaching profession. As indicated in the findings, many students believe that teachers are poor and don't make enough money to support a family. They think that teachers have to have second jobs just to make ends meet. There are disadvantages about teaching, as with any job, but clearly, most students aren't even considering this career as an option. RTU should approach high school campuses with a plan to dispel misconceptions and highlight the positive aspects of the teaching profession such as the potential to impact student lives, excellent retirement, ability to impart wisdom in the minds of young students, teach students science and math concepts and skills, and the big seller-summers off. RTU should also outline the requirements a student must complete on the road to being a teacher. Knowing how to complete the degree but also understanding the truths about the teaching profession could increase the number of students from rural towns who 
attend RTU to pursue a teaching degree in secondary science or math education. This would benefit the future students of rural schools.

\section{Grow Your Own}

River Town University shouldn't be the only stakeholder responsible for recruiting teacher candidates to their education program. It is also the rural school districts' duty to encourage their talented science and math students to pursue a career in education. Establishing a "Grow Your Own" program at rural schools would be a formal introduction to the field of teaching that students need to become familiar with the career. This kind of program could dispel misconceptions about being a teacher and provide students with facts about this rewarding occupation.

This program could take shape in many forms. A guest speaker series could be an easy, time saving way to disperse important information about becoming a teacher. It wouldn't take much class time away from teachers but would allow for students to learn about becoming a teacher. The series could be done over several sessions and could focus on areas such as RTU's requirements for obtaining a science or math secondary education degree, the truths about teacher pay and benefits, first-hand accounts of how teachers impact student's lives, what a typical teacher's day looks like, and other details about teacher life.

Something else rural schools could do to create a grown your own program is establish a chapter of the Future Teachers of America organization at their school. This organization would have to recruit members and form an active chapter of this club. They could form a partnership with RTU and do field trips to the University and listen to professors explain expectations and course requirements as well as what student teaching experiences are like. The Future Teachers of America club could also sponsor a "Become a Teacher" day at their school inviting in guest 
speakers from RTU and current teachers who could describe their real life experiences involving teaching that students don't get to see. Getting a glimpse of a teacher's life would be an important, and valuable experience for students. The idea here is recruitment. The idea is to accrue interest in becoming a teacher in small rural schools in hopes that those students will enter into teacher preparation programs and come back to their small towns to teach. If they are from the town they are teaching in, they are likely to stay put, decreasing the revolving door of teachers but also providing highly qualified teachers to rural schools who need them.

\section{Community Outreach}

Schools could also utilize their Future Teachers of America organization to provide information to community members who could potentially become teachers in their schools. These people could be active substitute teachers who currently have some college education but need a few classes to finish or they could be other working professionals who need additional education credits to complete their education degree. Sometimes communities may not be informed about teacher shortages and don't realize the impact not having a highly qualified teacher makes on students. Communicating shortages for highly qualified teachers may lead to community concern but there has to be awareness for problems to be solved.

\section{Preparedness of RTU Teacher Candidates}

A few participants in this study noted that they perceived some graduates of RTU having excellent content knowledge, but they saw room for improvement in areas such as curriculum design and structuring lessons, especially regarding preparation for multiple classes. Rural school administrators noted that having to prepare for several classes each day is commonplace in rural schools because of the smaller staff size. Many teachers have to create lesson plans for three or four classes each day which can be very challenging. This is something they believe 
RTU students need to be more prepared for when they enter the classroom as a professional. One administrator said that student teaching doesn't seem to prepare the teacher candidate for a real world experience in the rural classroom. It's sometimes hard for veteran teachers to release control of their classroom and that doesn't help the student teacher realize the amount of work and preparation that goes into being a teacher, but RTU also has a responsibility to prepare students for the reality of teaching in a diverse set of classrooms. Teacher candidates need to know how the environments of a variety of classrooms differ and how to adapt to schools with different instructional needs.

While RTU cannot control the experience student teachers have with their cooperating teachers, they can prepare teacher candidates for the different kinds of schools who may hire them in the future. Providing opportunities for teacher candidates to have specialized training in rural school education could help those who plan to pursue that route better understand how to be successful; thus, limiting the amount of surprise and frustration associated with first year teaching in a rural school district. Areas of focus should be planning an entire curriculum, prepping for multiple classes, managing schoolwork and coaching or advising of clubs, and understanding the unique lifestyle associated with rural living.

RTU should develop a formal recruitment plan to increase enrollment in their secondary education science and math programs and prepare teacher candidates for rural school teaching so they are aware of the unique challenges rural educators face every day. Additionally, rural schools should create a "Grow Your Own" program to cultivate teachers familiar with rural education so they will have a bigger pool of applicants to fill vacant positions. In following these recommendations, RTU and local rural schools will help to level the playing field for rural high 
school students who deserve the same access to highly qualified teachers and experiences as those students who are not enrolled in rural schools.

\section{Summary}

The perspectives of local high school administrators about the specific supply and demand relationship between science and math teacher graduates at this university and the vacancies in these disciplines in their school districts was explored in depth and all research questions were adequately answered in the findings. Although efforts have been made to equalize opportunity for all students, there is still a disparity between the resources available to students in rural areas and those in other areas. Elmore and Furhman (1995) said, "Opportunity to learn means providing all students in society equal opportunity to reach ambitious outcomes, and that implies that schools must not only have resources but use them well so that quality instruction results" (p. 438). The purpose of this mixed methods study was to seek understanding about the implications of the recent teacher shortage through qualitative and quantitative inquiry while applying Derrick Bell's interest convergence theory. The researcher was able to communicate findings to the appropriate policy makers and act as a change agent by advocating for equitable access to highly qualified teachers for students in rural America. In fact, Borman and Dowling (2008) said, "The resource demands associated with employing teachers and the strong empirical evidence linking teacher quality to improved achievement are compelling reasons to focus on policies related to teachers as key levers to improve efficiency, equity, and productivity in public education" (p. 368). High quality teachers must be provided to all students by whatever means possible because proper education is a fundamental right for all children, regardless of their location. 


\section{Significance of the Study}

Rural school leaders often face perpetual staffing challenges (Riley and Sakimura, 2018). The majority of schools in the southeast portion of this Midwestern state are identified as being "rural" districts. This designation alone implies that it will be more difficult for these districts to find and staff qualified teachers but recent research indicates that science and math teachers are even more difficult to locate.

This case study provides a unique glimpse into the problem surrounding the decline of science and math teachers graduating from a regional public university over the past ten years and the impact it has had on the rural school districts in the service area of this university to find and staff highly qualified science and math teachers. An up-close, in-depth, and detailed examination of this condition will allow for conclusions to be made about if and to what extent the decline of science and math teachers is having on the ability of local rural school districts to provide highly qualified teachers in the subjects of science and math.

Regardless of the relationship between the two variables, or the lack thereof, this study explored the perspective that students in rural America are not granted the same opportunities as students in other communities. Because of the way the current school funding model is structured, there are many rural districts which are lacking the necessary means to be competitive in the labor market for highly qualified teachers and this research study aims to bring that revelation to light (Kono, 2011). While current research shows that rural students perform as well as or better than students not educated in rural settings academically, it is worthwhile to ask what rural students could achieve if they were afforded the same resources as students not taught in rural districts (Logan and Burdick-Will, 2017).

This study explored the perspectives of rural school districts, focusing on the staffing of 
high school science and math teachers in this part of a Midwestern state. As a consequence of their location, students in these districts are being educated by teachers who receive a lower average salary than others in more affluent districts (Carr-Chellman, Raney, and Campbell, 2019). Studies have shown that students perform at lower levels when they are being educated by teachers with lower salaries (Ordway, 2018). This means that access to highly qualified science and math teachers may be more limited in this part of the state which, in turn, does not provide the same opportunity for learning to rural students. This research will point to the importance of policy makers to reevaluate their current funding model so as to supply rural districts with necessary funding to recruit and hire highly qualified teachers, especially in the science and math disciplines. It will also illuminate the responsibilities RTU has to recruit potential teachers from rural high schools in the service area of the university so that these rural schools will eventually have a bigger applicant pool of highly qualified science and math teachers to fill positions.

\section{Limitations, Assumptions, and Design Controls}

The obvious limitation to this study is that it was conducted during a nationwide pandemic. A time when schools were being shut down and administrators were being called on to deliver plans to keep students safe while maintaining an environment that promoted the same educational experiences students had prior to the outbreak of COVID-19. Administrators were already among some of the busiest professionals and their new on the job challenges only made them harder to get ahold of and potentially less willing to give up unscheduled time to take a survey and sit for an interview. Finding willing participants was the biggest challenge of this research study, specifically because they could only be from rural schools and had to complete both a survey and interview. The small sample size of this study is less than ideal, but the profound, emergent themes were established because of many similar responses within the 
limited responses the researcher did receive.

Additionally, a mixed methods case study, such as this one, presents a host of other limitations due to the nature of research methodology. Cresswell (2014) points to the importance of the researcher recognizing the challenges this type of research may pose indicating the "need for extensive data collection, the time-intensive nature of analyzing both qualitative and quantitative data, and the requirement for the researcher to be familiar with both quantitative and qualitative forms of research" (p. 218). 


\section{References}

Allegretto, S. A., \& Mishel, L. (2016). The Teacher Pay Gap Is Wider than Ever: Teachers' Pay Continues to Fall Further behind Pay of Comparable Workers. Economic Policy Institute.

Aragon, S. (2016). Teacher Shortages: What We Know. Teacher Shortage Series. Education Commission of the States.

Azano, A. P., \& Stewart, T. T. (2016). Confronting Challenges at the Intersection of Rurality, Place, and Teacher Preparation: Improving Efforts in Teacher Education to Staff Rural Schools. Global Education Review, 3(1), 108-128.

Barley, Z. A., \& Brigham, N. (2008). Preparing Teachers to Teach in Rural Schools. Issues \& Answers. REL 2008-No. 045. Regional Educational Laboratory Central.

Barnes, G., Crowe, E., \& Schaefer, B. (2007). The Cost of Teacher Turnover in Five School Districts: A Pilot Study. National Commission on Teaching and America's Future.

Barth, P., Dillon, N., Hull, J., \& Higgins, B. H. (2016). Fixing the holes in the teacher pipeline.

Berry, B., \& Shields, P. M. (2017). Solving the teacher shortage: Revisiting the lessons we've learned. Phi Delta Kappan, 98(8), 8-18.

Blank, R., Langesen, D., \& Petermann, A. (2007). State Indicators of Science and Mathematics Education: Washington, DC, The Council of Chief State School Officers.

Brenner, D. (2016). Rural educator policy brief: Rural education and the Every Student Succeeds Act. The Rural Educator, 37(2).

Brill, S., \& McCartney, A. (2008). Stopping the revolving door: Increasing teacher retention. Politics \& Policy, 36(5), 750-774. 
Chetty, R., Friedman, J. N., \& Rockoff, J. E. (2014). Measuring the impacts of teachers II: Teacher value-added and student outcomes in adulthood. American economic review, 104(9), 2633-79.

Cowan, J., Goldhaber, D., Hayes, K., \& Theobald, R. (2016). Missing elements in the discussion of teacher shortages. Educational Researcher, 45(8), 460-462.

Cole, C., \& Mitchell, R. (2017). Teacher shortages across the nation and colorado: Similar issues, varying magnitudes(pp. 1-49, Rep.). Denver, CO: Colorado Department of Higher.

Curtin, S. (2018). Teacher Recruitment and Retention in the Rural Midwest: Academic Leaders' Perceptions. Voices of Reform: Educational Research to Inform and Reform, l(1), 4487.

Creswell, J. W. (2014). Research design: Qualitative, quantitative, and mixed methods approaches. Sage publications.

Darling-Hammond, L. (2000). Teacher quality and student achievement. Education policy analysis archives, 8,1 .

Darling-Hammond, L. (2010). Teacher education and the American future. Journal of teacher education, 61(1-2), 35-47.

Darling-Hammond, L., \& Podolsky, A. (2019). Breaking the cycle of teacher shortages: What kind of policies can make a difference?. education policy analysis archives, 27, 34.

Dee, T. S., \& Goldhaber, D. (2017). Understanding and addressing teacher shortages in the United States. The Hamilton Project. 
D'Orio, W. (2019, September 18). Why colleges are struggling to graduate more teachers. Retrieved June 18, 2020, from https://www.educationdive.com/news/why-colleges-are-struggling-to-graduate-more-teac $\underline{\text { hers } / 563131 /}$

Eppley, K. (2009). Rural schools and the highly qualified teacher provision of No Child Left Behind: A critical policy analysis. Journal of Research in Rural Education (Online), 24(4), 1 .

Farber, B.A. (1991). Crisis in education: Stress and burnout in the American teacher. Jossey-Bass.

Fitchett, P. G., Heafner, T. L., \& Harden, S. (2016). Characteristics and working conditions of moonlighting teachers: Evidence from the 2011-2012 Schools and Staffing Survey. Current Issues in Education, 19(1).

Gallo, J., \& Beckman, P. (2016). A global view of rural education: Teacher preparation, recruitment, and retention. Global Education Review, 3(1).

Gagnon, D. J., \& Mattingly, M. J. (2015). State policy responses to ensuring excellent educators in rural schools. Journal of Research in Rural Education, 30(13), 1-14.

Garcia, E., \& Weiss, E. (2019, March 26). The teacher shortage is real, large and growing, and worse than we thought. Retrieved July 5, 2019, from https://www.epi.org/publication/the-teacher-shortage-is-real-large-and-growing-and-wo $\underline{\text { rse-than-we-thought-the-first-report-in-the-perfect-storm-in-the-teacher-labor-market-se }}$ ries/ 
Glennie, E. J., Mason, M., \& Edmunds, J. A. (2016). Retention and satisfaction of novice teachers: Lessons from a school reform model. Journal of Education and Training Studies, 4(4), 244-258.

Guha, R., Hyler, M. E., \& Darling-Hammond, L. (2017). The teacher residency: A practical path to recruitment and retention. American Educator, 41(1), 31.

Harmon, H. L., Gordanier, J., Henry, L., \& George, A. (2007). Changing Teaching Practices in Rural Schools. Rural Educator, 28(2), 8-12.

Haycock, K. (1998). Good Teaching Matters: How Well-Qualified Teachers Can Close the Gap. Thinking k-16, 3(2), n2.

Holme, J. J., Jabbar, H., Germain, E., \& Dinning, J. (2018). Rethinking teacher turnover: Longitudinal measures of instability in schools. Educational Researcher, 47(1), 62-75.

House, J., \& Chatlani, S. (2018, February 15). Declining education majors could impact the K-12 to college pipeline. Retrieved July 16, 2019, from https://www.educationdive.com/news/declining-education-majors-could-impact-the-k12-to-college-pipeline/517156/

Ingersoll, R. M. (1999). The problem of underqualified teachers in American secondary schools. Educational researcher, 28(2), 26-37.

Ingersoll, R. M. (2003). The teacher shortage: Myth or reality?. Educational Horizons, 81(3), 146-152. 
Ingersoll, R. M. (2004). Why Do High-Poverty Schools Have Difficulty Staffing Their Classrooms with Qualified Teachers?. Renewing Our Schools, Securing Our Future - A National Task Force on Public Education; Joint Initiative of the Center for American Progress and the Institute for America's Future, Retrieved from https://repository.upenn.edu/gse_pubs/493

Ingersoll, R. M., \& Perda, D. (2010). Is the supply of mathematics and science teachers sufficient?. American Educational Research Journal, 47(3), 563-594.

Johnson, S. M. (1990). Teachers at work: Achieving success in our schools. Basic Books.

King, E., \& Butler, B. R. (2015). Who cares about diversity? A preliminary investigation of diversity exposure in teacher preparation programs. Multicultural Perspectives, 17(1), 46-52.

Ladd, H. F., \& Sorensen, L. C. (2017). Returns to teacher experience: Student achievement and motivation in middle school. Education Finance and Policy, 12(2), 241-279.

Lee, C. (2007). Cultural convergence: Interest convergence theory meets the cultural defense. Ariz. L. Rev., 49, 911.

Lowe, J. M. (2006). Rural education: Attracting and retaining teachers in small schools. Rural Educator, 27(2), 28-32.

Malatras, J., Gais, T., \& Wagner, A. (2017). A background on potential teacher shortages in the United States. SUNY Rockefeller Institute of Government.

Matthews, C. M. (2007). Science, engineering, and mathematics education: Status and issues.

Milner IV, H. R. (2008). Critical race theory and interest convergence as analytic tools in teacher education policies and practices. Journal of teacher education, 59(4), 332-346. 
Monk, D. H. (2007). Recruiting and retaining high-quality teachers in rural areas. The future of children, 155-174.

Player, D. (2015). The supply and demand for rural teachers. Rural Opportunities Consortium of Ohio.

Powell, D., Higgins, H. J., Aram, R., \& Freed, A. (2009). Impact of No Child Left Behind on Curriculum and Instruction in Rural Schools. Rural Educator, 31(1), 19-28.

Raffel, J. A. and Groff, L. R. (1990) Shedding light on the dark side of teacher moonlighting, Educational Evaluation and Policy Analysis, 12, 403-414.

Ratcliffe, M., Burd, C., Holder, K., \& Fields, A. (2016). Defining rural at the US Census Bureau. American community survey and geography brief, 1,8 .

Robinson, B. (2017). Structural Poverty and College Enrollment: The Impact of Rural American Determinism.

Skaalvik, E. M., \& Skaalvik, S. (2011). Teacher job satisfaction and motivation to leave the teaching profession: Relations with school context, feeling of belonging, and emotional exhaustion. Teaching and teacher education, 27(6), 1029-1038.

Sleeter, C. E. (2017). Critical race theory and the whiteness of teacher education. Urban Education, 52(2), 155-169.

Stronge, J. H., \& Hindman, J. L. (2003). Hiring the best teachers. Educational Leadership, 60(8), 48-52.

Sutcher, L., Darling-Hammond, L., \& Carver-Thomas, D. (2016). A coming crisis in teaching? Teacher supply, demand, and shortages in the US. Learning Policy Institute. 
Tran, H., \& Smith, D. (2019). Insufficient money and inadequate respect: What obstructs the recruitment of college students to teach in hard-to-staff schools. Journal of Educational Administration, 57(2), 152-166.

Ulferts, J. D. (2016). A brief summary of teacher recruitment and retention in the smallest Illinois rural schools. The Rural Educator, 37(1).

Will, M. (2018, August 9). Enrollment is down at teacher colleges. So they're trying to change. Education Week, 38(1), 6. Retrieved July 16, 2019, from https://www.edweek.org/ew/articles/2018/08/09/enrollment-is-down-at-teacher-colleges $\underline{\text {-so.html }}$

Winters, J. V. (2010). Teacher moonlighting: evidence from the US Current Population Survey. Applied Economics Letters, 17(11), 1111-1114. 
SECTION V:

\section{CONTRIBUTION TO SCHOLARSHIP}




\title{
Target Journal
}

The peer-reviewed journal I plan to submit my research to is The Rural Educator. This journal aims to provide a greater understanding of the strengths and needs of rural education and to provide rural educators with resources that support their work. The Rural Educator publishes four kinds of articles. My research falls into one of these categories: Research Articles. According to their website, The Rural Educator defines research articles as "reports of empirical research that address problems of practice in rural education". Limiting student access to highly qualified teachers in the science and math disciplines because of their enrollment in a rural school district is very clearly a problem of practice and must be further studied.

\begin{abstract}
There has been a marked decline in the number of graduates from the secondary education science and math program at a regional public university in a Midwestern state over the last ten years. Using qualitative and quantitative data gathered from interviews and surveys, this study revealed that this trend damages the ability of rural schools in the service area of this university to find and staff highly qualified science and math teachers in their high schools; thereby, unfairly impacting rural school students opportunities to learn from highly qualified teachers in those disciplines. To address the struggles that rural school administrators and students face because of this troubling reality, this study constructed its recommendations to directly combat the issues related to production of new teachers from this university and staffing teachers in rural schools.
\end{abstract}




\section{Introduction}

Since the turn of the 21 st century scholars have studied one of the greatest educational problems in recent history. Specifically, the failure of American schools to ensure that they are finding and staffing qualified teachers (Ingersoll, 1999). A key contributing factor to this dilemma is the decline in highly qualified teachers to fill vacancies in schools. Sutcher, Darling-Hammond, \& Carver-Thomas (2016) contended that the demand for teachers is growing but the supply is shrinking. They argued that if current trends continue, there will be an estimated $20 \%$ increase in annual teacher demand from 2015 levels, reaching 316,000 teachers per year by 2025 and as few as 200,000 available teacher hires each year by 2025 , resulting in a gap of more than 100,000 teachers annually. More specifically, Blank, Langesen, \& Petermann (2007) point to the challenges associated with finding and staffing science and math teachers to fill open positions in high schools. They cite insufficient production of new science and math teachers to meet the growing demand as the root of the problem. Moin, Dorfield, \& Schunn (2005) emphasized, "During the past four decades, the science and math kindergarten through twelfth teaching field has witnessed a marked decline in recruitment” (p. 981). They move on to say that the number of undergraduates who are seeking science and math teaching degrees is decreasing. Thus, the labor market for schools who are looking to hire highly qualified science and math teachers is heavily impacted by this downward trend.

Paired with the struggles to find and staff science and math teachers is the mounting concern related to the quality of teachers in these disciplines which are employed by our nation's public school sector. One of the seminal studies indicating evidence of this national pandemic is Shugart (1983) who argued declining scientific literacy, negative student attitudes toward science, declining achievement, and substantially reduced federal program support are 
all evidence of this crisis. Since the 1980's, many schools have been forced to lower their standards by hiring teachers who are not highly qualified to occupy openings in the fields of science and math leading to greater levels of underqualified teachers in these areas (Ingersoll and Perda, 2010). Ingersoll (1999) found that about a third of all secondary school teachers who teach math do not have a major or a minor in math, math education, or related disciplines like engineering or physics. Likewise, he found that one fifth of all secondary school teachers who teach science do not have the minimum requirements of at least a minor in one of the sciences or in science education. A product of this circumstance is the rise in "out-of-field teaching". A product of this circumstance is the rise in out-of-field teaching, defined as the instance when teachers are assigned to teach subjects that do not match their training or education (Ingersoll, 1998). Ingersoll (1998) defined out-of-field teaching as the instance when teachers are assigned to teach subjects that do not match their training or education. In the second decade of the 21st century, scholars note that schools who employ teachers without proper training and education will make it difficult for students to achieve their adequate yearly progress (AYP) goals (Berry, 2013). This is because those out-of-field teachers lack the content knowledge necessary to effectively teach their students about the standards required for the course.

The deficit of highly qualified instructors poses a significant problem with the intended goals and outcomes of the American education system as a whole, but especially in the rural parts of our country. Specifically, the conversation among scholars has shifted to focus on rural areas of the country. For nearly two decades, scholars have been identifying rural schools as some of the most disadvantaged school systems in the United States (Ingersoll, 2004). This disadvantage stems from the challenges rural schools face when competing for appropriately 
trained teachers to staff their schools. Lower salaries, undesirable working conditions, decreased insurance coverage and other benefits, and geographical isolation are often cited by teachers as deterrents in accepting positions at rural schools and as reasons for the lack of teacher retention in these districts (Darling-Hammond \& Sikes, 2003; Townsell, 2007; Handal, Watson, Petocz, \& Maher, 2013). Adding to the difficulties of rural education, one scholar in particular, Barley (2009) noted that multiple teaching assignments and teaching across several grade levels is a common grievance of rural teachers. Many of these issues are systemic and cannot be solved at the local level which, in turn, perpetuates the revolving door of teacher turnover in rural districts and also corresponds with the difficulties in staffing (DarlingHammond \& Berry, 2006). The struggles to staff rural schools may be related to the inequities rural teachers face. Scholars must look at major funding changes to address fair compensation, benefits, resources, and duties of rural educators in comparison to their urban and suburban counterparts.

As the pool of highly qualified secondary science and math teachers available to occupy vacancies continues to dwindle, the quest to fill open positions by highly qualified individuals becomes more difficult for rural schools as they compete for viable candidates. Better and more equitable educational opportunities must be established for children and their families in rural America.

\section{Literature Review}

Educational outcomes of students are most heavily influenced by the work of the teachers entrusted with the great honor of educating them (Allegretto and Mishell, 2016). Likewise, Stronge and Hindman (2003) listed many factors that lead to higher student achievement such as smaller class size, funding, curricula, and family and community involvement, but very 
deliberately identified the single most important factor in student academic achievement is the teacher. In fact, Chetty, Friedman, and Rockoff (2014) reported that teachers are able to influence their students to attend college, earn higher salaries, and avoid teen pregnancy, among other things, which over time, is likely to have substantial economic and social benefits for the child during the entirety of their lifetime.

Why then are teachers from all disciplines, at all levels, in every geographic location in the United States not compensated the same as other professionals in occupations with a comparative training and education? Statistics from 2015 show that teachers' weekly wages are 17\% lower than those of comparable workers (Allegretto and Mishell, 2016). Put simply, teachers are severely underpaid and have, arguably, one of the most important jobs in today's society.

This disproportionate gap in equal pay for teachers and their peers of similar education and training, along with other factors, has stifled the supply of highly qualified teachers to fill vacancies in schools across America. Ingersoll (2003) found that of teachers leaving the profession, $54.3 \%$ identified poor salary as the motivating factor to change careers. Of those teachers who stay in the profession, approximately $19 \%$ of them "moonlight" to supplement their teacher salaries so they can provide for themselves and their families or raise their standard of living (Fitchett, Heafner, and Harden, 2016).

The pay-related inability to retain teachers isn't the only factor contributing to the discrepancy in supply and demand though. Berry and Shields (2017) stated that enrollments in teacher preparation programs dropped 35\% nationwide between 2009 and 2014. The reason for this decline is illuminated by D'Orio (2019) where he identified low pay as one of the key factors for the downward trend in enrollment of students in teacher preparation programs. The 
staggering amount of teachers leaving the profession each year due to unfair compensation paired with the downturn in enrollment in teacher education programs has created the perfect storm of chaos at the epicenter of staffing schools with highly qualified teachers.

To make matters worse, the decline in supply of teachers is impacting high need areas like special education, foreign languages, bilingual education, math, and science the worst (Barth, Dillon, Hull, \& Higgins, 2016). Sutcher, Darling-Hammond, and Carver-Thomas (2016) noted that in 2015-2016 school year, 48 states and the District of Columbia reported a shortage of special education teachers; 42 states and DC reported a shortage of math teachers; and 40 states and DC reported a shortage of science teachers. They also identified this same trend for the 2014-2015 school year but included bilingual education and foreign language as subject areas who were also facing a shortage of teachers.

With this dilemma having such a widespread impact across the country, it is more important than ever to increase the retention rate of America's teachers, especially in rural areas. Small, rural schools have the greatest problem with teacher retention, especially in science and math (Monk, 2007). Toropova, Myrberg, and Johansson (2020) reported that teacher job satisfaction regarding working conditions, such as pay, is closely related to retention. Geographic and social isolation have both been indicated as prominent reasons for leaving rural districts (Aragon, 2016). Toropova, Myrberg, and Johansson (2020) moved on to identify student discipline, teacher cooperation, and teacher workload to be other significant factors impacting job satisfaction. It is important to teachers that they have the support of their administrative team when faced with disciplinary issues regarding students who misbehaved in their classrooms. Likewise, they noted that teachers need to be part of an environment in which their coworkers collaborate well together. Toropova et al. (2020) uncovered the direct relationship between 
excessive teacher workload and emotional exhaustion paired with motivation to quit teaching. These factors, among others, are significant contributors to the job dissatisfaction of today's teachers.

Another key concern is that students in high minority, high poverty, rural, urban, or lowachieving schools are bearing the burden of the teacher shortage (Aragon, 2016; DarlingHammond and Podolsky, 2019). This means that students in these schools face inequities such as being taught by less qualified teachers. In fact, Sutcher et al. (2016) stated that high-minority and high-poverty schools had four times as many uncertified teachers as low-minority and lowpoverty schools. Robinson (2017) highlighted the relationship between rural locations and poverty noting that poverty manifests itself in these areas. Unfortunately, rural schools, because of their correlation with poverty, are more likely to employ teachers who lack conventional licensure (Dee and Goldhaber, 2017). Garcia and Weiss (2019) explained this phenomena by detailing the inability for schools in high poverty locations to attract and retain teachers because they are not able to offer a competitive wage like low poverty schools.

In 2015, President Barack Obama signed the Every Student Succeeds Act (ESSA) giving new hope to America's elementary and secondary school students. This bipartisan statute was a well received revision of the No Child Left Behind Act (NCLB) enacted in 2002 by the Bush administration and promised to ensure student success in all schools in the United States of America. While ESSA has made great strides in reshaping the American education system and making it more workable for schools and educators, there are still areas in which there must be a swift call to action. In particular, special attention must be paid to the challenges associated with finding and staffing highly qualified teachers in the United States, especially in the science and math disciplines at rural schools. There are many variables which impact student achievement; 
however, teachers are the single most important factor in influencing student performance (Haycock, 1998; Holme, Jabbar, Germain, \& Dinning, 2018). This scholarly review examines the conversation surrounding the impacts of the current teacher shortage crisis by specifically addressing the following topics: the current supply and demand of secondary school teachers in the United States, the specific trend in science and math teacher education graduates, student achievement, and challenges rural schools face relating to hiring highly qualified teachers. All sources used in this review met the following specific criteria: (a) scholarship, (b) quality, and (c) relevance.

\section{Problem of Practice}

The recession of 2008 brought about a time in American education where the supply of teachers far outweighed the demand. In recent years, however, the relationship between supply and demand of teachers has changed dramatically, especially in the subjects of science and math. As the economy began to recover, school systems were able to hire more teachers to staff their schools and provide them with classes and programs that were once eliminated because of insufficient funding. During this time, however, enrollment in teacher preparation programs had decreased by 35\% and teacher attrition had reached a high (Sutcher, Darling-Hammond, \& Carver-Thomas, 2016). The consequence of this reality is that finding and staffing highly qualified teachers to fill vacancies in school districts became increasingly challenging. Not only is it hard to find and staff highly qualified teachers, but it is even more difficult to procure teachers in the fields of science and math, especially for rural school districts (Cowan, Goldhaber, Hayes, \& Theobald, 2016; Bland, Church, \& Luo, 2016).

Often, rural public school students are not given the same opportunity as students not being educated in rural districts to learn from highly qualified teachers because finding teachers 
to serve in those districts is very challenging (Dee \& Goldhaber, 2017; Aragon, 2016; Malatras, Gais, \& Wagner, 2017; Barth et al. 2016; Brenner, 2016). This unfortunate circumstance threatens the intended goals and outcomes of the education system for rural students and could potentially inhibit or delay future student successes because of the possibility for lack of learning. While evidence shows insufficient funding contributes to difficulties rural schools face in being a competitive employment option for qualified teachers (Ulferts, 2016; Azano \& Stewart, 2016; Curtin, 2018; Bland et. al 2016), it does not specifically explore the perceptions of rural high school administrators regarding the decreasing number of science and math teacher graduates.

\section{Purpose of the Study}

Although the ratification of ESSA propelled the education system forward advancing equity for the disadvantaged and high need students, like those in rural areas, this area of oppression still needs to be explored so resolutions can be made. This study aimed its focus on rural administrators' perceptions of how their schools and students have been impacted by the sharp decline in science and math secondary education graduates from a public regional university in a Midwestern state. An explanatory sequential mixed methods design was used, and it involved the initial collection of quantitative data then explained those results with detailed qualitative data. In the first, quantitative phase of the study, survey data was collected from administrators at local rural high schools to establish a supply and demand relationship between teacher graduates from the local university and the vacancies in science and math positions from the last ten years in rural districts in the service area of the college. The second, qualitative phase was conducted as a follow up to the quantitative results to help explain those results. In this exploratory follow-up, administrators' perceptions about the decreasing number of science and 
math teachers graduating from River Town University was examined. Derrick Bell's interest convergence theory was then used as the lens to view the problem.

\section{Theoretical Framework: Interest Convergence Theory}

The problem at hand is that rural American students are not being afforded the same educational opportunities to learn by highly qualified teachers as those who are not being educated in rural school districts. This situation can be explored by identifying rural students as a subpopulation within all students in the American public education system and classifying them as the minority because they represent a smaller, more underprivileged population. This can be done by utilizing Derrick Bell's Interest Convergence Theory which he developed in 1980. This theory rests in the belief that when white self-interest is supported, the white/majority will also promote racial advances for the racial minority (Bell, 1980). This theory can be applied to any situation where a minority population exists. In this case, rural students are the disadvantaged group because, comparatively, enrollment in rural schools is much less. Data and statistics taken from the most recent census in 2010 show that rural schools enroll only $24 \%$ of students attending public schools in the United States (U.S. Department of Education, 2011). Rural students, in this situation, are considered the minority while all others are in the majority.

The dilemma rural students are facing is that they are not being granted equitable access to highly qualified teachers, especially in science and math (Harmon, Gordanier, Henry, \& George, 2007; Powell, Higgins, Aram, \& Freed, 2009). Although households in rural areas have lower poverty rates than those in urban areas, they also have lower household incomes than those in urban areas (Bishaw \& Posey, 2017). The way the current school funding model is set up, the average household income plays a large part in school funding. The federal government funds less than $10 \%$ of education expenses in the United States, which means that state governments 
are responsible for paying the balance (Derisma, 2013). They do so by using income and sales taxes to support the public education sector. The problem is that the revenue generated by these taxes is not stable. It could even drop in times of recession or when a population size decreases (Harmon et. al 2007). This model allocates more funding to areas where property and income taxes are higher; therefore, lower taxes in rural areas means that less money funnels into the school system. Sadly, funding insecurities could be unintentionally created by this approach (Derisma, 2013).

Essentially, rural students are not afforded the same resources as their urban and suburban counterparts simply because of their geographic location. There are many reasons why teachers have cited for not wanting to teach in rural districts such as inadequate benefits, lower pay, insufficient support through mentoring programs, and less than desirable teaching conditions but many of them could be solved with proper funding (Gannon and Mattingly, 2015). A huge deterrent of teachers contemplating taking a job in a rural school district is the low salary and sub par health benefits (Harmon et. al 2007; Ingersoll, 2004). Both of these issues could be resolved by redistribution of monies so that districts could recruit and hire highly qualified teachers and compensate them fairly. Fair compensation would mean that a teacher's geographical location does not directly impact their salary. Player (2015) noted that after experience and degree level are accounted for, rural teachers make almost $\$ 10,000$ less per year than their urban and suburban counterparts. Being able to compete in the labor market for competent teachers could have a huge impact in rural education.

Interest convergence theory is about action and the rhetoric surrounding that action. All students should have equitable access to highly qualified teachers, no matter where they live or what their socioeconomic status is. Unfortunately in this case, because the dominant group's 
needs are being met, the investment of inclusion has not yet emerged for rural schools. The conversation has not turned in such a way at this point so as to allow for rural districts to have the same means of recruiting and hiring highly qualified teachers.

Using Bell's interest convergence theory, the researcher examines this dilemma by calling attention to the fact that rural schools, the minority, are not being allotted the same resources as their urban and suburban counterparts because staffing highly qualified science and math teachers in those districts has not yet reached the level of crisis that is has in rural districts. Currently, the majority's needs are being met, therefore, a call to action has not been made to formalize a specific plan aimed to satisfy the urgency to fill science and math vacancies in rural schools. Despite the fact that nearly a quarter of all American students are being educated in rural districts, national educational policies in the United States do not fit with the needs of rural districts (Eppley, 2009). Gallo \& Beckman (2016) explained, "Without policies tailored to the unique context of rural schools and communities, ensuring equity of access, resources, and opportunity in schools across the United States becomes a difficult task” (p. 2). Unfortunately, when this problem is viewed using Bell's theory, meaningful change will only occur if the rhetoric involved shows a benefit for the majority.

When there is a convergence of interests between the majority and minority populations, equity will be established. Milner (2008) gives an example of the interest convergence theory in action when he cites an example between Whites and non-English speakers in a school system which introduced new policies to fund the busing and financing of additional resources for immigrant students in one of the "best" local schools in the county. The reason why these new policies were put in place is because the majority White students were going to benefit in some way. Specifically, the interest of the majority would be advanced because they would be 
provided with new resources which would allow them to become multilingual. Exposure to various linguistic, ethnic, and cultural differences would benefit the majority because it would prepare them for the ever changing, diverse world.

The interest convergence theory can be applied in a multitude of situations, even those in a legislative context. Lee (2007) used interest convergence to explain why some immigrant and minority criminal defendants who introduce cultural evidence in their defense are more successful than others. When the cultural norms of their defense align with those of the majority, their attempts to introduce cultural evidence are usually successful. Other notable cases Lee (2007) mentions in which interest convergence is utilized to explain United States Supreme Court decisions, lower state court cases, or legal enactments are as follows: Hernandez v. Texas, Plyler v. Doe, and Grutter v. Bollinger. The relevance of these court cases related to the application of interest convergence theory in this study lies in the ability to illuminate injustice of minority stakeholders like those in rural schools.

Interest convergence theory is also used to explain why the curriculum of many teacher education programs is not structured in a way that addresses racial, language, and/or cultural diversity and is also lacking in the preparation of teachers for the diverse students they will encounter in schools. Sleeter (2007) said, "It is very difficult to shift the center of gravity of a program in which the center is defined by White interests, and any proposed change must align with White interests to gain support" (p. 4). Many programs do have diversity courses integrated into their curriculum but they come in the form of one or two classes and race, ethnicity, and culture are not prominent themes through the remainder of the coursework (King \& Butler, 2015). 


\section{Summary of the Theory}

Derrick Bell's interest convergence theory is a tenet of critical race theory but can be applied to this condition because it allows the researcher to view the problem in a way that permits understanding that the interests of the minority group are impacted by those of the majority group. Specifically, the minority groups' interests will be advanced if the majority group also benefits. In this case, rural students' opportunities will be advanced if non-rural students are also benefited by new policy addressing the inadequacies of the current system.

\section{Trends in Supply and Demand of High School Teachers}

In 2016, the Learning Policy Institute released a powerfully candid report written by Leib Sutcher, Linda Darling-Hammond, and Desiree Carver-Thomas. This report about the state of education in America holds the only direct estimate of the national teacher shortage to date. Sutcher et. al (2016) said that the demand for teachers is growing but the supply is shrinking. Their research concluded that if current trends continue, there will be about a $20 \%$ increase in annual teacher demand from 2015 levels, reaching 316,000 teachers per year by 2025 and as few as 200,000 available teacher hires each year by 2025 , resulting in a gap of more than 100,000 teachers annually. Cole \& Mitchell (2017) also concluded that the teacher shortage is growing but that each state is experiencing these supply and demand trends in different ways and to varying degrees. The supply and demand relationship of teachers is not managed by federal or state governments; therefore, proper incentives are not created to attract more interest in the field of education, especially in specific disciplines (Darling-Hammond, 2010). Blank, Langesen, \& Petermann (2007) identified the subjects of science and math to be particularly challenging to staff. They cite insufficient production of new science and math teachers to meet the growing demand as the root of the problem. Moin, Dorfield, \& Schunn (2005) stated, "During the past 
four decades, the science and math K-12 teaching field has witnessed a marked decline in recruitment" (p. 981). They move on to say that the number of undergraduates who are seeking science and math teaching degrees is decreasing. Thus, the labor market for schools who are

looking to hire highly qualified science and math teachers is heavily impacted by this downward trend.

Another important element affecting the teacher shortage crisis is the decreasing rate of teacher retention. Beginning teachers, especially, are leaving the profession at an astounding rate, thus increasing the demand for qualified teachers (Brill \& McCartney, 2008). Unfortunately, $25 \%$ of beginning teachers in the United States leave the field before they start their fourth year and $40 \%$ leave by year five (Skaalvic \& Skaalvic, 2011). Barnes, Crowe, \& Schaeffer (2007) found that rural schools have a lower retention rate of teachers with less than ten years of experience than other schools. These high rates of attrition are having tremendous effects on the supply and demand for qualified teachers in the United States.

\section{Trends in Science and Math Education Graduates}

The number of students pursuing education degrees in the United States are trending downward. House \& Chatlani (2018) said in 2015, less than one out of ten students were studying education and even less planned to pursue an education degree in the future. This number equates to about $4.6 \%$ of college freshmen which is down nearly $10 \%$ since 2005 . Colleges who have education programs are needed now more than ever to train highly qualified teachers but this trend has been stifling their enrollment numbers. Will (2018) found that between the 2007-2008 and 2015-2016 academic years, there was a 23\% decline in the number of people completing teacher-preparation programs. More specifically, according to the U.S. Department of Elementary and Secondary Education, in 2016 only 2\% of all education majors 
were pursuing a science degree and only $3 \%$ were pursuing a math degree. An overwhelming $22 \%$ of education majors in 2016 were focusing their studies in elementary education. Secondary education majors in high need areas is dwindling and becoming a major crisis in the U.S. This comes at a time when the demand for highly qualified teachers is steadily increasing making it a struggle to find people to fill open positions. The impact of this trend is so immense that in his 2011 State of the Union address, President Barack Obama called on universities to train 100,000 new elementary and secondary school science and math teachers by 2021.

\section{Student Academic Performance}

The shortage of science and math teachers has many ramifications. Unfortunately, one of the greatest consequences of this reality is that students are adversely affected. Students' ability to learn is hampered by the deficiency of highly qualified teachers available to fill vacant positions (Darling-Hammond, 2000; Barnes et. al, 2007; Ladd \& Sorensen, 2017). The levels of underqualified teachers in the science and math disciplines are increasing because many schools are unwillingly lowering their standards in hopes of simply filling the open positions in those subjects (Ingersoll and Perda, 2010). In fact, Monk (2007) found that rural teachers are more likely than their urban counterparts to have majored primarily in education, which means they have completed less coursework in science and math. They are also less likely to have graduate degrees than urban teachers.

Another damaging outcome of the teacher shortage is the revolving door of teachers students see from year to year, or in some cases, term to term. Schools who serve the most underprivileged or vulnerable populations like those in rural America are the ones who most often experience this high teacher turnover which, in turn, has negative effects on student achievement and can lead to the ineffectiveness of teachers (Garcia \& Weiss, 2019; Guha, Hyler, 
\& Darling-Hammond, 2017). Novice teachers have a much higher turnover rate than experienced teachers which limits the effectiveness of the new teachers who are hired in rural areas (Glennie, Mason, \& Edmunds, 2016).

\section{Struggles in Staffing of Rural Schools}

Districts are finding it more difficult each passing year to recruit and retain teachers in rural schools in the United States (Lowe, 2006). Teacher shortages are most apparent in disadvantaged places throughout the country, like those in rural areas, and often force districts to hire teachers without conventional licensure to fill open positions (Dee \& Goldhaber, 2017). There are many reasons why rural districts have difficulties recruiting and retaining teachers. Some of the most common reasons why potential employees reject positions in rural districts or leave rural districts are social isolation, multiple grade or subject teaching assignments, insufficient salaries, and lack of familiarity with rural schools and communities (Barley \& Brigham, 2008; Garcia \& West, 2019).

Rural districts are unique in that each individual fills many rules. Oftentimes teachers in these districts are also coaches, bus drivers, mentors, and counselors (Sawchuk, 2018). This multiple responsibilities expectation is quite overwhelming and sometimes off putting to new teachers which can lead to the attrition of teachers in these districts. Additionally, even though teachers in these districts are often expected to take on many different duties, their pay is not substantial enough to compensate them for their additional roles. Tran \& Smith (2019) said that for rural districts to retain the teachers they do hire, present level salaries will have to be increased to be more comparable to the salaries of teachers in other parts of the country. Essentially, rural districts have a much greater difficulty hiring and retaining teachers because of factors specific to these areas in which there is no easy solution. 


\section{Teacher Decline, Rural Schools, and Student Achievement}

There are less science and math education degrees being conferred now than ever before. This has made a huge impact on the labor market for highly qualified teachers in the United States. Rural schools are constantly plagued by struggles relating to recruiting and retaining teachers, but their efforts are futile because of their inability to be competitive in the mission to hire and keep teachers. Unfortunately, students who are subjected to a revolving door of teachers are not afforded the same opportunity to succeed as those who have consistent instruction. All students should be offered a fair chance to be instructed by highly qualified teachers in every discipline, regardless of their location. The minority rural population deserves the same right as those not taught in rural districts to be taught by competent, effective teachers.

Rural districts have had to offer competitive benefits to attract potential candidates to fill vacancies in their districts. Oftentimes, recruitment for rural districts revolves solely around the ability to provide highly competitive perks. Ulferts (2016) identifies some of the most effective recruitment and retention factors as: ability to provide competitive insurance packages, salaries competitive with other states, financial assistance for advanced degrees, mentoring and support programs for new teachers, and assistance with student loan debt.

\section{Methods}

This mixed methods study focused on the meaning and understanding of the decline in the number of secondary science and math teachers graduating from River Town University. For the qualitative analysis piece of this study, the researcher was the primary instrument of data collection and relied on an inductive analysis process (Creswell, 2014; Merriam \& Tisdell, 2016). 
For quantitative analysis the researcher collected data through a Likert survey to determine the level of impact the declining trend in graduates from River Town University has on rural high schools' ability to find and staff highly qualified secondary science and math teachers. The combination of qualitative and quantitative approaches provided a more complete understanding of the research problem than either approach alone (Cresswell, 2014). An explanatory sequential mixed methods design was used in this case study, and it was involved in collecting quantitative data first and then explaining the quantitative results with indepth qualitative data. In the first, quantitative phase of the study, the researcher surveyed local rural high school administrators to assess the level difficulty their districts have had in finding and staffing highly qualified science and math teachers. The second, qualitative phase was conducted as a follow up to the survey results. In this explanatory follow-up, the researcher explored the perceptions of rural high school administrators (Cresswell, 2014). The validity of this study was based on utilizing three data collection tools: survey, interviews, and document analysis. Additionally, the researcher employed the adequate steps in developing good instruments to capture the richness of the qualitative findings (Creswell, 2014, p. 227).

\section{Setting}

The following university data has been collected from the university's fast facts webpage. This public university has an undergraduate population of approximately 9,524 students and a graduate population of just over 1,100 students. The female to male ratio is $59.9 \%$ to $40.1 \%$, respectively. The four-year graduation rate is $34.6 \%$; five-year $46.7 \%$; and six year $49.7 \%$. This university also offers more than 200 areas of study with approximately 1,500 courses extended for student registration each semester. There are also an impressive 300 courses offered online. The primary service area of this university is approximately 579 square miles and covers 26 
counties (River Town University Fact Book, 2018, p. 4). This study focused on the rural school districts located in the primary service counties of this university. There are 67 school districts in this service area who are classified as "rural". For the purposes of this study, the definition of rural schools as identified by Ratcliffe, Burd, Holder, and Fields (2016) is "what is not urbanthat is, after defining individual urban areas, rural is what is left" (p.1). This definition is the official definition used by the U.S. Census Bureau.

The demand for secondary science and math teachers who are being hired to fill vacancies in those 67 rural school districts paired with the decline in secondary science and math education graduates over the last ten years was examined in this study. Because survey respondents and interviewees came from multiple different school districts in the southeast portion of this Midwestern state, the location of the study is expansive. The study, however, only focused on a specific type of school district. Rural schools were the only kind of school considered to be part of the study even though there are other districts in the service area of the university who are not identified as rural.

\section{Participants}

Area administrators were used as the participant pool for the study. The researcher used an email to initiate contact between the researcher and the participants. Convenience sampling of the administrators who volunteer to participate in the interview was used to gather the qualitative data for the study. Due to the nature of the study, the researcher employed convenience sampling because data was only gathered by those participants who were willing and available for the interview (Creswell, 2014).

Administrators were chosen as appropriate participants because they are directly involved in hiring teachers to fill vacancies in their buildings. They were asked to complete a survey to 
gather data about the relationship of this decline in graduates and the ability to find and staff highly qualified science and math teachers. The survey was sent via Qualtrics software.

Amid the current global pandemic of COVID-19, alternate methods for conducting interviews were utilized. Phone interviews took place instead of face to face interviews to reduce person to person contact. Another helpful tool that was offered to participants in lieu of face to face conversations is the Zoom program. This virtual conference call can be done from any location with minimal technology.

\section{Data Collection Tools}

The literature review and principles of the interest convergence theory were used to create proper data collection tools including an electronic survey and interview questions. Proper ethical practices must be followed; therefore, all participation was voluntary and the study received IRB approval. A consent form was given to each participant before he or she began the study. The consent form reminded the respondent of their anonymity throughout the study as well as their voluntary participation. Participants were first asked to complete the electronic survey. The survey participants were a population of administrators in the rural school districts of the southeast portion of the state. This survey was composed of approximately 17 items. The survey asked both qualitative and quantitative questions, both open-ended and multiple choice. The researcher asked survey questions relating to the participant's demographic data, the response to the shortage of highly qualified science and math teachers needed to fill vacancies, trends in vacancies for high school science and math positions, qualifications of science and math teachers hired within the past ten years, and teacher retention. The researcher preferred there be a minimum of 20 responses to the survey; however, due to a typical response rate of surveys and the fact that this research was conducted during a pandemic, adjustments were made. 
Additionally, a minimum of five interviews were ideal for data collection, but six interviews took place. For any individuals who accepted the invitation for an interview, their permission was obtained to record the exchange. This provided the researcher with the opportunity to transcribe the conversation for a more accurate account of the interview. A series of open-ended questions was asked throughout the duration of the interview, which did not exceed one hour.

\section{Data Analysis}

Pre-existing data about graduation trends of science and math education majors of a regional public university in a Midwestern state over the past ten years was used to help validate the claim that there is a shortage of science and math teachers to fill vacancies in this area. The researcher examined the data collected in the survey responses and interviews to look for themes and code accordingly. Themes emerged as patterns in the administrators' responses in the survey were examined. While analyzing administrator survey responses, the researcher looked for commonalities in responses about demand for science and math teachers, teacher qualifications, and teacher retention. After transcription of the administrator interviews, the researcher performed a similar review of the data in search of parallel ideas relating to the hardships of rural education. The themes were then directly tied to the theoretical framework and research questions.

\section{Findings}

There has recently been a decline in the number of science and math secondary education graduates from River Town University (RTU). This study aimed to explore the depth and extent of the impact this trend had on the ability of rural schools in the service area of this university to find and staff secondary science and math teachers. Data were collected by conducting 13 surveys and six interviews. 


\section{Ability to Hire Teachers}

The decline in science and math graduates damages service area-rural high schools' ability to find and staff highly qualified secondary science and math teachers. In fact, the findings from this study highlight some of the problems caused by the declining pool of highly qualified candidates. The researcher created a scale for administrators to rate, over the last ten years, how the decline in secondary science and math education graduates at RTU has impacted their ability to find and staff highly qualified teachers in science and math. While the scale for this question ranged from one (high impact), three (moderate impact), to five (no impact), the average survey response for this study was 2.33 , with a standard deviation of 0.9428090416 , indicating moderate-to-high impact. Even though rural districts may be unique to their geographic area, culture, and size, one commonality they seem to share is their endeavor to place highly qualified instructors in front of their students. In fact, the declining number of graduates in the area has become an increasing problem for local school districts over the past decade. For example, 12 of the 13 survey respondents said that, over the last ten years, they have found it more difficult to find and staff highly qualified science and math teachers at the secondary level. The mean response of this survey question was 2.08 on a $1-5$ scale, where 1 was extremely difficult and 5 was not at all difficult. The standard deviation for this question was 0.8620067026. This coincides with the declining number of science and math secondary education graduates at RTU over the last ten years. Survey respondents were also asked to rate the feasibility of finding and staffing science and math teachers for their high schools. The average of the 13 respondents was 2.0 with a standard deviation of 1.08012345 , indicating a difficult to very difficult rating. 
Of the six interview participants, four were from a "small" school, one was from a "medium" school, and one was from a "large" school, according to the state high school activities association for this state. When asked about his perception regarding this trend, Louis Latham, from the large school said:

Sometimes it's not always easy to see the trend of graduates from year to year since we don't have to actually pursue and hire science and math teachers yearly, but I have had years that I have made calls to see what the graduate pool is like that year at RTU. I have noticed the applicant pool in general over the last several years has decreased though. Definitely less applicants for jobs now compared to when I first took this job. I've also noticed the placement of student teachers at my school has decreased as well.

Similarly, McKenzie Miller from the medium sized school said:

Since we are a larger, higher paying school, we really don't struggle very hard to find teachers and don't have a bunch of yearly turn over so I haven't really noticed a specific trend in graduates at RTU. We did have a science opening two years ago though and had three applicants. It worried me a little because it's not a huge number and is less than we typically get for an opening, but probably better than other smaller area schools. We picked the best candidate and offered her the position. She verbally accepted but then changed her mind and went to a school closer to her hometown so we had to reopen the position. We ended up choosing one of the other previous applicants and she is currently still with us

The two schools not identified as small both mentioned not recognizing a decline in the number of science and math secondary education graduates at RTU in particular and neither have 
significant retention problems, but both noted a decline in the general applicant pool over the past several years.

The four small school administrators who took part in an interview shared a common hardship regarding the staffing of science and math teachers. Small schools often welcome placement of student teachers in hopes of cultivating relationships with teachers who could potentially fill vacancies that are hard for them to staff. Steve Snow said:

It's always hard for us to find science and math teachers but I have noticed it has been worse over the last several years. We have a lot of turnover so it's a constant hardship. We beg for placement of student teachers hoping that we can hire them if needed or make relationships for the future but I have noticed the number of student teachers assigned to our school has become less frequent in recent years

\section{Partnership with RTU}

With the decline in student teacher placement, it is becoming harder and harder for schools to recruit new graduates to work in their schools. Many districts actively seek out these new graduates by contacting RTU directly asking them to refer upcoming graduates to their campus to apply for openings. Stuart Sweeney highlighted:

The first place I call when I know I have an opening coming up is RTU. I have a good working relationship with the people up there so I can get a good idea of how many people they're going to graduate. I let them know to send people my way if they want a job. We usually don't keep people for a long time unless they are from here already or somewhere close by so I make the call to RTU often. I have noticed they haven't been graduating as much as they used to so that's been difficult on me. I have had to struggle more to find people to fill spots 
Simon Strand noted taking a similar approach when trying to recruit new staff. He said:

I knew about the decline in grads from RTU's ed program before you contacted me about the study. I usually call them up to see if they can send anyone to me when I know someone is leaving and over time have gotten to know them and how they operate. They have been sorry to tell me on more than one occasion that they have very limited people ready to graduate or even ready for student teaching.

The affiliation these small schools have established with RTU is important to their recruitment efforts and have proven to be helpful in many instances. For example, Sharon Suntrup said:

We recently hired a guy for our science opening from RTU that is currently in his student teaching. I had to use my network at RTU to get a hold of him because we were pretty desperate. Because of the state guidelines, we can't start paying him until he completes 60 days of teaching so he will officially start his career before he even gets his diploma. We told him we would like to keep him for two years, at minimum, because it is so hard to get people to come here. This isn't the first time this has happened in our district. We actually get a lot of first year teachers who come here to get experience for their resume and then leave. Even that has been harder though in recent years.

\section{Less Qualified Applicants}

Additionally, with the decreased number of new teachers produced from RTU, schools have had to turn to other, less qualified job applicants just to fill vacancies in science and math. Administrators have had to become very resourceful when seeking out educators to fill openings. Steve Snow indicated that he had to look elsewhere in the community after he didn't get a single applicant for a recent opening. He explained:

We had no applicants for our math opening a couple years ago. Not one. I contacted 
every college from Commerce to Springfield trying to find someone that would be interested in filling the position. I turned to the community for help and found a retired engineer who was able to temporarily fill the spot until I could find someone. It wasn't ideal, but it was someone who knew math, had a college degree, and could keep the kids from killing each other.

Sharon Suntrup and Stuart Sweeney shared a similar story when they referenced hiring someone who didn't have the content qualification necessary to teach the class they were hired for. Ms. Suntrup noted:

We recently hired a young man that was not certified in high school science, only middle school 5-9 science.We really needed someone for our sophomore biology class but did not have any other qualified applicants. He was actually our only applicant so we took him. I moved the current 9th grade teacher up to 10th since she was certified for that class and the new hire filled the 9th grade spot. This was not ideal because he won't be able to teach any other classes during his time with us and we had to move our current teacher to a new class even though she is fantastic in the 9th grade class but it's what we had to do. Similarly, Stuart Sweeney stated:

We hired a teacher that wasn't qualified to teach the 11th grade science class at our school but she could teach both 9th and 10th grade. She had one section of the 11th grade class, or maybe two I can't remember, but she was our only applicant so we hired her with the contingency that she would obtain the additional certification before the next school year. From what I could tell she did well in the 11th grade class and did end up passing the content exam to be certified for the following year. 
In both cases the administrators hired teachers who did not have the content knowledge required for the posted position but manipulated the teaching assignments or created a contract contingency to legitimize the hire.

Small rural schools have struggled the most with this issue, but even the medium sized school in this study shed light on the consequence of this trend. To illustrate, McKenzie Miller explained:

In one instance, we had an opening for a science position and only had two applicants. One was a newly graduated teacher from RTU who did not have the certification to teach physical science, but did have one for biology. The other had three years of experience and was already certified for physical science but was let go of their previous job for unsatisfactory performance. We chose to hire the new teacher who was not qualified for the position and have her take the content knowledge test after she was hired so she would be certified to teach the class. We felt if she could pass the test she could teach herself the content throughout the year. With the limited pool of applicants, we thought it would be a better choice for students to choose the less qualified teacher who didn't have the negative mark on their resume.

Again, this new hire was not qualified for the position but was hired under the contingency that she would complete the certification test and teach herself the content since she had not received it during her post secondary education classes.

Some area administrators have noted that the quality of student teachers and/or new hires from RTU has changed in some areas such as curriculum development, planning, and classroom management. However, the content knowledge of science and math RTU grads and student teachers has consistently met expectations. The average answer of survey participants on a 1-5 
scale for content knowledge of RTU graduates was 4.75 with a standard deviation of 0.4330127019. Sharon Suntrup explained, "I have been consistently impressed with the content knowledge of the graduates I hire from RTU." Simon Strand concurs, but moves on to describe his evaluation of student teacher leadership and class management abilities.

I can't make a generalization about all RTU student teachers, but some of the ones I have spent time with don't seem confident in their ability to take lead in the classroom. Even though they seem to have excellent content knowledge, they are still hesitant to take control. I realize some of that is their personality but to be successful in the classroom you have to lead with confidence and maintain control of the classroom at all times. That could come with practice but RTU has to make sure teachers come out of their program with that ability.

\section{RTU Graduate Weaknesses}

Instructional design and lesson planning capabilities have also seemed to be a concern of area administrators. Steve Snow articulated his perception of RTU graduates' abilities to design curriculum through instructional design. He explained:

I have noticed that a few teachers we have hired from RTU are lacking the ability to create curriculum. For instance, we hired a secondary math teacher last year to start this year. He is struggling with the pacing of his class because the previous teacher did not leave him any materials and he has no experience. He doesn't know how to build a curriculum and he doesn't feel comfortable moving on to the next lesson if every student hasn't mastered the content. I spent a good deal of time texting him last night trying to explain that expectation is not reality and the students are never going to know as much as he knows. He is really struggling with building arranging his lessons and spent an hour 
in my office this morning talking about it. I tried to explain that he needs to look at the big picture, pick the important content, teach it, move on, and reteach specific kids when needed. I don't think he was expected to create a structured unit during his student teaching and probably just used whatever his cooperating teacher gave him. That probably wasn't RTU's fault because I believe they probably expect their student teachers to develop a whole unit of teaching, but this specific student was not prepared for starting from scratch. I suspect he isn't the only first year teacher to struggle with this. I have seen it in a few other recent RTU grads.

Learning to teach from an already established curriculum is almost a luxury to many rural school districts. Not even the district size can distinguish between the have's and have not's when it comes to learning the true art of teaching. For example, Louis Latham, from the large school in this study, had a similar view. He said:

We are getting less and less student teachers, especially in math. I don't spend a lot of time observing those we do get but I do try to stay informed about them in case I need to try to recruit them later. I ask for teacher feedback on them. They mostly have great things to say from student teachers at every level of the program, but instructional design has seemed to be a concern in some cases. I think just the ability to fill the class period with meaningful exercises or activities is important. That is tricky for a lot of new teachers though.

As rural communities in the service area of this university are experiencing a more difficult time finding highly qualified applicants for job openings, they are also receiving less and less student teaching placements. This paired with the changes in abilities of new teachers to 
create curriculum and plan lessons is allowing for gaps in opportunity to learn for rural school students who depend on these teachers and student teachers.

The perceptions of the six administrators who were interviewed about the trend in the decline of secondary science and math education graduates are diverse but common themes emerged through careful analysis of the data.

\section{Alternatively Certified Teachers}

The pool of applicants for vacant science and math teaching positions is not only decreasing, but those who are hired are less qualified. In some cases, administrators have to hire science and math teachers who have taken an alternative route to education because they cannot find highly qualified instructors to fill the vacant positions. By taking this alternative route, some administrators say that those new to the teaching profession are lacking the ability to communicate their knowledge to students. Simon Strand identified this reality during his interview. He said:

I have had to hire some people who followed the alternative certification route into education. I actually took that path myself. Some are brilliant in math, but they have no idea how to teach someone to do that math. They can solve problems and are very bright but they don't have the teacher talk they need to relay information to their students since they didn't actually go to college to learn to teach and plan lessons. They struggle with communicating content knowledge but also have a hard time recognizing when students have reached a satisfactory level of achievement and when they haven't. Getting a good read of the classroom is not always their strong suit since they haven't taken any formal student assessment classes in college.

Likewise, Sharon Suntrup stated: 
One of our current teachers left her job in the private sector because she wanted a better schedule since she has two small children and didn't want a commute to work. We were of course happy to have her since we were in need of a qualified math teacher in our high school. She has a math degree and completed the alternative certification to fulfill requirements. She does a good job in the classroom but I know it took her a few years to learn how to teach. It's harder than most people think to actually be able to communicate what you know in a way that's easy to understand.

Placing a knowledgeable, capable person in the classroom is important, but these two small school administrators indicated the struggles associated with hiring a teacher who has taken the alternative route to education. Still though, this route is better than having no teacher at all in the classroom. Stuart Sweeney, another small school administrator said:

We have very few applicants. When we needed a science teacher we received no applicants, so we hired our full-time sub. He doesn't have a science degree but we needed someone in the classroom who could control the kids and at least keep order in the room. $\mathrm{He}$ is in the process of completing his science ed degree now.

\section{Revolving Door of Teachers in Rural Schools}

Another common emergent theme revealed after dissection of the data is that many rural schools are considered "feeder" schools by administrators because they often hire and train teachers who only stay for a brief period of time before moving home or to a larger, better paying school. This is a recurring problem for small schools especially and these administrators have to combat this trend yearly. Steve Snow highlighted this truth by saying:

I have had 6 new math teachers for the same position in the last 5 years. I had to let one go midyear because of inappropriate behavior but luckily I was able to get a student 
teacher who we were able to pay during student teaching. It's a constant revolving door here. I am sure you have heard this from other people you've interviewed though. It's a pretty common problem in these really small schools. It's just something we've learned to adapt to over the years. Things just aren't like they used to be in education. A lot of people aren't lifers anymore because of the stress and expectations. It can be crazy. That's added to the turnover for sure. But back to your original question, I think it's been harder and harder to find people since not many people want to be teachers anymore. Simon Strand moved on to explain:

All new teachers want a job. That's why they spend years in school. And most take whatever they can get so they are happy to come work for us. The trend here though is that we take on new teachers, train them, then they leave us for more money the bigger schools can provide. It's a little frustrating because it seems like we are constantly on the hunt for someone who is qualified to teach here. Not just in science and math.

Unfortunately, this research study revealed several districts in the same situation. Many local rural schools have been in a pattern of experiencing a revolving door of teachers each year. Administrators cited pay and benefits as being two factors leading to this constant turnover. Sharon Suntrup explained:

We've just accepted the fact that we won't keep anybody very long. Except those who were born and raised here. That's not really common though. We have a couple. Everybody wants to make more money because teaching is hard and takes a lot out of you. We sort of funnel our teachers to the bigger schools because they can pay more and often offer better benefits. 
The large teacher turnover is a consistent problem recognized by many rural school administrators. Navigating the problems associated with this reality can be challenging but Stuart Sweeney has developed his own method for overcoming this troubling trend. He said:

Retaining teachers has been a focus here because training new teachers takes so much effort and time. I haven't really figured out the perfect solution yet but we try to make new teachers at our school feel welcomed and valued in hopes of keeping them around. I take time to show interest in their growth and development as a professional. I try to give as much feedback and evaluation as possible to build the new teachers but also realize they are an investment and hope that it pays off. I don't blame any of them for moving closer to home or going where there is more money, that's what anyone would do, I just try to make that decision a little harder for them by creating an environment they want to be in.

Even the medium sized rural school administrator spoke of her school district's inability to retain teachers. McKenzie Miller said:

We cannot keep people that use Meadowbrooke as a starting point. If they are from north of here they typically stay a few years and then go back north to be with family. They usually get paid more and have better benefits up in the large, urban schools too. An additional perception many administrators share is that they believe low pay is the biggest reason why teachers do not come to rural districts or do not stay very long once they get there. Rural school districts have a lower teacher salary, compared to larger districts and this salary differential is often a deterrent for those looking for a teaching job. Simon Strand explained:

The reasons why most people leave us is because we just can't compete with the bigger 
schools. We can't pay like the guys in Jonesboro or Commerce. The small town charm is great for some, but sometimes it's not enough to keep people here. When the dollar signs get bigger, people tend to go towards them. And it makes sense. Especially when a lot of those people are just starting out and want to save money for buying a house or starting a family.

Likewise, Steve Snow explained:

We simply cannot compete with other larger districts in terms of pay. We don't have a big enough tax base. I was lucky to fill a science spot last year with a girl who is a graduate of Stillwater so she was elated to have a job back at home. I don't see her leaving since she is from here but most of the time if we hire someone not from here or the immediate area they don't stay long.

Stuart Sweeney from a neighboring small school said, "We are so small and rural. It is not as difficult for us to get teachers as it is to retain them. We seem to be used as a stepping stone for experience and then are left for higher pay." Sharon Suntrup is faced with the same dilemma in her school but offers a possible solution to the problem. She says:

We don't have a grown your own program here, but I wish we did. I don't think people would consider coming and staying here for a long period of time if they aren't from here already because we don't have the ability to compete with the bigger areas like Commerce and those communities surrounding it since our base salary is so much lower. If we could sink some time into talking up the profession and showing our kids that teaching is a great career, then I think we might be able to begin a grow your own sort of thing here. Working that into our already jam packed schedule is the tricky part. 


\section{Other Variables Causing Turnover}

There are variables other than pay that impact the ability for small rural schools in the southeast portion of this Midwestern state to attract and retain science and math teachers. Additional responsibilities because of small size, larger, more diverse course loads, and social isolation are three additional factors cited by area administrators that play a key role in the ability to attract and retain teachers.

\section{Extra Duties}

Regarding multiple duties and responsibilities, administrators say that since their schools are so small, they often have to ask teachers to take on additional out of school assignments to be able to provide students with opportunities to engage in clubs and sports. These additional tasks placed on teachers are often taken begrudgingly to obtain or keep their current position, sometimes even being written into their hiring contract. Stuart Sweeney stated:

We have to ask many of our teachers to be coaches or sponsors of clubs because we want to offer as many extracurriculars as possible but with such a small staff, it's really difficult. Almost every staff member here is in charge of some after school activity or is a coach of some kind. There are several who are sponsors for multiple clubs and actually coach year round. Some people are meant for it, but some aren't. We have to ask our first year teachers to also fulfill these extra duties and it can be really overwhelming for them. They are usually included in the contract before hiring is complete. Many want to be in a school where they aren't expected to also coach or sponsor clubs, and I don't blame them. It's a lot of work, but unfortunately it's necessary at our school. I think this is one of the reasons why teachers haven't stayed long here.

Similarly, Steve Snow from another small school said: 
Many times we post a job but during the interview we ask the candidate if they are also okay with coaching or being a club sponsor. Even if they haven't coached the sport before or ever been the head of a club we have to have them so our kids can participate in these activities. We have had some people who weren't able to take on the extra duties because of other commitments but we can't possibly pile more onto the existing faculty. Some people even take the job but realize the extra responsibility isn't worth the money so they actively seek out another job the following year.

These extra roles being placed on new teachers is something administrators identified as a possible reason for turnover. Extra responsibilities means both extra work and extra time, something that is hard to find more of as a new teacher. As Stuart Sweeney said, the extra work is probably contributing to the turnover he experiences.

\section{Large Workload}

Being a science or math teacher in a rural school also lends itself to teaching many science or math classes instead of just one or two. Some rural teachers are the only science or math teacher at their school, which means their course load requires much planning. Sharon Suntrup illustrates this point stating:

It's challenging for new teachers to have multiple classes to prepare lessons for each day. It's hard for anyone, really. In our case we have one teacher for 9th-12th grade science and one for 9th-12th grade math. We do get a lot of first year teachers here trying to get experience for their resume and they give it their all, but I can tell they are not prepared for planning multiple classes. I don't think it's easy for anyone in the beginning but I think that's one of the reasons we have a lot of turnover. Most teachers, I would say, do teach more than one class per day so I feel like students in the student teaching process 
should have a better idea of what to expect when they actually go out on their own. I think this may be one of the reasons why people don't stay long at our school. The overwhelming workload can be so draining.

She indicates that she doesn't believe student teachers are prepared for the reality of planning for multiple classes each day and may decide to leave because of the stress associated with preparing for so many different courses. Simon Strand also identifies the same problem at his school. He said:

Something that is hard to combat is that both our math and science departments are the only faculty in their department, meaning they have multiple preps. They may teach 5 different classes throughout the day. That's a lot. Especially for a new teacher, which is what we get the most of here. They just don't stay around long because of that. New teachers are just trying to keep their head above water the first year, planning and preparing for multiple classes is extremely difficult. That's why a lot of new hires leave. And I don't blame them, but I don't have any other options. The workload is just so much for them and I don't think they are prepared for it. Student teaching doesn't always show real life.

He refers to this problem of a large course load as one of the reasons why teachers don't stay long at his school either. Being responsible for planning many different lessons is a very tough task, one that even veteran teachers can sometimes struggle with, but Sharon and Simon both identified the diverse workload of small, rural schools to be one of the factors that correlates to the retention of teachers. They both mentioned that new teachers are not prepared for this kind of extensive planning. Adding a new perspective, Louis Latham, from the large school in this study, shared a different story about how a diverse course load affects his employees. He said: 
Because we are a bigger school, we have been pushed by the board to have a more diverse set of math and science offerings over the last several years. This means that some of the core classes are a little larger than normal, but in turn, we are able to offer more electives or stepping stone classes. For example, a kid who hates math shouldn't be forced to take Algebra I as many times as it takes to pass the class. So we are able to offer Algebra A and Algebra B which is essentially just Algebra I in two years instead of just one. It has worked out well so far but has increased the course load for a few of our teachers. For example, one teacher who only taught biology and dual credit biology had to give up one of her biology classes and teach an elective science class. This means she got an additional class to prep for but the other biology teachers' classes got a little bigger. I know, in this case, the biology teacher wasn't thrilled to have an additional prep and more work, but I wasn't worried about losing her since she is from here and we are a good paying district. She knew it was best to provide opportunity to kids who need it. Opening opportunities for students is always a positive change but, even for big schools, this change can lead to more work for teachers.

\section{Social Isolation}

Social isolation is another key factor identified through data analysis that leads to low retention rates of new teachers and the inability to fill open positions in rural schools. Stuart Sweeney said:

We pretty much only have a gas station, a small grocery store, lots of churches, and some banks in our town. It's so small that most people who teach here don't live here but we are so isolated that the next closest place doesn't have a ton more stuff to offer, especially for young, newly graduated students looking for their first job. This isn't a place with a 
social scene where you can meet a bunch of new friends so it's definitely a challenge to get the new kids in here, especially if they aren't already from a small town.

He describes how the small town does not have the attractions of a larger, more populous area so it is hard to sell the location to potential new employees. He explains that neither the town nor surrounding areas have much to offer as far as things to do so it doesn't appeal to the young, new graduates. Simon Strand mirrored this concern saying:

Our town does not attract new people very often. Mostly because it's out here in the middle of nowhere and there's not much of anything to see or do. The thought of moving to an unfamiliar town that's isolated is not something many people want to do, especially since we can't afford to pay a lot.

Even rural schools who are able to pay more have similar struggles though. Sharon Suntrup illustrates this reality by describing the hardship she encounters when trying to fill an opening at her school.

For our area, we are one of, if not the highest, paying districts. We have increased our base pay to try and help in recruiting highly qualified staff. However, that doesn't always entice someone to come to our small community. It's a nice place, low crime, a great place to live. But if you didn't grow up here it can be hard to get used to being so far away from everything. Some people try it out and decide it's just not for them. There can be a feeling of loneliness for those who aren't used to the small town life, especially when they don't know many people. I'm glad the board approved the increase in base pay but sometimes that's just not enough to overcome the remote location of our school and town. 
McKenzie Miller, from the medium sized school moves on to describe how the location of her school doesn't really deter potential employees from coming to her district but she understands the hardships other local rural schools face when looking to hire new teachers. She said:

I know some of the more rural areas around our district struggle to find people because they are so far out of the way. I mean, they aren't close to anything. It's really hard to sell a school to someone when they are going to be thrown into the middle of corn fields and woods with nothing to do. We are lucky enough to be between two bigger areas that have large shopping areas and entertainment.

Clearly, these administrator perceptions suggest that remote locations of rural schools in this part of the state have a large impact on the school's ability to attract and retain teachers. The social isolation factor paired with the diverse course load and additional responsibilities placed on rural school teachers have all been identified by administrators as key elements in the formula of finding and staffing high school teachers. All of these variables are directly related to the location of the school. The rural location of these schools is what makes them socially isolated but also contributes to the large course load and additional responsibilities of teachers.

There has been a sharp decline in secondary science and math education graduates from River Town University in the last ten years. Local rural administrators have identified three main reasons why they believe this trend is happening. Low pay and lack of respect for the profession are two of the most common themes which emerged from analyzing the data collected from both the survey and interview process. Another important factor administrators believe is leading to the decline of secondary science and math education graduates from RTU is the lack of recruitment by RTU for students to enroll in the education program at the university. 


\section{Different Careers}

All agree that the single most influential factor that drives potential students away from the teaching profession is the low pay compared to the amount of stress and responsibility associated with the job. Additionally, those who have the aptitude to complete the rigorous science and math classes needed to obtain a secondary education degree in these disciplines can make more money by choosing a different career. Students could make more money in a different profession with the same level of math and science training. Those who excel at math and science are more likely to choose other careers because of the pay unless they are passionate about teaching kids. Simon Stand illustrated this point saying

In my opinion, those planning to go into the education field typically choose easier paths than science and math. Those that excel in science and math can make more money going into other fields besides education. It is rare to find someone who excels in these areas and has a passion to work with kids in education.

Stuart Sweeney made a very similar claim when he said. "With higher level math and science skills, I suspect many potential candidates are seeking careers with higher salaries." Sharon Suntrup also points to the idea that a potential teacher must possess a genuine passion for working with kids or else they will use their skills to pursue an alternate degree which will offer a larger salary. She said:

It's possible that young people do not have the same empathy and feeling of responsibility for the next generations. If they don't have a passion for working with kids and helping them prepare for what lies ahead, then teaching isn't going to be what they pursue, especially since they can make more money doing something different given that they possess a unique skill set to succeed in the fields of science and math. Or any subject 
for that matter.

Clearly, knowing that teachers do not receive the same kind of compensation as those in careers with comparable levels of education is a deterrent for students who have the skills to excel in science and math preparatory classes, unless they have an authentic love for teaching students.

\section{High Stress}

Administrators also noted that the stress level a teacher experiences is not equitable to the amount of pay they receive, which they believe is a reason why there has been a decline in the enrollment in the education program at RTU. Teaching is no longer an 8:00 to 3:00 job and teachers are made to fill many additional roles, not just teaching. They are often responsible for monitoring the social emotional well being of students as well as other variables that impact students' lives. Students know this prior to graduating high school. They know that teachers foster relationships with their students, they become the safe places and sounding board for many of their students. Administrators believe that these extra stressors are turning students away from the teaching field since it is well known that teachers are not making the kind of money other professionals are. McKenzie Miller stated:

I believe it's the field as a whole. Stressors are so much more than they used to be and it is not equal to the pay. Kids know that. They see their teachers struggling. That's got to be one of the reasons why there are less and less kids going into this field when they get to college.

Similarly, Sharon Suntrup explained:

I am always there to support my teachers, or I try to be. But I know they are continually feeling overworked and underpaid. They have to be more than teachers nowadays. They have to overcome lots of other significant factors that a student walks into the classroom 
with. Kind of like baggage. I think the students see this. We've put so much extra on the teachers' plates, but their pay hasn't changed. This is probably one of the reasons it has been harder for me to find newly graduated teachers to do this job.

Steve Snow asks the obvious question, "Why put yourself through the extra stress for low pay?" He moves on to say, "I would guess money is the number one factor. The pay doesn't equal the amount of time that needs to be spent to do the job effectively or the amount of stress I see my teachers deal with on a regular basis."

\section{Poor Man's Career}

Administrators believe that the teaching profession is not "celebrated" like it used to be. They noted that many students see teaching as a "poor" man's career. According to the administrators, many students believe teachers can't afford to support a family on a teacher's salary. Students know that teachers don't make as much money as those in other professions with comparable degrees and don't receive the amount of respect that other professions do. Steve Snow illustrated this idea saying:

In our small community, we can't pay our teachers a lot so many of them have second jobs and students see them out doing something other than teaching so they develop this idea that all teachers are poor and have to work two jobs to make ends meet. That may be true for some of my employees but certainly not all of them. Since kids see this happening some of them have the opinion that teaching isn't something they would ever do because you have to go to college and still end up working two jobs.

Similarly, McKenzie Miller stated, "I think the teaching profession does a poor job selling the merits of becoming a teacher. Too many people have the perception that teachers do not make enough money to support a family or that teachers deal with unruly students all day long." Stuart 
Sweeney condensed these ideas into a concise statement claiming, "Perhaps potential candidates think teaching is too difficult or not worth some of the negative stereotypes such as low pay and poor working conditions." Sharon Suntrup also mentioned the reality that teaching is not the same as it used to be, especially regarding discipline. She said:

I think there's less interest in becoming a teacher because it isn't respected the same way it used to be. It doesn't come with the same praise it once did. Students certainly don't respect authority like they used to either. Discipline problems have increased and the way we are allowed to hand out discipline has changed significantly. I've been doing this a long time and working in the classroom is harder now than it used to be and that's one of the reasons.

\section{No Recruitment by RTU}

The survey also brought to light another potential reason why there has been a decrease in secondary science and math education graduates from RTU in the last ten years. 13 out of 13 respondents were not aware of any efforts made by River Town University to recruit students to the education program. The data shows that RTU sends representatives to some rural schools but they are speaking about information related to the general admission requirements and majors offered at the university, not about entering the education program specifically. There is no active recruitment process by RTU whatsoever on any of the 13 rural campuses who took part in this survey. Steve Snow said:

RTU comes a couple times a year to talk about the application process. Being the biggest four year college around, we are always happy to have them and glad to see our kids get accepted since there isn't a large push to succeed academically down in this area. They do a great job explaining how to apply and helping the kids understand the requirements. 
I haven't heard them specifically talk about becoming a teacher though or what the requirements are for obtaining a teaching degree from RTU.

Similarly, McKenzie Miller stated, "RTU sends a representative to our school to recruit students but I would have to ask the counselor's office if they know about anything specifically related to the teaching program at RTU. I would think that if they really wanted to attract candidates they would send a specific rep to get kids interested in teaching." Simon Strand describes the same situation at his school. He said, "Someone from RTU comes to present to the senior class about the college but I have never heard them try to actively recruit students to join their education program." Additionally, 9 out of 13 survey respondents identified RTU as one of the primary four year colleges their students attend, but their students are not majoring in education. This failure to actively recruit education majors paired with student perceptions of the teaching career and the stress it brings with it are all factors that local rural administrators perceive to be the biggest reasons why there has been a decline in graduation rates in the education.

\section{Recommendations}

The focus of these recommendations is aimed at ways for River Town University to produce more high school science and math teachers and actions local rural schools could take to cultivate a "grow your own" program in their schools to encourage and prepare their current high school students for entry into teacher preparation programs, specifically at RTU. The "grow your own" plan could provide rural schools in the southeast portion of the state, who are in the service area of RTU, with highly qualified teachers willing to live and work in their communities. Additionally, recommendations were made about how RTU can better prepare students who do end up teaching in districts that will expect them to plan for multiple classes each day and fulfil additional responsibilities. 


\section{Recruitment}

None of the administrators who took part in the survey or interview said they were aware of any formal recruitment practices by RTU for the purposes of attracting students to enroll in their secondary education program. RTU does send representatives to rural schools to give interested students information about attending the university, but none of that information is targeted at pointing students toward pursuing a degree in secondary education. It seems RTU has not made efforts to garner interest for obtaining a secondary education degree in science or math in secondary education, given the number of graduates in these two programs has plummeted over the last ten years, but also since they have not established a recruitment program for science and math education majors. This research study has established that local administrators believe it is very challenging for rural schools in the southeast portion of this state to find and staff highly qualified science and math teachers, and the failure of RTU to recruit new science and math teacher candidates accentuates the problem.

Derrick Bell's interest convergence theory highlights how rural students are not afforded the same resources as their urban and suburban counterparts simply because of their geographic location. Put plainly, because of their rural school status, rural school students are not provided with the same access to highly qualified teachers that other non-rural students are. Rural schools do not have the funding available to attract highly qualified teachers by offering a competitive salary. This means that, in the fight to attract and retain teachers, rural schools are often struggling to fill their open positions in these content areas. This is not a new trend. Many participants in this study noted that they make regular contact with RTU to ask if they have any soon to be graduates they could send them in an effort to fill vacancies. RTU is aware of the struggles these small schools face and has yet to address this problem. ICT would suggest that 
because the needs of the non-rural schools are being met, RTU has not yet pivoted toward taking responsibility for production of teachers who will teach in these rural towns.

This isn't an easy task, but any efforts toward helping these rural schools attract high school science and math teachers would benefit students in those districts. As the literature review pointed out, many students move back to their hometowns to start their career. If attempts were made to pull kids out of rural schools and into the teacher preparation program at RTU, specifically in the areas of high school science and math, then there may be a larger pool of candidates for these rural schools to choose from when attempting to fill a vacant position. Some schools would be satisfied with even one highly qualified applicant.

Conscious efforts are made to attract new students to RTU, as stated above. Rural schools welcome RTU representatives into their schools every year to speak about admission. But they have not developed a program aimed at teaching students about the realities of teaching. No efforts are made by RTU to help students overcome the misconceptions they may have about the teaching profession. As indicated in the findings, many students believe that teachers are poor and don't make enough money to support a family. They think that teachers have to have second jobs just to make ends meet. There are disadvantages about teaching, as with any job, but clearly, most students aren't even considering this career as an option. RTU should approach high school campuses with a plan to dispel misconceptions and highlight the positive aspects of the teaching profession such as the potential to impact student lives, excellent retirement, ability to impart wisdom in the minds of young students, teach students science and math concepts and skills, and the big seller-summers off. RTU should also outline the requirements a student must complete on the road to being a teacher. Knowing how to complete the degree but also understanding the truths about the teaching profession could increase the number of students from rural towns who 
attend RTU to pursue a teaching degree in secondary science or math education. This would benefit the future students of rural schools.

\section{Grow Your Own}

River Town University shouldn't be the only stakeholder responsible for recruiting teacher candidates to their education program. It is also the rural school districts' duty to encourage their talented science and math students to pursue a career in education. Establishing a "Grow Your Own" program at rural schools would be a formal introduction to the field of teaching that students need to become familiar with the career. This kind of program could dispel misconceptions about being a teacher and provide students with facts about this rewarding occupation.

This program could take shape in many forms. A guest speaker series could be an easy, time saving way to disperse important information about becoming a teacher. It wouldn't take much class time away from teachers but would allow for students to learn about becoming a teacher. The series could be done over several sessions and could focus on areas such as RTU's requirements for obtaining a science or math secondary education degree, the truths about teacher pay and benefits, first hand accounts of how teachers impact student's lives, what a typical teacher's day looks like, and other details about teacher life.

Something else rural schools could do to create a grown your own program is establish a chapter of the Future Teachers of America organization at their school. This organization would have to recruit members and form an active chapter of this club. They could form a partnership with RTU and do field trips to the University and listen to professors explain expectations and course requirements as well as what student teaching experiences are like. The Future Teachers of America club could also sponsor a "Become a Teacher" day at their school inviting in guest 
speakers from RTU and current teachers who could describe their real life experiences involving teaching that students don't get to see. Getting a glimpse of a teacher's life would be an important, and valuable experience for students. The idea here is recruitment. The idea is to accrue interest in becoming a teacher in small rural schools in hopes that those students will enter into teacher preparation programs and come back to their small towns to teach. If they are from the town they are teaching in, they are likely to stay put, decreasing the revolving door of teachers but also providing highly qualified teachers to rural schools who need them.

\section{Community Outreach}

Schools could also utilize their Future Teachers of America organization to provide information to community members who could potentially become teachers in their schools. These people could be active substitute teachers who currently have some college education but need a few classes to finish or they could be other working professionals who need additional education credits to complete their education degree. Sometimes communities may not be informed about teacher shortages and don't realize the impact not having a highly qualified teacher makes on students. Communicating shortages for highly qualified teachers may lead to community concern but there has to be awareness for problems to be solved.

\section{Preparedness of RTU Teacher Candidates}

A few participants in this study noted that they perceived some graduates of RTU having excellent content knowledge, but they saw room for improvement in areas such as curriculum design and structuring lessons, especially regarding preparation for multiple classes. Rural school administrators noted that having to prepare for several classes each day is commonplace in rural schools because of the smaller staff size. Many teachers have to create lesson plans for three or four classes each day which can be very challenging. This is something they believe 
RTU students need to be more prepared for when they enter the classroom as a professional. One administrator said that student teaching doesn't seem to prepare the teacher candidate for a real world experience in the rural classroom. It's sometimes hard for veteran teachers to release control of their classroom and that doesn't help the student teacher realize the amount of work and preparation that goes into being a teacher, but RTU also has a responsibility to prepare students for the reality of teaching in a diverse set of classrooms. Teacher candidates need to know how the environments of a variety of classrooms differ and how to adapt to schools with different instructional needs.

While RTU cannot control the experience student teachers have with their cooperating teachers, they can prepare teacher candidates for the different kinds of schools who may hire them in the future. Providing opportunities for teacher candidates to have specialized training in rural school education could help those who plan to pursue that route better understand how to be successful; thus, limiting the amount of surprise and frustration associated with first year teaching in a rural school district. Areas of focus should be planning an entire curriculum, prepping for multiple classes, managing schoolwork and coaching or advising of clubs, and understanding the unique lifestyle associated with rural living.

RTU should develop a formal recruitment plan to increase enrollment in their secondary education science and math programs and prepare teacher candidates for rural school teaching so they are aware of the unique challenges rural educators face every day. Additionally, rural schools should create a "Grow Your Own" program to cultivate teachers familiar with rural education so they will have a bigger pool of applicants to fill vacant positions. In following these recommendations, RTU and local rural schools will help to level the playing field for rural high 
school students who deserve the same access to highly qualified teachers and experiences as those students who are not enrolled in rural schools.

\section{Summary}

The perspectives of local high school administrators about the specific supply and demand relationship between science and math teacher graduates at this university and the vacancies in these disciplines in their school districts was explored in depth and all research questions were adequately answered in the findings. Although efforts have been made to equalize opportunity for all students, there is still a disparity between the resources available to students in rural areas and those in other areas. Elmore and Furhman (1995) said, "Opportunity to learn means providing all students in society equal opportunity to reach ambitious outcomes, and that implies that schools must not only have resources but use them well so that quality instruction results" (p. 438). The purpose of this mixed methods study was to seek understanding about the implications of the recent teacher shortage through qualitative and quantitative inquiry while applying Derrick Bell's interest convergence theory. The researcher was able to communicate findings to the appropriate policy makers and act as a change agent by advocating for equitable access to highly qualified teachers for students in rural America. In fact, Borman and Dowling (2008) said, "The resource demands associated with employing teachers and the strong empirical evidence linking teacher quality to improved achievement are compelling reasons to focus on policies related to teachers as key levers to improve efficiency, equity, and productivity in public education" (p. 368). High quality teachers must be provided to all students by whatever means possible because proper education is a fundamental right for all children, regardless of their location. 


\section{Significance of the Study}

Rural school leaders often face perpetual staffing challenges (Riley and Sakimura, 2018). The majority of schools in the southeast portion of this Midwestern state are identified as being "rural" districts. This designation alone implies that it will be more difficult for these districts to find and staff qualified teachers but recent research indicates that science and math teachers are even more difficult to locate.

This case study provides a unique glimpse into the problem surrounding the decline of science and math teachers graduating from a regional public university over the past ten years and the impact it has had on the rural school districts in the service area of this university to find and staff highly qualified science and math teachers. An up-close, in-depth, and detailed examination of this condition will allow for conclusions to be made about if and to what extent the decline of science and math teachers is having on the ability of local rural school districts to provide highly qualified teachers in the subjects of science and math.

Regardless of the relationship between the two variables, or the lack thereof, this study explored the perspective that students in rural America are not granted the same opportunities as students in other communities. Because of the way the current school funding model is structured, there are many rural districts which are lacking the necessary means to be competitive in the labor market for highly qualified teachers and this research study aims to bring that revelation to light (Kono, 2011). While current research shows that rural students perform as well as or better than students not educated in rural settings academically, it is worthwhile to ask what rural students could achieve if they were afforded the same resources as students not taught in rural districts (Logan and Burdick-Will, 2017).

This study explored the perspectives of rural school districts, focusing on the staffing of 
high school science and math teachers in this part of a Midwestern state. As a consequence of their location, students in these districts are being educated by teachers who receive a lower average salary than others in more affluent districts (Carr-Chellman, Raney, and Campbell, 2019). Studies have shown that students perform at lower levels when they are being educated by teachers with lower salaries (Ordway, 2018). This means that access to highly qualified science and math teachers may be more limited in this part of the state which, in turn, does not provide the same opportunity for learning to rural students. This research will point to the importance of policy makers to reevaluate their current funding model so as to supply rural districts with necessary funding to recruit and hire highly qualified teachers, especially in the science and math disciplines. It will also illuminate the responsibilities RTU has to recruit potential teachers from rural high schools in the service area of the university so that these rural schools will eventually have a bigger applicant pool of highly qualified science and math teachers to fill positions.

\section{Limitations, Assumptions, and Design Controls}

The obvious limitation to this study is that it was conducted during a nationwide pandemic. A time when schools were being shut down and administrators were being called on to deliver plans to keep students safe while maintaining an environment that promoted the same educational experiences students had prior to the outbreak of COVID-19. Administrators were already among some of the busiest professionals and their new on the job challenges only made them harder to get ahold of and potentially less willing to give up unscheduled time to take a survey and sit for an interview. Finding willing participants was the biggest challenge of this research study, specifically because they could only be from rural schools and had to complete both a survey and interview. The small sample size of this study is less than ideal, but the profound, emergent themes were established because of many similar responses within the 
limited responses the researcher did receive.

Additionally, a mixed methods case study, such as this one, presents a host of other limitations due to the nature of research methodology. Cresswell (2014) points to the importance of the researcher recognizing the challenges this type of research may pose indicating the "need for extensive data collection, the time-intensive nature of analyzing both qualitative and quantitative data, and the requirement for the researcher to be familiar with both quantitative and qualitative forms of research" (p. 218). 


\section{References}

Allegretto, S. A., \& Mishel, L. (2016). The Teacher Pay Gap Is Wider than Ever: Teachers' Pay Continues to Fall Further behind Pay of Comparable Workers. Economic Policy Institute.

Aragon, S. (2016). Teacher Shortages: What We Know. Teacher Shortage Series. Education Commission of the States.

Azano, A. P., \& Stewart, T. T. (2016). Confronting Challenges at the Intersection of Rurality, Place, and Teacher Preparation: Improving Efforts in Teacher Education to Staff Rural Schools. Global Education Review, 3(1), 108-128.

Barley, Z. A., \& Brigham, N. (2008). Preparing Teachers to Teach in Rural Schools. Issues \& Answers. REL 2008-No. 045. Regional Educational Laboratory Central.

Barnes, G., Crowe, E., \& Schaefer, B. (2007). The Cost of Teacher Turnover in Five School Districts: A Pilot Study. National Commission on Teaching and America's Future.

Barth, P., Dillon, N., Hull, J., \& Higgins, B. H. (2016). Fixing the holes in the teacher pipeline.

Berry, B., \& Shields, P. M. (2017). Solving the teacher shortage: Revisiting the lessons we've learned. Phi Delta Kappan, 98(8), 8-18.

Blank, R., Langesen, D., \& Petermann, A. (2007). State Indicators of Science and Mathematics Education: Washington, DC, The Council of Chief State School Officers.

Brenner, D. (2016). Rural educator policy brief: Rural education and the Every Student Succeeds Act. The Rural Educator, 37(2).

Brill, S., \& McCartney, A. (2008). Stopping the revolving door: Increasing teacher retention. Politics \& Policy, 36(5), 750-774. 
Chetty, R., Friedman, J. N., \& Rockoff, J. E. (2014). Measuring the impacts of teachers II: Teacher value-added and student outcomes in adulthood. American economic review, 104(9), 2633-79.

Cowan, J., Goldhaber, D., Hayes, K., \& Theobald, R. (2016). Missing elements in the discussion of teacher shortages. Educational Researcher, 45(8), 460-462.

Cole, C., \& Mitchell, R. (2017). Teacher shortages across the nation and colorado: Similar issues, varying magnitudes(pp. 1-49, Rep.). Denver, CO: Colorado Department of Higher.

Curtin, S. (2018). Teacher Recruitment and Retention in the Rural Midwest: Academic Leaders' Perceptions. Voices of Reform: Educational Research to Inform and Reform, l(1), 4487.

Creswell, J. W. (2014). Research design: Qualitative, quantitative, and mixed methods approaches. Sage publications.

Darling-Hammond, L. (2000). Teacher quality and student achievement. Education policy analysis archives, 8,1 .

Darling-Hammond, L. (2010). Teacher education and the American future. Journal of teacher education, 61(1-2), 35-47.

Darling-Hammond, L., \& Podolsky, A. (2019). Breaking the cycle of teacher shortages: What kind of policies can make a difference?. education policy analysis archives, 27, 34.

Dee, T. S., \& Goldhaber, D. (2017). Understanding and addressing teacher shortages in the United States. The Hamilton Project. 
D'Orio, W. (2019, September 18). Why colleges are struggling to graduate more teachers. Retrieved June 18, 2020, from https://www.educationdive.com/news/why-colleges-are-struggling-to-graduate-more-teac hers/563131/

Eppley, K. (2009). Rural schools and the highly qualified teacher provision of No Child Left Behind: A critical policy analysis. Journal of Research in Rural Education (Online), $24(4), 1$.

Farber, B.A. (1991). Crisis in education: Stress and burnout in the American teacher. Jossey-Bass.

Fitchett, P. G., Heafner, T. L., \& Harden, S. (2016). Characteristics and working conditions of moonlighting teachers: Evidence from the 2011-2012 Schools and Staffing Survey. Current Issues in Education, 19(1).

Gallo, J., \& Beckman, P. (2016). A global view of rural education: Teacher preparation, recruitment, and retention. Global Education Review, 3(1).

Gagnon, D. J., \& Mattingly, M. J. (2015). State policy responses to ensuring excellent educators in rural schools. Journal of Research in Rural Education, 30(13), 1-14.

Garcia, E., \& Weiss, E. (2019, March 26). The teacher shortage is real, large and growing, and worse than we thought. Retrieved July 5, 2019, from https://www.epi.org/publication/the-teacher-shortage-is-real-large-and-growing-and-wo rse-than-we-thought-the-first-report-in-the-perfect-storm-in-the-teacher-labor-market-se $\underline{\text { ries/ }}$ 
Glennie, E. J., Mason, M., \& Edmunds, J. A. (2016). Retention and satisfaction of novice teachers: Lessons from a school reform model. Journal of Education and Training Studies, 4(4), 244-258.

Guha, R., Hyler, M. E., \& Darling-Hammond, L. (2017). The teacher residency: A practical path to recruitment and retention. American Educator, 41(1), 31.

Harmon, H. L., Gordanier, J., Henry, L., \& George, A. (2007). Changing Teaching Practices in Rural Schools. Rural Educator, 28(2), 8-12.

Haycock, K. (1998). Good Teaching Matters: How Well-Qualified Teachers Can Close the Gap. Thinking k-16, 3(2), n2.

Holme, J. J., Jabbar, H., Germain, E., \& Dinning, J. (2018). Rethinking teacher turnover: Longitudinal measures of instability in schools. Educational Researcher, 47(1), 62-75.

House, J., \& Chatlani, S. (2018, February 15). Declining education majors could impact the K-12 to college pipeline. Retrieved July 16, 2019, from https://www.educationdive.com/news/declining-education-majors-could-impact-the-k12-to-college-pipeline/517156/

Ingersoll, R. M. (1999). The problem of underqualified teachers in American secondary schools. Educational researcher, 28(2), 26-37.

Ingersoll, R. M. (2003). The teacher shortage: Myth or reality?. Educational Horizons, 81(3), 146-152. 
Ingersoll, R. M. (2004). Why Do High-Poverty Schools Have Difficulty Staffing Their Classrooms with Qualified Teachers?. Renewing Our Schools, Securing Our Future - A National Task Force on Public Education; Joint Initiative of the Center for American Progress and the Institute for America's Future, Retrieved from https://repository.upenn.edu/gse_pubs/493

Ingersoll, R. M., \& Perda, D. (2010). Is the supply of mathematics and science teachers sufficient?. American Educational Research Journal, 47(3), 563-594.

Johnson, S. M. (1990). Teachers at work: Achieving success in our schools. Basic Books.

King, E., \& Butler, B. R. (2015). Who cares about diversity? A preliminary investigation of diversity exposure in teacher preparation programs. Multicultural Perspectives, 17(1), 46-52.

Ladd, H. F., \& Sorensen, L. C. (2017). Returns to teacher experience: Student achievement and motivation in middle school. Education Finance and Policy, 12(2), 241-279.

Lee, C. (2007). Cultural convergence: Interest convergence theory meets the cultural defense. Ariz. L. Rev., 49, 911.

Lowe, J. M. (2006). Rural education: Attracting and retaining teachers in small schools. Rural Educator, 27(2), 28-32.

Malatras, J., Gais, T., \& Wagner, A. (2017). A background on potential teacher shortages in the United States. SUNY Rockefeller Institute of Government.

Matthews, C. M. (2007). Science, engineering, and mathematics education: Status and issues.

Milner IV, H. R. (2008). Critical race theory and interest convergence as analytic tools in teacher education policies and practices. Journal of teacher education, 59(4), 332-346. 
Monk, D. H. (2007). Recruiting and retaining high-quality teachers in rural areas. The future of children, 155-174.

Player, D. (2015). The supply and demand for rural teachers. Rural Opportunities Consortium of Ohio.

Powell, D., Higgins, H. J., Aram, R., \& Freed, A. (2009). Impact of No Child Left Behind on Curriculum and Instruction in Rural Schools. Rural Educator, 31(1), 19-28.

Raffel, J. A. and Groff, L. R. (1990) Shedding light on the dark side of teacher moonlighting, Educational Evaluation and Policy Analysis, 12, 403-414.

Ratcliffe, M., Burd, C., Holder, K., \& Fields, A. (2016). Defining rural at the US Census Bureau. American community survey and geography brief, 1,8 .

Robinson, B. (2017). Structural Poverty and College Enrollment: The Impact of Rural American Determinism.

Skaalvik, E. M., \& Skaalvik, S. (2011). Teacher job satisfaction and motivation to leave the teaching profession: Relations with school context, feeling of belonging, and emotional exhaustion. Teaching and teacher education, 27(6), 1029-1038.

Sleeter, C. E. (2017). Critical race theory and the whiteness of teacher education. Urban Education, 52(2), 155-169.

Stronge, J. H., \& Hindman, J. L. (2003). Hiring the best teachers. Educational Leadership, 60(8), 48-52.

Sutcher, L., Darling-Hammond, L., \& Carver-Thomas, D. (2016). A coming crisis in teaching? Teacher supply, demand, and shortages in the US. Learning Policy Institute. 
Tran, H., \& Smith, D. (2019). Insufficient money and inadequate respect: What obstructs the recruitment of college students to teach in hard-to-staff schools. Journal of Educational Administration, 57(2), 152-166.

Ulferts, J. D. (2016). A brief summary of teacher recruitment and retention in the smallest Illinois rural schools. The Rural Educator, 37(1).

Will, M. (2018, August 9). Enrollment is down at teacher colleges. So they're trying to change. Education Week, 38(1), 6. Retrieved July 16, 2019, from https://www.edweek.org/ew/articles/2018/08/09/enrollment-is-down-at-teacher-colleges $\underline{\text {-so.html }}$

Winters, J. V. (2010). Teacher moonlighting: evidence from the US Current Population Survey. Applied Economics Letters, 17(11), 1111-1114. 
SECTION VI:

SCHOLARLY PRACTITIONER REFLECTION 


\section{Becoming a Scholarly Practitioner}

Nearly four years ago I found myself in a state of undesired intellectual dormancy. Although I was very content with my career and genuinely loved being a high school science teacher, I did not feel challenged by my daily routine. I knew I needed a new adventure, a new opportunity to investigate my personal perspectives, a healthy disturbance of my complacency. It was at this juncture that I discovered the University of Missouri's Educational Leadership and Policy Analysis (ELPA) program. After careful review of what the program had to offer, I felt as though it would be the perfect answer to my need for growth. I knew I wanted to learn more and this program was going to quench my thirst for knowledge. As Abigail Adams once said, "Learning is not attained by chance, it must be sought for with ardor and attended to with diligence," and that was exactly what I intended to do, should I be awarded a seat in the prestigious ELPA program. Thankfully, I was fortunate enough to be accepted and in the spring of 2017, my journey began.

This road has taken me through a myriad of emotions as I have participated in careful self-reflection during my coursework and research. I have observed myself develop new ideas and beliefs as well as modify old ones. My experience has been truly transformational and this adventure has bolstered personal revelations of my strengths, weaknesses, capacity for leadership, and my ability to conduct ethical research through growth into a scholarly practitioner.

\section{Leadership}

Since those first days of reading articles and learning the craft of scholarly writing and research, I have developed a new understanding and appreciation for leadership and inquiry. Prior to beginning the ELPA program, I had never given much consideration to my own personal 
leadership ideas and practices and had not considered how I could make an impact through leadership. It was not until I began to dive into the readings and coursework that I realized I wanted to start enacting change. I did not know then what to change or how to change it, but I knew that my growing leadership skills would prove to be a tremendous tool that would help to achieve my goals. I started to seek out ways in my professional environment that I could become part of change instead of being a passive part of my institution of employment like I had been in years past. I found new confidence and new skills that would lead to my slow, but steady, professional growth. Reading about "emotional intelligence" (EI) became the catalyst I needed to begin my transition from follower to leader. Prior to this reading, I honestly did not think I had "what it takes" to be a good leader. I never scored a 30 on my ACT, I performed very poorly on my GRE, and I always had to try extra hard to do well in my college courses. I earned a 4.0 GPA during my Master of Natural Science in Biology degree, but that wasn't because I am brilliant and know biology content like the back of my hand. I had to study for hours upon hours and work diligently to do well. Prior to the ELPA program, I really didn't have the confidence I needed to lead. That all changed after learning about emotional intelligence.

Goleman (2011) said that IQ and technical skills are not what makes a good leader; instead, it is that of emotional intelligence which helps the leader flourish and become distinguished among the rest. After reviewing the skills that are necessary for a person with a high level of emotional intelligence to possess, I found that I already had a solid foundation of EI and was excited to further develop these skills. I find that my tendency to enjoy the challenge of meeting new people and building a rapport with them is an important aspect that helps me to be successful in the social skill component of EI (Clifton, Anderson, \& Schreiner, 2006). Goffee and Jones (2011) also pointed to the importance of "tough empathy", the ability to passionately 
and realistically empathize with people. Appropriately, the StrengthsQuest survey identified empathy as one of my top five strengths. Aiming to understand other people's emotions and feelings while having an accepting nature allows me to have empathy for others, thus increasing my emotional intelligence. I find being empathetic allows me to find peace in situations that could turn chaotic and turbulent very quickly. That is because emotions often drive decisions so understanding someone's emotions will help me to learn how their responses are impacted by their feelings. Coming to the realization that I could become a difference maker, a true leader, really helped me to pour myself into the ELPA program and begin my evolution towards being an advocate for positive change.

Prior to my involvement in ELPA, I recall having a vague sense of my leadership identity. As my studies continued and thoughtful reflection occurred, I became more aware of my personal leadership styles and practices and began to see how I could make an impact in my professional environment. During the interview for my current teaching position, my interviewer, a University of Missouri ELPA graduate, asked me what I would identify as the biggest take away from the program. I proudly stated that the program has helped me learn who I am as a leader and the magnitude of my potential. Careful personal reflection following the many readings and assignments throughout the two years of coursework has exposed my unique leadership style and unveiled my strengths and weaknesses.

I have found that I employ the path-goal theory most often in my leadership experiences. House and Mitchell (1975) define this theory as the ability of the leader to motivate their followers in such a way that the followers strive for and are even "satisfied" by the leader's ability to encourage goal attainment. The achievement of these goals is often increased when this method is utilized by the leader because it allows the subordinates to feel valued. The path-goal 
theory articulates the role of motivation and its correlation between the behavior of the leader and the satisfaction and performance of followers (Evans, 1996). Upon reflection, I began to see that I had been utilizing this theory in my professional practice when working with the "hard to reach" or apathetic students in my classroom. When working with challenging students, I have found that establishing structure and communicating rewards for accomplishing tasks yields the greatest results (Downey, Sheridan, \& Slocum, 1975). I believe this works best for students because it allows me to "meet them where they are", meaning that I identify the motivational needs of the students and begin to intervene.

I also strongly identify with the servant leadership paradox. I feel that when working with students, coworkers, community members, administrators, or parents it is imperative to put them first while empowering and empathizing with them (Northouse, 2016). I have found from personal experience that being nurturing and attentive with students helps develop deep personal connections. Students who feel welcome and safe are more likely to subscribe to what I am teaching them and are therefore more inclined to be successful in my classroom (Souers, 2016). Making sure that other's highest level needs are being served is important, especially in the classroom (Greenleaf, 1970). Prior to this program, I had always held personal relationships in high regard, but I didn't yet know about real servant leadership. However, like a true servant leader, I have never compromised ethical principles in order to achieve success. Whether it is regarding my own personal student data reflecting my success in the classroom or dealing with a student who needs to achieve a certain grade in order to receive scholarships or entry into a program, I strive to be an ethical decision maker. I believe that imparting my ethical standards onto students, coworkers, and peers has helped me to become a more respected leader. The type of respect garnered through these actions allows me to bolster a certain degree of power and trust 
from my followers (Mihelic, Lipicnik, \& Tekavcic, 2010). I am very pleased with the leader I am becoming but know there is still much to learn.

\section{Scholarship}

For me, the organizational analysis piece of this program has been the most exciting part of this journey, and possibly the most impactful. It was this part of the program that has influenced me most as a scholar. I believe the reason why is because this course was taken during the infamous summer one, lovingly dubbed by many ELPA students as "Bootcamp". This was an important time for us as Ed.D students because we got a real taste of what doctoral coursework was all about. Expectations were high and stress was peaking during this time of self-discovery and revelation. It was here that I began my evolution into a scholarly writer and researcher. This was the first time I was charged with reading many peer-reviewed journal articles and synthesizing the information in such a way that pointed to truths in the literature that would support my claims and ideas, a major component of scholarly writing.

Initially, one of my biggest challenges was understanding how to use frameworks to analyze an organization. Prior to my coursework, I looked at situations through one viewpoint only, my own. I didn't realize it is essential to utilize multiple viewpoints. I viewed organizational dilemmas using my own perspectives and did not give considerations to utilizing different frameworks. Luckily, as a result of learning, I can now actively employ works such as Bolman and Deal to guide my organizational analysis endeavors.

Since Bolman and Deal published their first book about the theory of organizational framing in 1991, it has been widely used across many disciplines to assess operations via multiple outlooks. Bolman and Deal have identified four "frames" from which people view their world. Within each frame lies a variety of concepts, metaphors, and principles which provide an 
organizational construct to aid us in development of diagnoses and strategies by looking at situations in more than one way (Bolman and Deal, 2013).

Through the trenches of summer one, I learned that the four frames can be compared to lenses. The lenses allow the leader to focus on some aspects and let others pass through, permitting the leader to order his or her experience in such a way that promotes reflection. I found that areas of ineffectiveness and inefficiency are more clearly observed when processing experiences through these different lenses, something I was not able to do prior to learning. These frames also provide context for actions to be taken in response to specific problems. No one uses only one frame all the time; however, some people do show a preference for one or two of the frames (Bolman and Deal, 2013). I personally prefer utilizing the human resource frame because I find the human component most engaging. Bolman and Deal (2013) emphasize that the human resource framework focuses on what organizations and people to do and for one another, which is an aspect I find myself gravitating towards most often.

At the beginning of the 2018-2019 school year, we experienced a massive change in the faculty and staff at my previous place of employment. At the end of the 2017-2018 school year, almost $30 \%$ of our employees retired, moved to a different school district, or chose a different professional career, including our head principal. Therefore, the following year became an opportunity to create a fresh, new climate. Our new principal asked for voluntary participation in a "School Culture and Climate Committee". Of course, I jumped at the chance to be part of this group because I saw an opportunity to put my organizational analysis skills into action.

I knew that I, along with the rest of the committee, was up for a challenge because of the transition to a new administrative team, new faculty and staff, and new policies that would soon envelop our climate. Organizational change of this magnitude is difficult and most often leads to 
failure (Jansson, 2013). Our new principal wanted to ensure that faculty and staff felt as though they had a voice, felt included, and considered themselves welcome. She most definitely knew that the change would be a burdensome task. As a member of ELPA's cohort 10, my boss is an incredible leader whom I have really enjoyed learning from. When I observe her leadership skills I can see parts of the program shining through and I smile because I think to myself, "She learned that from ELPA."

As we worked as a group to tackle this dilemma of learning to navigate the waters of new working relationships while creating a highly functioning and effective team at our school, we used the human resource frame which offers a unique viewpoint for this problem. It is useful to look through this lens to identify the needs of the staff, administrators, and students involved as well as the relationships of those stakeholders with each other. Bolman and Deal (2013) say that, "Organizations exist to serve human needs rather than the converse" (p. 117). The employees depend on the organization as a place of employment and the students depend on the organization as their source of educational opportunity; therefore, the school's employees must work like a well-oiled machine so as to serve their students.

Within this complex situation, the people involved are very clearly positioned in a hierarchical manner. Being placed at the top of the strategic apex, as described by Mintzberg (2005), my principal was charged with the overall responsibility and functioning of the organization. By using the human resource frame to assess the situation, she communicated to the committee that the energy, skills, attitude, and commitment of the faculty and staff are all critical resources that can lead to the ultimate success or failure of the organization. Keeping this in mind, we immediately began to brainstorm ways to establish buy-in, build trust, show appreciation, and promote efficiency. Additionally, our school was rebounding from prior years 
of persistent administrative inconsistency regarding decision making and policy enforcement; therefore, my principal also wanted to set a precedent of consistency for the new school year. According to Manning (2013), consistency is more certain when standard practices are utilized. Creating these standard practices was a necessary part of the new operational procedures. I am glad that I took the opportunity to be part of this committee so I could participate in the organizational analysis of our reformed organization. It was a great experience to watch a previous graduate of ELPA lead this endeavor and I was excited to be able to contribute in ways that I wouldn't have been able to do prior to the learning I have taken part in over the last two years. Knowing about how to conduct a proper organizational analysis gave me the skills I needed to provide meaningful input.

Through the writing of this dissertation, I have begun to understand how to put my leadership skills into practice as well as hone my skills as a scholarly writer. I have developed the important skills leaders must possess to be successful. I am now able to develop strong arguments backed by peer reviewed journal articles, conduct my own ethical research to establish and support my claims, understand different points of view by utilizing various lenses to observe a dilemma, and identify my own strengths and weaknesses which will allow me to be a more objective leader. This opportunity has changed me in the best way possible. 


\section{Appendix A}

\section{CONSENT FORM}

Identification of Researchers: This research is being conducted by Kelsey Powell, a doctoral student with the University of Southeast Missouri State University Cohort of the University of Missouri-Columbia Cooperative EdD Program.

Purpose of the Study: The purpose of this mixed methods case study is to explore stakeholder perspectives of the decline in science and math secondary education majors at a Southeast Missouri State University over the last ten years. The perspectives local rural high school administrators, administrators in the secondary education department at SEMO, and SEMO students who have changed their major from secondary science or math education to something else will be utilized to determine why there has been a decline in enrollment of these majors and what, if any, impact this trend has had on local, rural public schools.

Request for Participation: I am inviting you to participate in a study about the decline in enrollment of secondary science and education majors at SEMO. It is up to you whether you would like to participate. If you decide not to participate, you will not be penalized in any way. You can also decide to stop at any time without penalty. If you do not wish to answer any of the questions, you may simply skip them. You may withdraw your data at the end of the study.

Description of Research Method: This study involves a survey (for high school administrators only) and interviews. The interviews will ask you about your perceptions of the trend mentioned above. The interviews will be audio recorded.

Privacy: All of the information we collect will be kept confidential. Your personal information will not be shared with anyone outside of my university advisor. After the interviews are completed, the information will be de-identified, and I will not keep your name on file.

Questions: If you have any questions about this study, please contact my advisor Dr. Bret Cormier at bcormier@ semo.edu or at (573) 651-2000. If you have any questions about your rights as a research participant, please contact the University of Missouri, Columbia Institutional Review board at (573) 882-3181. IRB@ missouri.edu

If you want to talk privately about your rights or any issues related to your participation in this study, you can contact University of Missouri Research Participant Advocacy by calling 888280-5002 (a free call), or emailing MUResearchRPA@ missouri.edu.

If you would like to participate and agree to this informed consent, please sign below. Signature Date 
Appendix B

\section{Recruitment Email}

Identification of Researchers: This research is being conducted by doctoral student Kelsey Powell. I am with the Southeast Missouri State University Cohort of the MU Cooperative EdD Program.

Hello, my name is Kelsey Powell. I am a doctoral student from the University of Missouri Cooperative EdD program, with the Southeast Missouri State University cohort. I am conducting a study about the perspectives local rural high school administrators, administrators in the secondary education department at SEMO, and SEMO students who have changed their major from secondary science or math education to something else to determine why there has been a decline in enrollment of these majors at SEMO and what, if any, impact this trend has had on local, rural public schools. I would like to invite you to participate in a survey and possible follow-up interview with me regarding your thoughts about the downward decline in graduates with a secondary math or science education degree from SEMO. Participation is completely voluntary, and participant identities will be confidential. If you would be willing to help me, please fill out the survey.

Thank you!

Kelsey Powell (Doctoral Candidate)

(573)587-6910

kpowell@jr2mail.org

Southeast Missouri State University Cohort

University of Missouri-Columbia 


\section{Appendix C}

\section{Interview Protocol}

Interview protocol is as follows:

1. Gather names and email addresses from all administrators who currently work in one of the 67 rural districts within the service area of RTU.

2. Send an email introducing myself and the study and ask for participation.

3. Proper ethical practices must be followed; therefore, inform all participants that their participation is voluntary and the study received IRB approval.

4. Provide then collect a consent form from each participant before he or she begins the study. The consent form will remind the respondent of their anonymity throughout the study as well as their voluntary participation.

5. Distribute the electronic survey. This survey is composed of 17 items. The survey asks both qualitative and quantitative questions, both open-ended and multiple choice. The survey has items relating to the participant's demographic data, the response to the shortage of highly qualified science and math teachers needed to fill vacancies, trends in vacancies for high school science and math positions, qualifications of science and math teachers hired within the past ten years, and teacher retention.

6. Reach out to administrators who indicated that they would participate in an interview.

7. For any individuals who accept the invitation for an interview, ask permission to record the exchange. This will allow the researcher to have the opportunity to transcribe the conversation for a more accurate account of the interview. A series of open-ended questions will be asked throughout the duration of the interview, which will not exceed one hour. 


\section{Appendix D}

\section{Survey Items: Rural High School Administrators}

1. What is your name?

2. Which school district do you work for?

3. How long have you been in your current position at your current school?

4. On a scale of 1-5 how would you rate the easability of finding highly qualified instructors to fill vacant secondary science and math positions?

5. On a scale of 1-5, how would you rate the subject matter knowledge of science and math secondary education teachers you employ that have graduated from Southeast Missouri State University?

6. On a scale of 1-5, how would you rate the ability of science and math secondary education teachers you employ that have graduated from Southeast Missouri State University to create well-structured units and lessons?

7. Over the last ten years, have you found it more difficult to find and staff highly qualified science and math teachers at the secondary level?

8. On a scale of $1-5$, identify how the decline in secondary science and math education graduates over the last ten years has impacted your ability to find and staff highly qualified teachers in those disciplines.

9. On a scale of 1-5 how would you rate your school's ability to retain highly qualified teachers.

10. How would you rate your district's current process of recruiting and attracting highly qualified science and math secondary instructors?

11. Given its close proximity to your campus, please describe your school's relationship with Southeast Missouri State University. Please detail any partnerships between your institution and SEMO.

12. Rate the ability of your school to hire highly qualified secondary science and math teachers.

13. Rate your school's ability to compete with other schools for highly qualified secondary science and math teachers.

14. Were you aware of the downward decline of secondary science and math teacher education graduates at Southeast Missouri State University over the last ten years?

15. Are you aware of any recruitment efforts by Southeast Missouri State University at your school to attract secondary science and math education majors?

16. Do you recall a notable change in the number of students graduating from your school and enrolling at Southeast Missouri State University over the past 10 years?

17. Do you recall a notable change in the number of students graduating from your school that want to become a high school science or math teacher? 


\section{Appendix E}

\section{Interview Questions: Rural High School Administrators}

1. What is your name and how do you spell it?

2. Tell me a little about yourself.

3. What school do you work at and how long have you worked there?

4. What are your roles and responsibilities at your school?

5. Please briefly describe your district's hiring practice.

6. Tell me about the relationship between the decline of secondary education science and math graduates from Southeast Missouri State University and your district's ability to find and staff highly qualified teachers in those disciplines.

7. Describe your school's retention rate of teachers.

8. When is hiring most difficult for you as an administrator?

9. Describe the typical pool of applicants you have to fill a vacant position for secondary science or math.

10. What does a typical hiring process look like for you as an administrator?

11. Tell me about a time when the hiring pool was less than ideal.

12. Has the geographic location of your high school impacted your hiring process?

13. What is your perception of the preparedness of SEMO applicants?

14. Do you believe the decreasing number of secondary science and math graduates from SEMO has impacted your ability to find and staff highly qualified teachers to fill vacancies in those disciplines?

15. Tell me about how or if the decline in science and math education majors at SEMO has impacted your students.

16. Approximately what percentage of your graduating seniors attend SEMO each year?

17. What kind of college preparatory options does your school provide to high school students?

18. Does your school have any partnerships with SEMO such as dual credit options through this university?

19. Have you or your staff members ever encouraged students to pursue a degree in secondary science or math education?

20. Describe teacher retention at your school. Compare it to surrounding schools. How do you think this impacts your students? 


\section{VITA}

Kelsey Powell was born in Cape Girardeau, Missouri. She graduated from Jackson High School in 2007 and began college at Southeast Missouri State University the same year. She graduated from SEMO in 2011 and started her master's degree in the spring semester of 2012. She graduated with her Master of Natural Science in Biology degree in the spring of 2013. Kelsey began her teaching career at Farmington High School in the fall of 2013. In the spring of 2017, Kelsey began her doctorate degree at the University of Missouri-Columbia. She moved back home to Jackson, Missouri in 2019 where she is currently in her eighth year of teaching. She graduated from MIZZOU with her Educational Leadership and Policy Analysis Ed.D in 2021. 